\title{
Immunomodulating Therapies in Acute Myocarditis and Recurrent/Acute Pericarditis
}

\section{OPEN ACCESS}

Edited by:

Silvia Piantoni,

ASST-Spedali Civili and University of

Brescia, Italy

Reviewed by:

Bernhard Maisch,

University of Marburg, Germany Kazuko Tajiri,

University of Tsukuba, Japan

*Correspondence:

Enrico Ammirat

enrico.ammirati@ospedaleniguarda.it

Antonio Brucato

antonio.brucato@unimi.it

Specialty section: This article was submitted to Rheumatology,

a section of the journal

Frontiers in Medicine

Received: 17 December 2021 Accepted: 28 January 2022

Published: 07 March 2022

Citation:

Ammirati $E$, Bizzi $E$, Veronese $G$, Groh $M$, Van de Heyning $C M$, Lehtonen J, Pineton de Chambrun M, Cereda A, Picchi C, Trotta L, Moslehi JJ and Brucato A (2022) Immunomodulating Therapies in Acute Myocarditis and Recurrent/Acute Pericarditis. Front. Med. 9:838564. doi: 10.3389/fmed.2022.838564

\author{
Enrico Ammirati ${ }^{1 *}$, Emanuele Bizzi ${ }^{2}$, Giacomo Veronese ${ }^{3}$, Matthieu Groh ${ }^{4,5}$, \\ Caroline M. Van de Heyning ${ }^{6}$, Jukka Lehtonen ${ }^{7}$, Marc Pineton de Chambrun ${ }^{8,9,10}$, \\ Alberto Cereda ${ }^{11}$, Chiara Picchi ${ }^{2}$, Lucia Trotta ${ }^{2}$, Javid J. Moslehi ${ }^{12}$ and \\ Antonio Brucato ${ }^{2,13 *}$
}

${ }^{1}$ De Gasperis Cardio Center and Transplant Center, Niguarda Hospital, Milano, Italy, ${ }^{2}$ Internal Medicine, Fatebenefratelli Hospital, Milano, Italy, ${ }^{3}$ Department of Health Sciences, University of Milano-Bicocca, Monza, Italy, ${ }^{4}$ National Reference Center for Hypereosinophilic Syndromes, CEREO, Suresnes, France, ${ }^{5}$ Department of Internal Medicine, Hôpital Foch, Suresnes, France, ${ }^{6}$ Department of Cardiology, Antwerp University Hospital, and GENCOR Research Group, Antwerp University, Antwerp, Belgium, ' Department of Cardiology, Heart and Lung Center, Helsinki University Hospital, Helsinki, Finland, ${ }^{8}$ Sorbonne Université, Assistance Publique-Hôpitaux de Paris (APHP), Hôpital La Pitié-Salpêtrière, Service de Médecine Intensive-Réanimation, Paris, France, ${ }^{9}$ Sorbonne Université, APHP, Hôpital de la Pitié-Salpêtrière, Service de Médecine Interne 2, Centre de Référence National Lupus et SAPL et Autres Maladies Auto-immunes et Systémiques Rares, Paris, France, ${ }^{10}$ Sorbonne Université, INSERM, UMRS_1166-ICAN, ICAN, Paris, France, ${ }^{11}$ Cardiovascular Department, Association Socio Sanitary Territorial Santi Paolo e Carlo, Milano, Italy, ${ }^{12}$ Section of Cardio-Oncology and Immunology, Division of Cardiology and the Cardiovascular Research Institute, University of California, San Francisco, San Francisco, CA, United States, ${ }^{13}$ Department of Biomedical and Clinical Sciences "Luigi Sacco," Fatebenefratelli Hospital, University of Milano, Milano, Italy

The field of inflammatory disease of the heart or "cardio-immunology" is rapidly evolving due to the wider use of non-invasive diagnostic tools able to detect and monitor myocardial inflammation. In acute myocarditis, recent data on the use of immunomodulating therapies have been reported both in the setting of systemic autoimmune disorders and in the setting of isolated forms, especially in patients with specific histology (e.g., eosinophilic myocarditis) or with an arrhythmicburden. A role for immunosuppressive therapies has been also shown in severe cases of coronavirus disease 2019 (COVID-19), a condition that can be associated with cardiac injury and acute myocarditis. Furthermore, ongoing clinical trials are assessing the role of high dosage methylprednisolone in the context of acute myocarditis complicated by heart failure or fulminant presentation or the role of anakinra to treat patients with acute myocarditis excluding patients with hemodynamically unstable conditions. In addition, the explosion of immune-mediated therapies in oncology has introduced new pathophysiological entities, such as immune-checkpoint inhibitor-associated myocarditis and new basic research models to understand the interaction between the cardiac and immune systems. Here we provide a broad overview of evolving areas in cardio-immunology. We summarize the use of new imaging tools in combination with endomyocardial biopsy and laboratory parameters such as high sensitivity troponin to monitor the response to immunomodulating therapies based on recent evidence and clinical experience. Concerning pericarditis, the normal composition of pericardial fluid has been recently elucidated, allowing to assess the actual presence of inflammation; indeed, normal pericardial fluid is rich in nucleated cells, protein, albumin, LDH, at levels consistent with inflammatory exudates in other 
biological fluids. Importantly, recent findings showed how innate immunity plays a pivotal role in the pathogenesis of recurrent pericarditis with raised C-reactive protein, with inflammasome and IL-1 overproduction as drivers for systemic inflammatory response. In the era of tailored medicine, anti-IL-1 agents such as anakinra and rilonacept have been demonstrated highly effective in patients with recurrent pericarditis associated with an inflammatory phenotype.

Keywords: acute myocarditis, pericarditis, immunosuppressive therapy, eosinophilic myocarditis, COVID-19, cardiac sarcoidosis, corticosteroids, anti-IL-1 therapy

\section{INTRODUCTION}

The field of inflammatory disease of the heart or "cardio-Immunology" is rapidly evolving thanks to the wider use of non-invasive diagnostic tools able to detect and monitor myocardial inflammation, such as cardiac magnetic resonance imaging (CMRI) and fluorodeoxyglucose positron emission tomography (FDG-PET) (1). In acute myocarditis (AM), recent data on the use of immunomodulating therapies have been reported both in the setting of systemic autoimmune disorders and in the setting of isolated forms, especially in patients with specific histology (i.e., eosinophilic myocarditis, giant cell myocarditis [GCM] or cardiac sarcoidosis [CS]) or characterized by an arrhythmic burden (2). We elucidate the rationale to test the use of immunomodulating therapies in patients with lymphocytic AM. In addition, AM has also emerged as a complication in the setting of coronavirus disease 2019 (COVID19), mRNA vaccine (3-7), and immune checkpoint inhibitors (ICI) (8-10). Here, we summarize the clinical approach toward the use of immunosuppressive therapies in these specific settings. Finally, we propose the use of new imaging tools in combination with endomyocardial biopsy (EMB) and laboratory parameters such as high sensitivity troponin to monitor the response to immunomodulating therapies based on recent evidence and clinical experience.

In the second section of this review, we examine the rationale and the evidence of immunosuppression in pericarditis. We highlight recent findings defining a pivotal role for innate immunity in the pathogenesis of recurrent pericarditis with raised C-reactive protein (CRP), focusing on the emerging role of anti-IL-1 agents (i.e., anakinra and rilonacept) for this subset of patients with recurrent pericarditis.

\section{LYMPHOCYTIC MYOCARDITIS}

Lymphocytic AM is the most common histologic subset reported in AM cohorts (11). Due to the fact that in the setting of suspected AM, histologic diagnosis is more often recommended in specific scenarios (e.g., acute heart failure [HF], presence of ventricular arrhythmias (VA) or II/III-degree atrio-ventricular block $[\mathrm{AVB}])(1,12)$, the prevalence of lymphocytic AM is frequently estimated on cohorts of complicated AM. From a recent international retrospective case collection of $\mathrm{AM}$ presenting with left ventricular (LV) systolic dysfunction, the prevalence of lymphocytic AM has been estimated to be $\sim 72 \%$, being the most frequently diagnosed form both in fulminant myocarditis [FM], a clinical entity defined by the need of circulatory support, and non-FM (11). The etiology of lymphocytic AM is broad and includes heterogeneous pathogens, drugs or autoimmune-mediated injury in the setting of systemic inflammatory diseases $(10,13,14)$. The role of viruses in myocarditis etiology has been historically recognized, with Parvovirus (PV)B-19, adenoviruses, Human Herpesvirus (HHV)-6, enteroviruses being the most common agents identified in the myocardium of patients with $\operatorname{AM}(15,16)$. Whether viruses have a direct or indirect causal relationship in clinical myocarditis etiology has been a matter of great debate throughout the years with expert opinions varying according to the evidence of the moment (17). The controversy matters as it has been stated that the presence of specific viruses in the heart may be a contraindication to the use of immunosuppression (18). A growing body of literature indicates that viruses, particularly PVB-19 and HHV6, may be found in a large proportion of patients who do not have myocarditis, questioning their direct causal role in the pathogenesis of myocarditis $(19,20)$. Of note, PVB-19 was the only virus identified in patients with lymphocytic FM in an international registry (21). Except for enteroviruses $(22,23)$, such as coxsackievirus, whose ability to cause direct myocardial damage has been demonstrated and seems more common in newborns/infants (24), most of the available evidence suggests that virus-triggered immune-mediated reactions are the principal cause of cardiomyocyte injury (1). Respiratory viruses, such as influenza and coronaviruses, are examples of common viruses that can trigger immune-mediated lymphocytic myocarditis with no evidence of viral genome in the myocardium $(25,26)$. Molecular mimicry between viral and cardiac antigens is suspected to be a key mechanism of myocardial injury in virus-triggered $\operatorname{AM}(27,28)$. Furthermore, the concept that FM may resemble the presentation of a high-grade cellular rejection observed after heart transplantation (HTx) is recently emerging. These findings may suggest that the identification of viruses in the setting of AM may not represent an absolute contraindication to immunosuppression (29). At present, the role of a routine viral genome search on EMB in guiding patient management and immunosuppression therapy in patients with AM remains unknown (17). This concept holds true especially in FM where early immunosuppression may be crucial to damper the inflammatory process sustaining AM. However, most studies focusing on immunomodulation have included patients with chronic inflammatory cardiomyopathy with HF 
symptoms for more than 6 months rather than those with a fulminant or complicated course (30-32). Though not supported by evidence from randomized clinical trials, recommendations for immunosuppression exist in the setting of complicated AM based on case series, expert opinions, and pathophysiological considerations (1) (Figure 1). The American Heart Association (AHA) suggests that, if a high suspicion for immune-mediated FM exists, pulse steroid therapy (i.e., $1 \mathrm{~g}$ of methylprednisolone) should be administered urgently, before biopsy-confirmed diagnosis or further diagnostic testing (33). Intravenous (IV) immunoglobulin (IG) (at a dose ranging from $0.5 \mathrm{~g}$ to $1 \mathrm{~g} / \mathrm{kg}$ ) is frequently used in pediatric lymphocytic myocarditis with evidence of some benefits in terms of functional recovery and survival, but the experience in adults has been limited $(34,35)$. Even though not standardized, maintenance therapy with low dose steroids often in combination with mycophenolate mofetil, cyclosporine, azathioprine (AZA) as steroid-sparing drugs may be used in those patients showing poor functional recovery associated with persistence of troponin release or any evidence of residual myocardial inflammation $(30,36)$. Standardized Corticosteroid therapy (IV methylprednisolone $200-400 \mathrm{mg}$ or dexamethasone 20-40 mg) qd for 3-5 days and then gradually down titrated and weaned in 7-10 days, and IVIG $10-20 \mathrm{~g}$ qd for 3-5 days followed by $10 \mathrm{~g}$ for another 3-5 days has been described from a Chinese registry of $138 \mathrm{FM}$ and has been associated with improved survival (37). According to several researchers, even though robust evidence is substantially lacking in the setting of AM, high viral loads may contraindicate the use of immunosuppression in favor of treatment with antiviral drugs or with agents boosting the native immune response (e.g., interferon- $\beta$ ) (38). Lymphocytic AM can also be associated with systemic autoimmune or inflammatory disorders (e.g., systemic lupus erythematosus [SLE], inflammatory bowel disorders, COVID-19) (39). The Lombardy registry of AM reported that $7.2 \%$ of patients had associated autoimmune or systemic disorders, being more frequent in patients presenting with complicated AM (40). The identification of the myocarditisassociated condition is essential to initiate disease-specific treatments. IV corticosteroids have been successfully used in cases of SARS-CoV-2 related FM, suggesting the relevance of the systemic inflammatory response in determining cardiac injury in COVID-19, even though more evidence is needed $(41,42)$.

\section{Ongoing Trials}

Anakinra is the recombinant form of the naturally occurring interleukin $1 \alpha(\mathrm{IL}-1 \mathrm{R} \alpha)$ and blocks the activity of both IL$1 \alpha$ and IL-1 $\beta$. The Anakinra vs. Placebo for the Treatment of Acute Myocarditis (ARAMIS) trial (ClinicalTrials.gov identifier: NCT03018834) is a double-blind randomized clinical trial testing the superiority of anakinra in addition to standard of care, defined as the maximum tolerated dosage of any beta-blockers and angiotensin receptor blockade in acute myocarditis. The ARAMIS trial has completed the randomization phase and will directly assess the role of the IL-1 immune innate pathway in the setting of AM. The rationale of blocking the (IL-1 $\beta$ ) pathway in myocarditis relies on prior studies that suggested the central role of the Nucleotide-binding domain (NACHT) and Leucine-rich repeat (LRR) and Pyrin domain (PYD) (NLR) containing protein 3 (NLRP3) inflammasome predominately expressed in macrophages (43-45). Despite anecdotal evidence, ARAMIS will directly test this concept and the results are expected by the end of $2022(46,47)$. This double-blinded French study has assessed 120 patients with symptomatic AM defined by elevated cardiac troponin (at least 1.5 -fold upper the normal reference limit) and CMRI consistent with myocarditis performed within $72 \mathrm{~h}$ after admission (Figure 2). Patients in the treatment arm received a daily subcutaneous dose of anakinra $100 \mathrm{mg}$ during the hospitalization including an angiotensinconverting-enzyme inhibitor (ACE-i) and a beta-blocker. The primary endpoint of this study is the number of days alive free of any myocarditis complications including (1) VA, (2) $\mathrm{HF}$, (3) recurrent chest pain requiring medication, (4) left ventricular ejection fraction (LVEF) $<50 \%$, up to 28 days after randomization. This trial has also a sub-study that has assessed ACE-i continuation or discontinuation after 1 month in patients with normal LVEF that are followed for 1 year. This trial excluded the patients with the poorest outcome, specifically those on mechanical ventilation or temporary mechanical circulatory supports (t-MCS). To address specifically patients with FM or acute HF the MYocarditis THerapy with Steroids (MYTHS) trial (ClinicalTrials.gov identifier: NCT05150704) will randomize 288 patients with FM (need for inotropes and/or t-MCS) or AM complicated by HF and severely impaired LVEF $(<41 \%)$ to pulsed corticosteroid therapy (methylprednisolone $1 \mathrm{~g}$ IV qd for 3 days) on top of standard therapy and maximal supportive care vs. placebo (Figure 2). The combined primary endpoint is defined as the time from randomization to the first event occurring within 6 months including (1) all-cause death, or (2) HTx, or (3) long-term left-ventricular assistance device (LVAD) implant, or (4) need for an upgrading of the t-MCS, or (5) a ventricular tachycardia (VT)/fibrillation (VF) treated with direct current (DC) shock (excluding VT/VF in patients on t-MCS other than intra-aortic balloon pump [IABP]), or (6) first rehospitalization due to HF or VA, or advanced AVB. The trial started the enrollment in October 2021 and the estimated duration is $\sim 3-4$ years. The rationale for the MYTHS trial is based on clinical practice. Indeed, several case series and case reports support the effectiveness of high dosage corticosteroids (48-50).

\section{SPECIFIC SUBSET OF MYOCARDITIS}

\section{Myocarditis in Systemic Lupus Erythematosus and Antiphospholipid Antibody Syndrome}

SLE is a rare disease (prevalence $48-350$ per 100,000 individuals) in which the immune system attacks healthy cells and tissues. Immune system activation is characterized by exaggerated $\mathrm{B} / \mathrm{T}$ cell responses and loss of tolerance against self-antigens. Production and defective elimination of antibodies, tissue deposition of immune complexes, and complement and cytokine activation contribute to clinical manifestations ranging from joint and skin inflammation to life-threatening organ damage 
FIRST-LINE

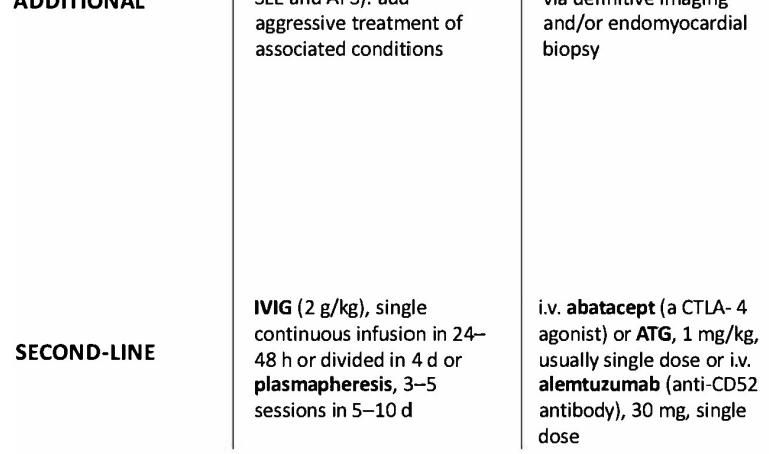

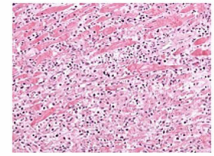

ICI-ASSOCIATED

Hold ICI therapy

Confirm $\mathrm{Cl}$-myocarditis

via definitive imaging

and/or endomyocardia

- If associated systemic autoimmune disorders (eg. SLE and APS): add aggressive treatment of

\section{SUSPECTED FULMINANT OR COMPLICATED ACUTE MYOCARDITIS \\ $\downarrow$ \\ i.v. pulse methylprednisolone $7-14 \mathrm{mg} / \mathrm{kg} /$ day for $3 \mathrm{~d}$, then $1 \mathrm{mg} / \mathrm{kg} / \mathrm{day}$}

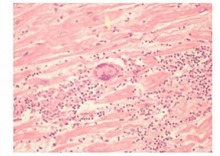

GIANT CELL

\section{- If hemodynamically
unstable pts: ATG, from 1}

$\mathrm{mg} / \mathrm{kg}$, usually single-dose to $300 \mathrm{mg}$ in 3 days or

(alternative) i.v.

alemtuzumab (anti-CD52

antibody) single dose of 30

mg plus oral CyA, BID, target

through levels $150-250$

$\mathrm{ng} / \mathrm{mL}$

- If hemodynamically stable

pts: only oral CyA, BID, target trough levels $150-250 \mathrm{ng} / \mathrm{mL}$

i.v. rituximab $375 \mathrm{mgxm} \mathrm{m}^{2}$ (BSA) $\mathrm{mg}$ (once a wk for $4 \mathrm{wk}$ and then every 4 mo as

maintenance therapy) for $1 \mathrm{yr}$

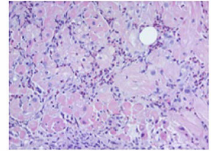

EOSINOPHILIC

- If EG PA: consider i.v. cyclophosphamide (especially in ANCA-positive pts), 600 $\mathrm{mg}^{*} \mathrm{~m}^{2}$ at days 1,15 , and 30 - If clonal (myeloproliferative) HES: imatinib $100-400 \mathrm{mg}$ OD - If helminthic infection: albendazole $400 \mathrm{mg}$ BID for 2-4 wk

- If hypersensitivity reaction: withdraw suspected drug

- If DRESS, EGPA or idiopathic HES: anti-IL5 agents (e.g., benralizumab $30 \mathrm{mg}$ s.c./4-8wk or mepolizumab 100-300 $\mathrm{mg} / 4 \mathrm{wk}$ ) s.c. methotrexate 15-20 $\mathrm{mg} / \mathrm{wk}$ or i.v. infliximab 5 $\mathrm{mg} / \mathrm{kg}$ (up to $500 \mathrm{mg}$ ) at time 0 and after 2 and 4 whand then every $6-8$ wk and then every 6-8 wk or s.c. adalimumab 40 $\mathrm{mg} / 2 \mathrm{wk}$

FIGURE 1 | Immunosuppressive treatment strategies used for fulminant myocarditis or complicated acute myocarditis not supported by evidence from clinical trials but based on published case reports/series. i.v., intravenous; d, day; IVIG, intravenous immunoglobulin; h, hour; SLE, systemic lupus erythematosus; APS, antiphospholipid syndrome; ICl, immune checkpoint inhibitor; pts, patients; ATG, anti-thymocyte globulin; wk, week; CyA, cyclosporine; mo, month; EGPA, eosinophilic granulomatosis with polyangiitis; ANCA, antineutrophil cytoplasmatic antibodies; DRESS, drug reaction with eosinophilia asn dystemic symptoms; HES, hypereosinophilic syndrome; s.c., subcutaneous. Adapted from Ammirati et al. (1).

(51). Young women are disproportionately affected by SLE with a female-to-male sex ratio around 10:1 (52). Lupus myocarditis is a rare manifestation of SLE occurring in $<5 \%$ of patients $(53,54)$ frequently at disease onset $(\approx 60 \%$ of cases) (55). Cardiac manifestations of SLE-myocarditis are nonspecific: elevated troponin $80 \%$, abnormal electrocardiogram 90\%, altered LVEF ( $\leq 45 \%$ ) 66\%, pericardial effusion 69\% (55), and usually associated with other SLE clinical features (e.g., fever, skin rash, joint inflammation, lupus nephritis). When isolated lupus myocarditis is suspected, SLE diagnosis relies on: positive anti-nuclear, anti-dsDNA (ELISA, Crithidia luciliae or Farr tests) or anti-extractable nuclear antigen (especially anti-SM) antibodies; low C3 complement fraction and/or elevated serum interferon-alpha $(56,57)$. CMRI usually reveals cardiac inflammation and the presence of late gadolinium enhancement (LGE) (69\%) (55). EMB for the diagnosis of lupus myocarditis has shown disappointing results (58) and its use is debatable owing to the numerous non-invasive diagnosis methods of SLE, at least in the case of patients with stable hemodynamic conditions. Moreover, the histopathologic abnormalities of lupus myocarditis (lymphocytic myocarditis) are non-specific, even if SLE can be occasionally associated with GCM (59). The management of lupus myocarditis is not specifically addressed in the latest guidelines for the management of SLE (60). General consensus suggests the use of high-dose corticosteroids with the addition of an immunosuppressive drug (e.g., cyclophosphamide) in patients who are refractory to corticosteroids alone (Figure 1). Under these therapies, LVEF can recover to a normal value in most patients (>80\%) (55).

Antiphospholipid antibody syndrome (APLAS) is a rare systemic autoimmune disease responsible for thrombotic events and obstetric morbidity in patients with persistent antiphospholipid autoantibodies (lupus anticoagulant, anticardiolipin and/or anti-beta2 glycoprotein [GP]-1 antibodies) (61). APLAS is the leading cause of acquired thrombophilia accounting for $10 \%$ of arterial or venous thrombosis. The disease mainly occurs in young adults (mean age at diagnosis $34-54$ years) with a sex ratio slightly favoring women $(55-82 \%)(62,63)$ and can be associated with other autoimmune diseases, especially SLE. APLAS can induce chronic valvular lesions (Libman-Sacks endocarditis) responsible for mitral (more frequently) and/or aortic stenosis and/or regurgitation (64). Myocardial infarction in the setting of APLAS can be related to macrovascular thrombosis of coronary vessels or to microvascular thrombosis (myocardial infarction with non-obstructive coronary arteries [MINOCA]). The clinical features of APS-related MINOCAs are non-specific and associated with chest pain, electrocardiographic changes, a rise in cardiac necrosis markers, and evidence of myocardial LV systolic dysfunction. Macrovascular or microvascular thrombosis frequently occurs as thrombotic storm termed catastrophic APLAS (C-APLAS). The C-APLAS is defined as the occurrence of (1) at least the involvement of 3 organs, tissues, or systems in $<7$ days; (2) with biopsy-proven small vessel occlusion; (3) in patients with persistent high title of antiphospholipid antibodies 
ARAMIS TRIAL Anakinra for the Treatment of Acute MyocarditIS

Study duration: $\mathbf{4}$ years Study Start: May 2017 Follow up: 28 days

Double blind, randomized controlled, multicenter, national, phase III trial - Coordinating center: Pitié-Salpêtrière, Paris, FRANCE PI: Dr. Mathieu Kerneis

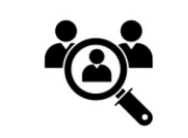

Suspected AM

(excluding patients on

t-MCS or MV)
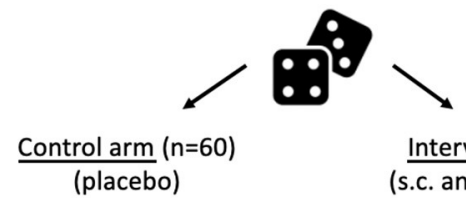

(placebo)

Primary endpoint:

G

Number of days alive free of any myocarditis complications

(VA, HF, recurrent chest pain, $\mathrm{LVEF}<50 \%$ )

\section{MYTHS TRIAL}

MYocarditis THerapy with Steroids

Study duration: $\mathbf{3}$ years Study Start: Oct. 2021 Follow up: 6 months

Single blind, randomized controlled, multicenter, international, phase III trial - Coordinating center: Niguarda hospital, Milan, ITALY PI: Dr. Enrico Ammirati

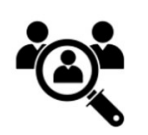

Suspected AM complicated by acute

$\mathrm{HF} /$ cardiogenic shock (LVEF $<41 \%$ \&

LVEDD $<56 \mathrm{~mm}$ on echo)

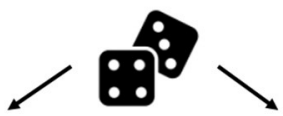

Control arm ( $n=144)$

(placebo)

Intervention arm ( $n=144)$

(i.v. methylprednisolone $1 \mathrm{~g} \times 3 \mathrm{~d}$ )

Primary endpoint:

C)

To demonstrate a reduction in the rate of all-cause death, HTx, LVAD implant, need for upgrading t-MCS, VA treated with DC shock, hospitalization due to HF, VA, AVB
Clinicaltrials.gov: NCT03018834

Sponsor: Assistance Publique - Hôpitaux de Paris
Clinicaltrials.gov: NCT05150704

Funded by the Italian Ministry of Health (GR-2019-12368506)

FIGURE 2 | Ongoing trials in the setting of acute myocarditis evaluating the use of immunosuppressive drugs. PI, principal investigator; AM, acute myocarditis; HF, heart failure; LVEF, left ventricular ejection fraction; LVEDD, left ventricular end-diastolic diameter; iv, intravenous; d, days; HTx, heart transplant; LVAD, left ventricular assist device; t-MCS, temporary-mechanical circulatory support; VA, ventricular arrhythmias; AVB, atrioventricular block; MV, mechanical ventilation; sc, subcutaneous.

(65). These classification criteria should be considered with great caution as they do not encompass the full spectrum of severe APLAS microvascular thrombotic episodes and some patients may require treatment escalation even though they do not fulfill the criteria for C-APLAS (66). When available, EMB can reveal myocyte necrosis with small vessels occlusions (67). However, EMB is generally not performed as it is perceived at increased risk of a bleeding complication. Small vessel occlusion can alternatively be disclosed on biopsy from other organs (i.e., skin) and CMRI can help identify microvascular occlusion (68). Nevertheless, in critically-ill patients EMB can differentiate scenario where inflammatory infiltrates prevails over the small vessels occlusions or it can reveal a GCM (1). The treatment of APS relies on anticoagulation as neither corticosteroids nor immunosuppressants nor biologics have proven their efficacy (69). Nevertheless, patients with C-APLAS should be given a triple therapy associating anticoagulation, high-dose corticosteroids, and either IVIG or plasma exchange (70). Rituximab has been also frequently used in combination with plasma exchange in C-APLAS with myocarditis $(67,71,72)$. In refractory cases, the use of complement inhibitors (i.e., eculizumab) can be discussed on a case-by-case basis (73).

\section{Immune Checkpoint Inhibitor Associated Myocarditis}

ICIs have transformed cancer treatment and include monoclonal antibodies which block immune brakes such as CTLA-4 (cytotoxic T-lymphocyte antigen-4), PD-1 (programmed death receptor-1), and its ligand (PD-L1 [programmed death-ligand $1]$ ), leading to reinvigoration of $\mathrm{T}$ cell responses against cancer (74). By activating the immune system, ICI can also lead to immune-related adverse events (irAE) which can affect any organ $(75,76)$. Myocarditis is one of the most serious irAE associated with ICI use (77). Initially described in 2016, ICI-myocarditis is now considered an infrequent but potentially lethal complication of ICI (78). ICI-myocarditis is especially arrhythmogenic and is pathologically characterized by T-cell and macrophage infiltration of the myocardium (79). Systolic HF occurs in about half of patients. On the other hand, ICI-myocarditis often occurs concomitantly with myositis, as well as a myasthenialike syndrome (80-82). The main risk factor is combination ICI treatment, for example, when ipilimumab (anti-CTLA-4) and nivolumab (anti-PD1) are combined for more effective treatment (9). Clinical definitions have been established and advocate for the use of biomarkers, imaging, and EMB for optimal and prompt diagnosis of treatment $(83,84)$. Preclinical models of ICImyocarditis have been established and suggest a critical role for immune checkpoints in the heart. For example, genetic absence of Pdcd1 (encoding PD-1) and Ctla4 (encoding for CTLA-4) haploinsufficiency recapitulate various features of ICI-associated myocarditis, including myocardial infiltration by $\mathrm{T}$ cells and severe electrocardiographic abnormalities (i.e., sinus node dysfunction, sinus arrest, and atrioventricular conduction block) $(85,86)$. Therapeutic intervention with abatacept (recombinant CTLA-4 immunoglobulin) rescues the fatal myocarditis in this 
mouse model, providing mechanistic support for inhibition of $\mathrm{T}$ cell co-stimulation mediated by CTLA- 4 as a treatment for ICI-associated myocarditis. Anecdotal evidence supports the use of abatacept in severe cases of ICI-myocarditis (87). ICIinduced myocarditis affects elder patients (median age of 65 years) with more comorbidities compared with non-ICI-induced myocarditis (median age between 30 and 40 years) (40, 8890). One of the largest case series of 122 patients with ICIassociated myocarditis had early onset of symptoms (median 30 days after initial exposure to ICI), and up to $50 \%$ of deaths (9). A systematic analysis of the World Health Organization pharmacovigilance database confirmed a $32.5 \%$ of mortality in patients who had myocarditis associated with the administration of ICIs with a median time-to-onset of 33 days (10). The increased reports of cases in the last years are perhaps consistent with growing recognition of this new clinical syndrome, as well as the more widespread use of ICIs. High-dose IV corticosteroids and withdrawal of ICI are considered the first-line therapy $(1,91$, 92), while alemtuzumab (anti-CD52 antibody), antithymocyte globulin (anti-CD3 antibody), and abatacept (a CTLA-4 agonist) have been proposed in corticosteroid-resistant forms (Figure 1) $(87,93,94)$. Retrospective data suggest that earlier (within the first $24 \mathrm{~h}$ ) and high doses (501-1,000 mg/day) of corticosteroids lead to an improved outcome (95). Prompt diagnosis and immediate treatment of ICI-myocarditis becomes a critical issue among the cardio-oncology population, as indications for ICI increase for various cancer types. In 2021, nearly 50\% of cancer patients are eligible for ICI treatment. In many cases, ICIs are combined with other cancer therapies with their own inherent cardiotoxicities (96-98). In addition, long-term cardiovascular effects of ICI become an important consideration as a growing number of cancer patients respond to therapy (99-101). Finally, the emergence of ICI-myocarditis has opened new avenues for more fundamental investigation about the role of immune checkpoints (e.g., PD-1/PD-L1 signaling) in other forms of inflammatory heart disease $(102,103)$. These issues need to be a focus of future investigations.

\section{Ventricular Arrhythmias and Myocarditis}

AM can be complicated by VA. Specifically, $\sim 40 \%$ of patients presenting with life-threatening VA can experience a recurrence at a median time of 8 months based on a recent international registry including 156 patients (104). Factors associated with arrhythmic recurrence were initial presentation with sustained VT, LGE involving $\geq 2$ myocardial segments, and absence of T2-weighted short-tau inversion recovery (STIR) signal suggestive for residual edema on CMRI (104). In this registry, 98 patients underwent EMB showing in the large majority of cases a lymphocytic myocarditis (88.8\%). An immunosuppressive therapy was initiated in $21 \%$ of cases and there was no difference in the use of immunosuppressive therapy between patients who subsequently experience an arrhythmic recurrence vs. those who did not (104). A second registry of 185 patients with VA (including VF/VT, non-sustained VT, and Lown's $\geq 2$ premature ventricular complexes [PVC]) and myocarditis confirmed a $30 \%$ of recurrence of malignant VA at 2 years (105). Another study evaluated 58 patients with histologically proven lymphocytic myocarditis and VA as above described who underwent immunosuppressive therapy vs. a matched population of 58 cases not treated with immunosuppressive agents (2). Immunosuppressive therapy in most patients was a combination of prednisone $1 \mathrm{mg} / \mathrm{kg}$ for 6 month and AZA $2 \mathrm{mg} / \mathrm{kg}$ for 1 year. Alternatively, mycophenolate mofetil at dosage of 1-3 g/day was used instead of AZA. At 24-month follow-up, no significant differences in VF/VT occurrence were observed in patients treated with immunosuppressive agents vs. those who did not (10 vs. $17 \%$, respectively, $p=0.42$ ), even if patients who were treated with immunosuppressive agents showed a significant reduction in the PVC burden (2). Another prospective registry included 107 symptomatic patients with $>5,000 \mathrm{PVCs} / 24 \mathrm{~h}$ without ischemic etiology who underwent a combination of laboratory testing, FDG-PET scan, CMRI and EMB (106). A positive FDG-PET scan consistent with cardiac inflammation was observed in up to $51 \%$ of patients and CS was the final diagnosis in $24 \%$ of patients with positive FDG-PET scan. Patients with signs consistent with myocarditis started an immunosuppressive therapy (prednisone $40 \mathrm{mg}$ for 3 months) alone or in combination with catheter ablation, showing an optimal response in $67 \%$ of cases. Optimal response was defined as a reduction in the PVC burden $>80 \%$ and negative FDG-PET scan at follow up. Furthermore, patients with LV systolic dysfunction showed an improvement in $37 \%$ of cases with a mean increase in LVEF of $13 \%$ (106). Although these studies are promising, the lack of randomization vs. a control group, the absence of reports of side effects and the fact that the immunosuppression therapy did not significantly reduce VF/VT or cardiovascular death cannot routinely support the use of corticosteroids in the management of patients with myocarditis complicated by VA or frequent PVC. Specific randomized trials are required to assess whether immunosuppression can ameliorate myocardial inflammation and reduce the risk of major VA. In addition, VA is especially a hallmark of ICI-myocarditis. In an international registry of patients with ICI-myocarditis, consisting of 147 patients, a total of $22(15.0 \%)$ patients experienced 1 or more life-threatening ventricular arrhythmia episodes, including 16/147 (10.9\%) sustained ventricular tachycardia, 4/147 (2.7\%) ventricular fibrillation, and 2/147 (1.4\%) torsade de pointes (107).

\section{COVID-19 Associated Acute Myocarditis}

Cardiac injury with release of troponin has been observed quite often in patients who were hospitalized with COVID-19 (108), nevertheless cases of well-characterized AM are anecdotal (3). Data on clinically suspected AM complicated by acute HF among hospitalized patients with COVID-19 suggests a $0.12 \%$ incidence (109). Nevertheless, good data on the incidence of $\mathrm{AM}$ are still lacking. It has been recognized that asymptomatic forms of AM associated with severe acute respiratory syndrome coronavirus 2 (SARS-CoV-2) exposure range between 0.3 and $3 \%$ based on a CMRI diagnosis. This population has been largely studied among athletes who underwent systematic cardiac tests (ECG, troponin assessment, or transthoracic echocardiography) and, when clinically indicated, CMRI (110-112). It must be acknowledged that proportionally, individuals with mild 
COVID-19 related symptoms have a higher likelihood of signs of myocardial inflammation compared with asymptomatic individuals. Patients with cardiac tests consistent with AM should be advised not to practice vigorous physical activities in the 3-6 months following SARS-CoV-2 exposure if they have preserved LVEF, whereas if patients have reduced LVEF, patients should initiate specific HF therapies (113), while there is no indication for immunosuppression. Patients complaining of cardiac symptoms or signs associated with COVID-19 and diagnostic findings consistent with AM can be further divided between those with COVID-19 associated AM with concurrent pneumonia and those without pneumonia (isolated COVID-19 myocarditis). Delayed-onset AM has been described after SARSCoV-2 exposure and typically these patients can present with high titer of SARS-CoV-2-specific antibodies and recent history consistent with COVID-19 in the absence of SARS-CoV-2 by RT-PCR on a nasopharyngeal swab. Delayed-onset myocarditis is thought to be triggered by SARS-CoV-2 induced immunemediated reactions. Immunomodulating therapies include nonsteroidal anti-inflammatory drugs (NSAIDs) to relieve chest pain, low dosage of colchicine in case of associated pericardial involvement. Corticosteroids are generally used in patients with delayed onset AM that present an associated hyperinflammatory status $(114,115)$. In severe COVID-19 AM presenting as FM, EMB can be deemed necessary with the aim to differentiate AM from sepsis-induced acute cardiomyopathy, especially in patients with hyperinflammatory status. Identification of inflammatory infiltrates in the myocardium could support the empirical use of immunosuppressive drugs (33), even if, diffuse inflammatory infiltrates have been rarely seen (116). Hyperinflammatory status and acute HF/cardiogenic shock in which a predominant septic state has been excluded could be treated with immunosuppressive treatments, as suggested by small series where intravenous corticosteroids have been associated with a favorable prognosis $(114,115)$. This condition has been termed multisystem inflammatory syndrome in adults (MIS-A) and is often associated with a delayed onset of myocarditis. The condition is usually associated with high levels of inflammatory biomarkers and ferritin (117). The Multisystem inflammatory syndrome in children (MIS-C) presents overlapping characteristics with myocarditis in adults (118). It has been that although a third of patients with MIS-C can require a t-MCS, but none died in a series of 35 children who were treated with IVIG plus a third with the addition of corticosteroids (119). Finally, patients with concurrent severe myocarditis, pneumonia, and respiratory insufficiency should receive corticosteroids (120). A review article that collected data on 38 published cases of COVID-19 associated AM reported use of corticosteroids in $34 \%$ of cases and a mortality of $15 \%$ (121), even if larger series are needed to better understand optimal therapies.

\section{mRNA COVID19 Vaccine-Related Acute Myocarditis}

The association between vaccine administration and the onset of myocarditis is supported by several case reports, case series, and at the level of the national health care system $(4-7,122-$ 124). The United States Vaccine Adverse Event Reporting System (VAERS), even if subject to bias, also revealed a clear signal for vaccine-associated myocarditis with nearly 1,300 cases reported from more than 350 million doses in the United States (8). Most cases have been reported in young men, thus, for 18-24year-old males, the expected prevalence of vaccine-associated myocarditis is $\sim 3$ cases per 100,000 doses $(0.003 \%)$ based on VAERS data (8). Nationwide observational data confirmed a COVID-19 vaccine-associated myocarditis at $\sim 3$ per 100,000 patients $(0.003 \%)$ vs. $\sim 11$ per 100,000 patients $(0.01 \%)$ for acute COVID-19 myocarditis (125). An analysis conducted in England revealed that the increased risk of myocarditis associated with the two mRNA vaccines was present only in those younger than 40 years (6).

Historically, the vaccine that is most associated with myocarditis is the anti-smallpox $(10,126)$. Smallpox vaccine was associated with eosinophilic myocarditis, while almost all the present cases of mRNA COVID-19 vaccine are not associated with eosinophilia. We revised 90 cases published of mRNA COVID-19 vaccine myocarditis up to the end of August 2021 (see Supplementary Tables 1, 2), and we summarized major features, and anti-inflammatory and immunomodulatory drugs used. The median age at presentation was 25 years (interquartile range $17-27)$, in agreement with a median age observed in VAERS (8), with a marked male prevalence (93\%). Even if a higher number of BNT162b2-related myocarditis is reported, disproportionality analyses using the Bayesian information component, revealed a higher likelihood of association between mRNA 1273 and myocarditis (126). In $90 \%$ of cases, myocarditis occurs after the second dose, following a median time of 3 days between the last dose and symptoms' onset, including chest pain (observed in $96 \%$ of cases) generally preceded by fever (in 85\%). All these findings suggest an immune-mediated reaction related to vaccine administration. AM is generally not severe. While electrocardiographic abnormalities are present in $77 \%$ of cases, diagnostic tools revealed only a slight reduction in the LVEF (mean value of 53\%) with a pericardial effusion observed in $14 \%$ of cases. Information on anti-inflammatory/immunomodulatory therapy was available for 56 of 90 patients (62.2\%). In 38 out of 56 patients, the administered drugs were reported as follows: aspirin, NSAIDs, corticosteroids, IVIG, colchicine, and anakinra. Patients who received anti-inflammatory/immunomodulatory therapy did not differ in relation with age (23 \pm 9 vs. $29 \pm 19$ years, $p$-value 0.10$)$ and LVEF on the first echocardiogram (53 \pm 11 vs. $53 \pm 13 \%$, $p$-value 0.90$)$. The use of immunosuppressive therapy was similar in the adult and pediatric populations $(39.5$ vs. $44.4 \%, p$-value 0.72 ). Overall, NSAIDs (including aspirin) were the most used drugs (23/56 patients, $41.1 \%)$, and aspirin was used only in 3 out of 56 patients (5.4\%). Corticosteroids were used in 19 of 56 patients (33.9\%), IVIG in 12 patients (21.4\%), colchicine in 15 patients $(26.8 \%)$, and anakinra in only 2 patients. Most of the time, immunosuppressive agents were used in combination. NSAIDs were used together with the corticosteroids in 5 patients. IVIG along with corticosteroids was used in 11 patients, including 10 pediatric patients. NSAIDs along with colchicine were used in 11 of 56 patients (19.6\%). Prognosis 
is considered favorable, with only three (3.3\%) deaths reported out of 90 patients, a figure in line with the one observed in AM patients in pre-COVID19 era (40). These data are largely consistent with a series of 139 adolescents (all with age $<21$ years) with suspected AM within 30 days of COVID-19 vaccination (7). In fact, the male prevalence was $91 \%$, symptoms started a median of 2 days after vaccination, and the most common symptom was chest pain (99\%) (7). Again, NSAIDs were the most used drugs in $81 \%$ of cases, followed by corticosteroids (22\%) and IVIG (22\%), while colchicine was administered in $8 \%$ (7). No patient died or required a t-MCS.

\section{EOSINOPHILIC MYOCARDITIS}

Eosinophils have widespread procoagulant effects, including the production of tissue factor (127), oxidation of phospholipids (128) (both of which activate the intrinsic pathway), the release of platelet-activating factor (129), reactive oxygen species, and eosinophil extracellular traps (130). Moreover, activated eosinophils are potent producers of vasospastic mediators (including histamine, leukotrienes $\mathrm{C}_{4}$ and $\mathrm{D}_{4}$ and prostaglandin $\mathrm{D}_{2}$ ) and are able to modulate mast cell functions (131). Lastly, the shedding of both cytotoxic granules and proinflammatory mediators (i.e., tumor necrosis factor $[\mathrm{TNF}]-\alpha$, IL-1 and IL-6) are contributing factors of endothelial injury and procoagulant state (132). Eosinophil-mediated toxicity can lead to protean cardiovascular manifestations, including venous thromboembolism (133), eosinophilia-related coronary vasospasm (134), thromboangiitis obliterans-like disease (135), eosinophilic coronaritis, systemic eosinophilic vasculitis (136), eosinophilic myocarditis (137), and Loeffler cardiomyopathy, a chronic inflammatory cardiomyopathy $(1,138)$. The natural history of eosinophil-related heart involvement involves three successive (and potentially overlapping) phases: (1) $\mathrm{AM}$, due to eosinophilic infiltration of the endocardium, that can be either asymptomatic or lead to acute HF or FM (137). High troponin levels, LV systolic dysfunction, and subendocardial LGE pattern on CMRI can be observed $(2,137)$ a thrombotic stage characterized by the occurrence of ventricular thrombi and the risk of systemic embolism; (3) a fibrotic stage, characterized by endomyocardial fibro-thrombosis that can lead to restrictive cardiomyopathy (i.e., Loeffler cardiomyopathy) and/or atrioventricular valvular disease (139). The diagnosis of eosinophilic myocarditis is usually straightforward in the presence of hypereosinophilia, increased cardiac troponin, and CMRI consistent with subendocardial inflammation (137). EMB can be considered when the initial presentation is characterized by cardiogenic shock $(1,33)$, or CMRI findings are atypical (i.e., subepicardial LGE) or when absolute eosinophil counts are within the normal range (which has been reported in up to $25 \%$ of patients with biopsy-proven eosinophilic myocarditis) $(137,139)$. Conversely, EMB is at risk of thromboembolism if ventricular thrombi are present, and can yield false-negative findings when endomyocardial fibrosis is prominent and eosinophil infiltration has partially or completely vanished (138). Eosinophil-related heart involvement can be encountered within the full spectrum of eosinophil-associated diseases (137), including drug hypersensitivity (even in the absence of skin manifestations) (10), parasitic infections (namely toxocariasis, trichinosis, filarial infections or sarcocystosis), aspirinexacerbated respiratory disease, eosinophilic granulomatosis with polyangiitis (EGPA, formerly Churg-Strauss syndrome), hypereosinophilic syndromes (HES) (mainly idiopathic and FIP1L1-PDGFRA-associated HES, formerly chronic eosinophilic leukemia) and high-grade hematological malignancies [e.g., Hodgkin and angioimmunoblastic T-cell lymphomas, as well as B-cell acute lymphoblastic lymphoma with $\mathrm{t}(5,14)$ (q31;q32); IGH-IL3 rearrangement (140). In a review of 179 cases of biopsy-proven eosinophilic myocarditis, the main identified causes were drug hypersensitivity, EPGA, HES and parasitic infection, accounting for $34 \%, 13 \%$ and $8 \%$ of cases, respectively, while $36 \%$ of cases were idiopathic or eosinophilic myocarditis with undefined cause (137).

Heart involvement is the leading cause of death in patients with EGPA and is more frequent in antineutrophil cytoplasmic antibodies (ANCA)-negative patients (141). Of note, the differential diagnosis between ANCA-negative EGPA and HES is a frequent diagnostic and therapeutic dilemma. The European Respiratory Society and European Federation of Internal Medicine-endorsed Task Force suggested restriction in the use of EGPA to patients with eosinophilic asthma who test positive for ANCA and/or who exhibit genuine features of vasculitis (either biopsy-proven or clinical surrogates) (142). Likewise, in a retrospective analysis of 166 patients with blood eosinophilia $>1,000 / \mathrm{mm}^{3}$ and systemic manifestations, it was recently suggested that serum CRP levels could be a reliable biomarker able to distinguish EGPA from idiopathic HES, with low (i.e., < $36 \mathrm{mg} / \mathrm{L}$ ) levels being suggestive of idiopathic HES rather than EGPA (143). A workup to identify associated systemic disorders should be performed in all patients with eosinophilic myocarditis. The workup should include testing for ANCA (positive in 10-40\% of EGPA patients), serological testing for toxocariasis (which has a broad geographic distribution), ova and parasite tests (while further serologies for parasitic infections are generally guided by the patient's country of origin, travel history and dietary habits), serum vitamin B12 and tryptase levels (which are sensitive for the diagnosis of myeloid variant HES), total IgE levels (which are suggestive of reactive polyclonal eosinophilia mediated by IL-5, when elevated), lactate dehydrogenase (suggestive of lymphoma), thoraco-abdominopelvic CT scan (seeking for extra-cardiac eosinophil-related organ involvements as well as underlying solid or hematological malignancies). Furthermore, brain CT or brain MRI should be performed when embolic stroke is suspected in patients with eosinophilic myocarditis or Loeffler cardiomyopathy (144). Additionally, testing for FIP1L1PDGFRA fusion gene should be performed in selected cases when clinical (e.g., male sex, splenomegaly), biologic (e.g., high B12 vitamin and/or tryptase levels) features and/or primary resistance to steroids are observed (145). Polymerase chain reaction testing for specific viruses (e.g., Herpesviridae, especially $\mathrm{HHV}$ 6) and the RegiSCAR scoring system can be useful in patients with suspected Drug Reaction with Eosinophilia and Systemic Symptoms (DRESS) (146). Additional imaging, endoscopic and histologic investigations are usually performed on a caseby-case basis after first-line investigations. In a retrospective 
series of 19 patients with biopsy-proven myocarditis with fulminant presentation, the rate of either cardiac death or heart transplantation at 60 days was up to $26 \%$ (11).

The cornerstone of the treatment relies on systemic glucocorticoids, starting dose: $1 \mathrm{mg} / \mathrm{kg}$ qd, preceded in case of severe LV systolic dysfunction by intravenous pulses of 7.5$15 \mathrm{mg} / \mathrm{kg}$ of methylprednisolone for 1-3 days (Figures 1, 3) $(137,139)$. In patients at risk of strongyloidiasis (owing to their past travel history), concomitant prescription of a single dose of ivermectin $(200 \mu \mathrm{g} / \mathrm{kg})$ is warranted to prevent Strongyloides stercoralis hyperinfection. When toxocariasis or trichinosis are evidenced, a 10/15-day course of albendazole (400 mg bid) is warranted (147). Likewise, in patients with evidence of intracavitary thrombus, anticoagulation should be initiated (while prophylactic anticoagulation is mandatory in all other patients until absolute eosinophil counts normalize). The diagnoses of myeloid variant HES, DRESS or EGPA should be suspected and investigated accordingly, after 24 days of corticosteroid-refractory eosinophilia. Specifically, the treatment of FIP1L1-PDGFRA-positive HES relies on the tyrosine kinase inhibitor imatinib (100 mg/d), and eosinophils generally plummet within days after imatinib initiation (145). Yet, transient worsening of HF after onset of imatinib has been reported, likely due to treatment-induced lysis of eosinophils (148). Conversely, IVIG and/or cyclosporine are the most common drugs used for the treatment of corticosteroidrefractory DRESS $(149,150)$, yet benralizumab (a humanized afucosylated monoclonal antibody that targets IL-5 receptor $\alpha$ ) is on the rise in this setting (151). Historically, besides systemic corticosteroids, the treatment of EGPA-associated eosinophilic myocarditis complicated by severe HF relies on cyclophosphamide pulses $(152,153)$, yet it should be emphasized that there is no data proving that adding cyclophosphamide pulses to steroids improves outcomes. Whatever the underlying disorder, the aim is to quickly and persistently normalize eosinophil count $\left(<500 / \mathrm{mm}^{3}\right)$. Of note, both in EGPA (154$156)$ and in FIP1L1-PDGFRA-negative HES $(157,158)$ targeting IL-5 has emerged as clinically relevant. Anti-IL-5 agents, such as mepolizumab and benralizumab are likely to become game changers and tend to replace the use of disease-modifying anti-rheumatic drugs (i.e., AZA, methotrexate, peginterferon alpha-2a and hydroxycarbamide), even if trials are needed. In case of persistent eosinophilia and subsequent occurrence of endomyocardial fibrosis, heart surgery with resection of fibrotic endocardium (endomyocardectomy) combined with valve repair or replacement can be considered (159). Finally, in case of refractory end-stage $\mathrm{HF}$, orthotopic heart transplantation has been reported to be safe and feasible in both EGPA and HES $(160,161)$.

\section{GIANT CELL MYOCARDITIS}

GCM is a rare but often fatal form of AM. The pathophysiology of GCM is thought to be a T-cell mediated autoimmune process leading to diffuse or multifocal inflammatory infiltrate, including lymphocytes with multinucleated giant cells, and definitive diagnosis requires EMB. An immune-mediated mechanism in the etiology of GCM is further supported by the fact that no nucleic acids from viruses implicated in myocarditis were detected in cardiac tissue samples from 9 patients with GCM (162).

However, the characteristic giant cells can take 1-2 weeks to appear, therefore, while EMB in the first few days of the illness may suggest myocarditis, it may render a false negative result for GCM; for this reason, EMB repetition can increase sensitivity in GCM diagnosis (163). It has been estimated to occur at a rate of 1 case per 200 patients with AM and constitutes about $10 \%$ of FM $(11,13)$. GCM affects men and women equally with a median age at onset between 43 and 53 years. Association with other autoimmune disorders has been observed in about $20 \%$ of cases, especially autoimmune thyroiditis and inflammatory bowel disease (59). Recent data where RNA-Sequencing (RNASeq) was applied to a small series of GCM cases reveals a distinct transcriptomic signature for GCM compared to other forms of myocarditis (164). Specifically, it has been observed downregulation of pathways involved in muscle contraction, ion homeostasis, and cardiac conduction, potentially explaining the typical patient presentation with acute heart failure and arrhythmias) (164).

Clinically, GCM generally presents with rapid hemodynamic deterioration (FM), VA, and at times bradyarrhythmia. The rate of death or HTx has been estimated at $81 \%$ at 3 years from the initial admission when GCM presents specifically as FM (11); whereas a $73 \%$ mortality rate at 5 years has been estimated more recently considering all GCM (165). It is characterized by the lack of spontaneous recovery on t-MCS which more commonly occurs in FM. Prolonged use of intravascular microaxial pump and VA-ECMO has been reported (166-168). Pharmacologic treatment includes multi-drug immunosuppression that typically involves combinations of anti-T-cell drugs (i.e., antithymocyte globulin, muromonab and cyclosporine) and high dose corticosteroids. No standardized protocols exist, though several regimens have been proposed in recent review articles (1, 169). Clinically relevant, immunosuppressive therapy should be initiated promptly. Treatment with antiT-lymphocyte-based and calcineurin inhibitor therapy can lead to clinical remission in up to two-thirds of patients, in particular in those not requiring t-MCS $(163,168)$. The initial approach may vary based on the clinical presentation. In case of FM, antithymocyte globulin (dose raging from $1 \mathrm{mg} / \mathrm{kg}$ to $300 \mathrm{mg}$ in the first 3 days) associated with pulsed high-dose corticosteroids (generally $1 \mathrm{~g}$ methylprednisolone per 3 days) is preferred; even if alternative protocols including alemtuzumab (an anti-CD52 antibody; at dose of $15 \mathrm{mg}$ per 2 days) instead of antithymocyte globulin have been reported. Cyclosporine is then added and titrated to trough levels of 150 to $250 \mathrm{ng} / \mathrm{L}$ as maintenance therapy. There is a variable rate of LVEF recovery without transplant. Dosage of oral prednisone after the acute phase is generally $1 \mathrm{mg} / \mathrm{kg}$ in the $1 \mathrm{st}$ months with subsequent slow tapering over 1 year, while cyclosporine is generally maintained $>2$ years, with a target plasma through level of $80-100 \mathrm{ng} / \mathrm{L}$. AZA at $1-2 \mathrm{mg} / \mathrm{kg} /$ day divided into 2 daily doses or mycophenolate mofetil (500-1,000 mg BID) can be 


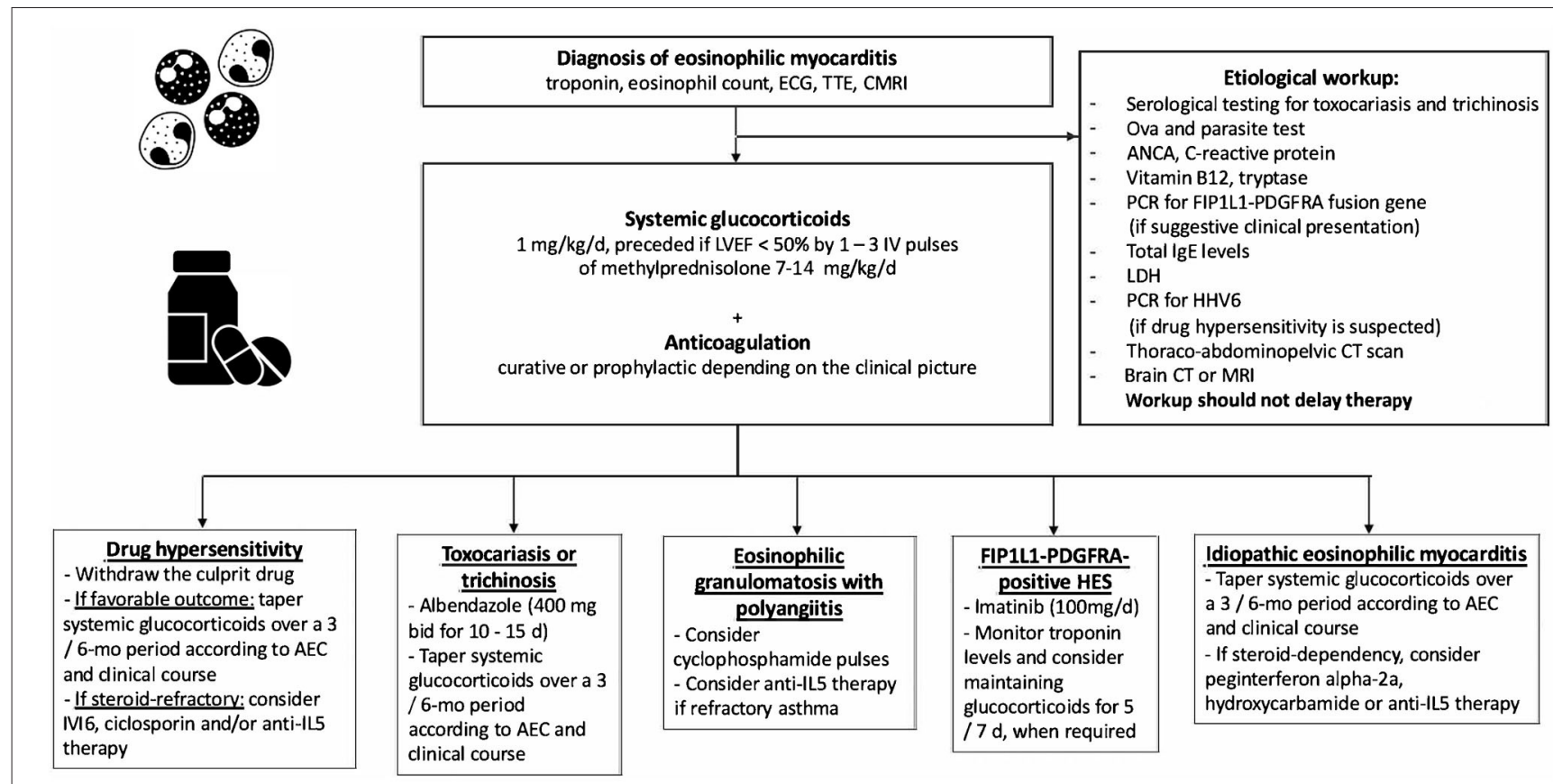

FIGURE 3 | Etiological workup and immunosuppressive treatment strategies used for eosinophilic myocarditis. TTE, transthoracic echocardiography; CMRI, cardiac magnetic resonance; LVEF, left ventricular ejection fraction; ANCA, antineutrophil cytoplasmic antibodies; PCR, polymerase chain reaction; LDH, lactate dehydrogenase; HHV6, human herpes virus 6; CT, computed tomography; d, day; mo, month; AEC, absolute eosinophil count; HES, hypereosinophilic syndrome.

added. In case of non-fulminant presentation a combination of mycophenolate mofetil and cyclosporine (or tacrolimus, trough levels in the first 6 months: $10-15 \mathrm{ng} / \mathrm{mL}$ ) and corticosteroids can be added. Also, in cases with less severe presentation, pulsed high-dose corticosteroids are still suggested. If no recovery is obtained, HTx is an effective therapy, with similar posttransplant survival in patients with GCM as in those with other causes (170). Nevertheless, recurrence of GCM can happen in up to $25 \%$ of transplant patients, and again warrants aggressive immunosuppression which is typically sufficient for disease remission (169).

\section{CARDIAC SARCOIDOSIS}

CS can present as a chronic inflammatory cardiomyopathy, while infrequently can manifest as an $\operatorname{AM}(1,165)$. The most reported clinical cardiac features are complete AVB, VA, LV systolic dysfunction and HF $(165,171)$. CS can be isolated or be part of a systemic disorder that meanly affects lungs and hilar lymph nodes. About $5 \%$ of patients with systemic sarcoidosis have clinically manifest CS (172). Myocardial histology is the gold standard of CS diagnosis but has low sensitivity (20-30\%) (1). Histology is characterized by the presence of epithelioid granulomas with associated giant cells and lymphocytes, welldefined areas of inflammation and fibrosis, and absence of significant myocardial necrosis (1). Therefore, quite often the diagnosis of CS can be supported by clinical and imaging findings with contrast-enhanced CMRI and FDG-PET $(1,173)$. Based on this assumption, it must be accepted that if the diagnosis of CS relies on clinical and imaging criteria, we could face the risk of treating with immunosuppressive therapies patients with other inflammatory or non-inflammatory cardiomyopathies that are potentially less responsive to long-term steroid therapy or might be potentially harmed by the treatment. The immunosuppressive therapeutic approach to patients with CS is similar either presenting as a chronic inflammatory cardiomyopathy or as an AM, and it is based on corticosteroids as first line therapy (Figures 1, 4) (1). Unfortunately, no randomized controlled trial supports the immunosuppressive therapy in CS, neither for corticosteroids nor for any disease-modifying therapy. Despite lack of evidence almost all patients with CS receive systemic therapy. This is distinctly different from pulmonary sarcoidosis in which only half of the patients need systemic therapy (174). We do not know at present whether these patients with a good prognosis and mild myocardial involvement benefit from immunosuppressive therapy. Patients having at the time of initial presentation, normal LV function and only $5 \%$ of LGE, have very few adverse events (175).

\section{Corticosteroids}

There is still controversy about the clinical efficacy, the optimal initial dose and duration of corticosteroid treatment for CS. It is plausible to assume that corticosteroids have similar effect in CS than in other forms of sarcoidosis. Consistent with this idea glucocorticoid treatment decreases myocardial troponin (176). By expert consensus, corticosteroids still constitute the first-line treatment at relatively high doses for 12 years. Although mechanistically plausible, we do not currently know if corticosteroid treatment improves prognosis in CS. Nevertheless, some patients do not respond to glucocorticoids. 


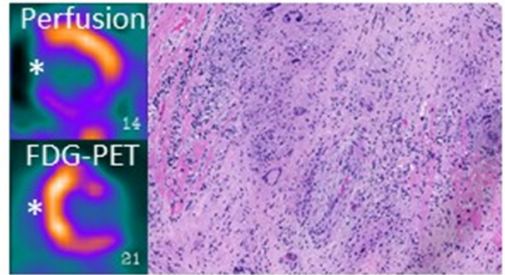

\section{Active cardiac sarcoidosis}
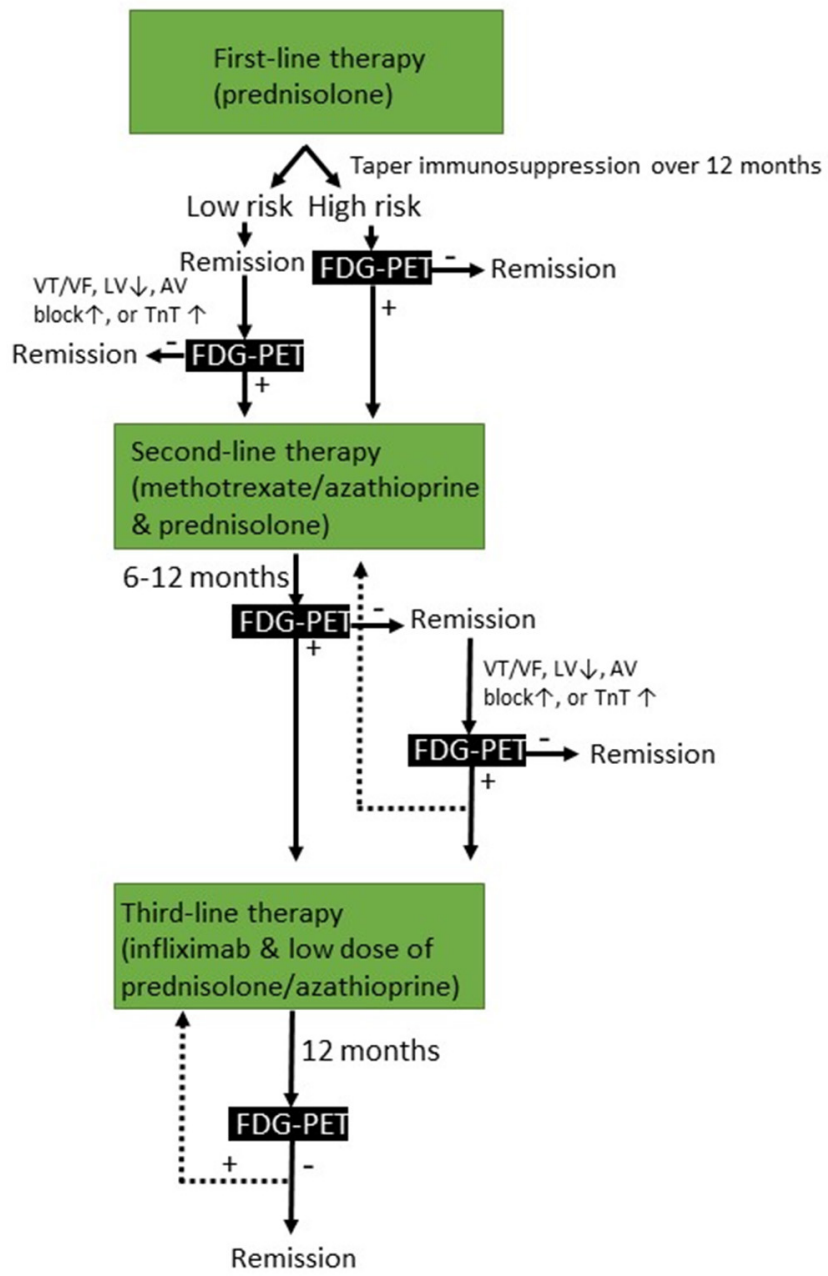

FIGURE 4 | Immunosuppressive treatment strategies used for cardiac sarcoidosis based on clinical and imaging-based monitoring. FDG-PET, fluorodeoxyglucose positron emission tomography; VTNF, ventricular tachycardia/ventricular fibrillation; LV, left ventricular ejection fraction; TnT, troponin.

The clinical evidence for the utility of corticosteroids is based on retrospective, uncontrolled observational studies (177). Corticosteroids have been reported to improve LV systolic function at least in some patients $(176,178,179)$, reverse AVB (180), and decrease VA in some studies but not in others $(181,182)$.

\section{DNA Synthesis Inhibitors}

DNA synthesis inhibitors (such as AZA or methotrexate) that prevent nucleotide synthesis are used as steroid-sparing agents (183). AZA acts by suppressing the activation of Racl target genes such as NF- $\kappa$ B in T-cells (184). AZA and methotrexate have been used to enable rapid reduction in the glucocorticoid doses in order to reduce the dose-dependent side effects of glucocorticoids. Methotrexate combined with glucocorticoids decreases the risk of radiologic relapse in CS $(183,185)$. In pulmonary sarcoidosis, steroid-sparing agents-treated patients had a higher rate of infections compared to prednisone monotherapy (186). The major weakness of glucocorticoids and DNA synthesis inhibitors are their wide-ranging effects beyond immunosuppression.

\section{Infliximab or Other Anti-TNF- $\alpha$ Agents}

TNF- $\alpha$ governs formation of granuloma thought NF- $\kappa$ Bmediated orchestration of cytokine expression and hence controls the hallmark tissue response in sarcoidosis (187). TNF- $\alpha$ antagonists are more selective and effective inhibitors of NF-кB activation than glucocorticoids and thus lack most of glucocorticoid side effects. However, not all the immunosuppressive effects of glucocorticoids may be mediated via NF-кB. Current recommendations based on expert consensus suggest anti-TNF- $\alpha$ agents to be used as a third-line therapy in the management of severe refractory sarcoidosis (188). Infliximab is a chimeric IgG1 monoclonal antibody that binds TNF$\alpha$ with high affinity and neutralizes its effect in promoting inflammatory response. In pulmonary sarcoidosis, randomized, controlled trials with infliximab have shown that it is safe to use if proper precautions are followed $(189,190)$. Infliximab decreases inflammatory activity measured by FDG-PET and this correlated with improvement in forced vital capacity. In pulmonary sarcoidosis FDG-PET activity is predictive for treatment response in severe and refractory pulmonary sarcoidosis (190) and might add value in individualizing infliximab treatment. The effectiveness of adalimumab in pulmonary sarcoidosis was shown in a small open-label study (191). Adalimumab reduces the relapse rate as measured by FDG-PET (183). In CS, infliximab has been used successfully as a bailout therapy in glucocorticoid failures $(192,193)$. In addition to being more specific and potent inhibitor of granulomatous inflammation, a major benefit of TNF- $\alpha$ blockers is the lack of numerous side effects typical of corticosteroids. Despite TNF- $\alpha$ antagonists being very effective immunosuppressants, risk of serious infections is not higher than in corticosteroids (194). TNF- $\alpha$ is well-tolerated at dosage $<10$ $\mathrm{mg} / \mathrm{kg}$ even in patients with HF (195). To reduce the production of neutralizing antibodies, infliximab and adalimumab are often combined with low-dose methotrexate or AZA (196).

\section{Ongoing Trials}

The Cardiac Sarcoidosis Multi-Center Randomized Controlled Trial (CHASM CS-RCT) is a multicenter randomized controlled trial designed to compare treatment with a higher dose prednisone vs. prednisone plus methotrexate (197). The aim is to evaluate whether a low dose prednisone/methotrexate combination have similar efficacy to standard dose prednisone 
leading to an improvement in the quality of life, as a result of a reduced burden of side effects. Eligible subjects will have active clinically manifest CS with advanced conduction system disease, non-sustained or sustained VA, LV or right ventricular systolic dysfunction. The primary endpoint is a measure of myocardial fibrosis/scar, summed perfusion rest score on FDG-PET scan after 6 months from randomization.

\section{IMAGING TO GUIDE IMMUNOSUPPRESSIVE THERAPY IN MYOCARDITIS AND CARDIAC SARCOIDOSIS}

Echocardiography is routinely performed in patients with suspected AM to evaluate LV systolic and diastolic function and the presence of pericardial effusion. However, its role to guide therapy is limited, since it does not allow tissue characterization. CMRI has emerged as a powerful non-invasive diagnostic tool for the assessment of edema, inflammation and fibrosis (198). According to the Updated Lake Louise Criteria, AM can accurately be diagnosed if both edema and myocardial injury (necrosis or fibrosis) are demonstrated by, respectively, T2-weighted (STIR or T2-mapping) and T1-weighted imaging (T1 mapping or LGE) (198). In healed myocarditis, residual scar can be depicted by LGE (with or without elevated focal T1-values), while persistence of edema, as assessed by T2weighted imaging, suggests active inflammation. Moreover, CMRI is the gold standard for quantification of ventricular volumes and function. In this respect, CMRI can be used to select patients who might benefit from immunosuppressive therapy, as well as to evaluate the impact of treatment on myocardial function, ongoing inflammation and scar formation. Furthermore, assessment of the disease stage of myocarditis is especially relevant for patients with myocarditis and drugrefractory $\mathrm{VT}$, as recent data show a high recurrence rate post VT ablation if signs of active myocarditis are present on EMB or CMRI (199). Importantly, the Lake Louis Criteria are less accurate in detecting active myocarditis in the context of systemic immune-mediated diseases $(200,201)$, making CMRI less suitable to guide therapy in this setting. In sarcoidosis, the presence of LGE is a sensitive marker of cardiac involvement, but assessment of active inflammation by T2-weighted imaging is not well-validated. However, extensive LGE ( $>20 \% \mathrm{LV}$ mass) is associated with a poor prognosis and absence of $L V$ recovery after immunosuppressive therapy with corticosteroids (202). In this respect, CMRI is mainly used for diagnosis and prognostication in CS.

New advances in the field of CMRI include the enhancement of ultrasmall superparamagnetic particles of iron oxide (USPIO), which are nanoparticles that are taken up by monocytes and macrophages, to directly visualize cardiovascular inflammatory processes (203). A pre-clinical study in a rat model with experimental auto-immune myocarditis showed that USPIOenhanced CMRI outperformed conventional CMRI regarding the detection of myocardial inflammatory cellular infiltrates (204), but the only study in humans failed to show a difference between patients with AM $(n=9)$ and healthy volunteers
( $n=10)$ (205). Therefore, there is currently no role in clinical practice for USPIO-enhanced CMRI in the diagnosis or followup of patients with myocarditis.

FDG-PET can detect T cells, macrophages, or granulocytes that infiltrate the myocardium, either as non-specific response to cell injury or as primary lesion in CS by an enhanced glucose metabolism after a carbohydrate-free diet. FDG-PET is recommended by several guidelines in patients with suspected active CS $(172,206)$, in fact, it can reveal hypermetabolic mediastinal and hilar lymph nodes differentiating CS from other autoimmune disease with cardiac involvement (e.g., vasculitis). Since FDG uptake correlates well with the level of granulomatous inflammation, it is assumed that immunosuppression should be up titrated in patients with increased metabolic activity on FDG-PET after steroid therapy has been initiated (207), while a dose reduction can be considered in patients with reduced FDG uptake. A recent study by Ning et al. (208) showed that serial FDG-PET in patients with CS altered patient management in most cases, resulting in complete weaning or significant tapering of prednisolone in 48 and 20\%, respectively (Figure 4), while outcome was generally favorable. FDG-PET can be also considered as an alternative non-invasive diagnostic tool in hemodynamically stable patients with contraindication to CMRI or in patients with suspected autoimmune disease to guide immunosuppression (Figure 5) (1).

\section{NEW INSIGHTS ON PERICARDITIS}

Pathologies of the pericardium are a heterogeneous group, spanning from minimal pericardial effusion, often asymptomatic, to incessant multidrug-resistant pericarditis (209). Acute pericarditis is diagnosed based on two of the following criteria (210): chest pain, pericardial rubbing, typical changes in the electrocardiogram, with new and widespread ST elevation or PR depression in the acute phase, and pericardial effusion, which is generally mild. Increased CRP levels can support the diagnosis. The natural history of acute pericarditis can vary. In most cases, it can be self-limiting with complete resolution of the symptoms, whereas in some cases it can relapse. The development of relapses increases by up to $50 \%$ in patients who have received corticosteroid therapy for symptomatic control of the first episode. Some patients can develop incessant pericarditis, a pericarditis whose symptoms continue without interruption even for months (210). The etiology of pericarditis changes considerably depending on the geographic regions (211). In developing countries, pericarditis is often secondary to tuberculosis (212). On the other hand, in developed countries, pericarditis is more often idiopathic, secondary to autoinflammatory or autoimmune processes or following pericardial injury such radiotherapy or cardiac surgery (211).

\section{The Autoinflammatory Processes in Recurrent Pericarditis}

Clinical and laboratory similarities between relapsing pericarditis and some autoinflammatory disorders (i.e., familial Mediterranean fever [FMF], cryopyrin-associated periodic syndromes [CAPS], TNF receptor associated periodic 

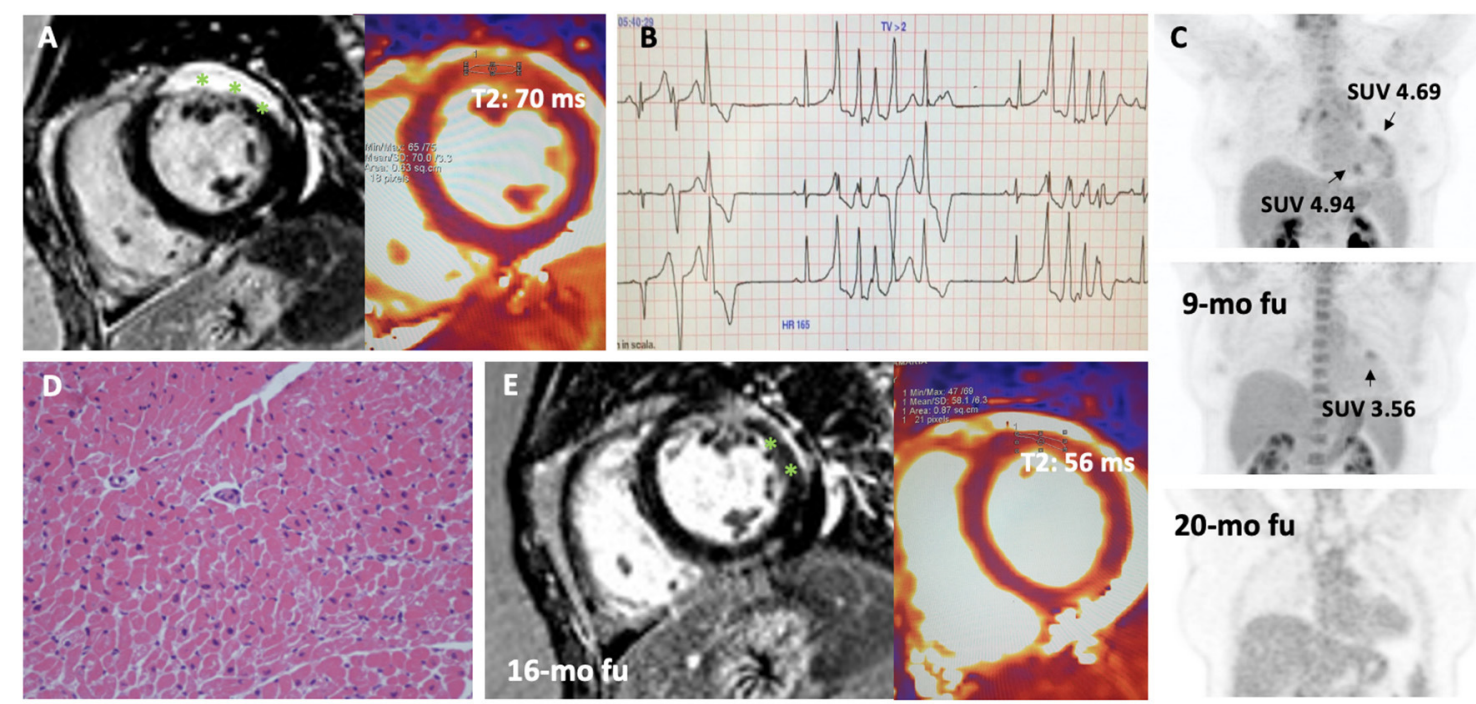

Presenting features

Peak hs-tnT 2342 ng/L - CKMB 59 U/L

CMRI: increased T2 signal, LVEF 58\%, LGE

Arrhythmic burden

FDG-PET uptake in the heart and hilar nodes

Negative coronary CTA, EMB not diagnostic

\begin{tabular}{|l|}
\hline Therapy \\
Pulsed methylprednisolone \\
Maintenance therapy with \\
prednisone and MTX plus \\
bisoprolol \\
Shift to MMF and colchicine
\end{tabular}

Follow-up

Normalization of hs-tnT levels

CMRI: reduction of $T 2$ signal,

LGE remains suggesting residual fibrosis

Reduction of PVC burden

No residual inflammation on FDG-PET

FIGURE 5 | Representative patient with acute myocarditis in whom immunosuppression was guided by FDG-PET and cardiac magnetic resonance imaging (CMRI). A 49-year-old woman with a previous history of ANA positive pericarditis presented with acute myocarditis. On CMRI she presented a transmural lesion in the anterior wall as demonstrated by late gadolinium enhancement (LGE, highlighted with asterisks) and increased T2 signal (normal value $<55 \mathrm{~ms}$ ) (A). Left ventricular ejection fraction (LVEF) remain preserved, but a ventricular arrhythmic burden was observed on telemetry monitoring with frequent premature ventricular complexes (PVC) and non-sustained ventricular tachycardia (NSVT) (B). An FDG-PET showed 3 focal areas of uptake in the heart with increased standardized uptake values (SUV), and an uptake in hilar nodes raising the suspect for cardiac sarcoidosis (C). A septal endomyocardial biopsy (EMB) from the right ventricle was non-diagnostic for myocarditis or cardiac sarcoidosis (D). Peak high sensitivity troponin T (hs-tnT) levels was 2,342 ng/L. After initial pulsed methylprednisolone, prednisone was started in combination with methotrexate (MTX) and later shift to mycophenolate mofetil (MMF) and colchicine plus bisoprolol with normalization of troponin levels, and no signs of residual inflammation on FDG-PET (C), and a reduction of PVC burden. Accordingly, CMRI showed a reduction of T2 signal while LGE remains suggesting an area of residual fibrosis (E).

syndromes [TRAPS] and systemic-onset juvenile idiopathic arthritis [Still's disease]) suggested a common etiological pathway (213-224). Likely, relapsing pericarditis presents family aggregation in $10 \%$ of patients (225). FMF is an autosomalrecessive disease that mainly affects patients in the Mediterranean basin (213-218). Symptoms are characterized by self-limiting and recurrent fevers associated to serositis, affecting the pleura, peritoneum, and synovium. Although not common, pericardial effusions are found in $27 \%$ of patients with FMF, while typical chest pain is found in about $50 \%$ of pediatric patients with FMF. FMF is caused by various missense mutations of the $M E F V$ gene, which encodes a pyrin that composes the NLRP3 inflammasome, NOD-like receptor family pyrin domain 3, altering its functionality. Inflammasomes play a fundamental role in innate immunity and can respond to various stimuli, including damage associated molecular patterns (DAMPs) and pathogen associated molecular patterns (PAMPs) $(226,227)$. DAMPs, also known as alarmins, are released from dying cells. They consist of cytosolic or nuclear-derived proteins which, in contact with the extracellular matrix, undergo denaturation processes with consequent activation of the inflammasome through interaction with pattern recognition receptors (PRRs). In this way they give rise to an inflammatory response on a non-infectious basis (termed sterile inflammation). PAMPs, on the other hand, can be identified as phylogenetically conserved molecular patterns in some microorganisms and viruses, which are recognized by toll-like receptors (TLRs), which in turn activate the inflammasome in response to an infection (227). The inflammasome is a cytosolic macromolecule composed of procaspase, ASC adapter protein and a sensor molecule containing a nucleotide-binding oligomerization domain-like receptor (NLR), which is activated by various stimuli. In FMF, functional changes in NLRP3 inflammasome cause an increased activity of the protein complex (228-230) leading to increased caspase1 activity, higher proIL-1beta into IL-1beta cleavage, and higher circulating levels of IL-1B, a master cytokine of inflammation (231). Thus, FMF manifestations are induced by increased IL-1 levels that cause a hyperactive inflammatory state.

TRAPS are autosomal dominantly inherited syndromes characterized by periodic fevers, occurring every 5-6 days for about 1-3 weeks, associated with serositis, migrating myalgia and rash, caused by missense mutation of the TNF- $\alpha$ receptor gene 
(219-222, 232). Previous studies reported an incidence of acute pericarditis in $7 \%$ of patients with TRAPS, while $25 \%$ of these patients reported chest pain with characteristics that resembles typical pericarditis pain (222). There are also oligosymptomatic forms of TRAPS, caused by mutations in TNFRSF1A, and characterized by delayed onset in which pericarditis can be the only manifestation (221). All these observations shed light on the inflammasome, and the hyperproduction of IL1 in relapsing pericarditis. Similarly, to what observed in the above-mentioned autoinflammatory disorders, in patients with relapsing pericarditis physical injuries via DAMPs as well as infectious agents via PAMPs' pathways can elicit inflammasome hyperactivity and IL-1 overproduction.

\section{Pericarditis as an Autoimmune Process}

Pericarditis can also be a complication of various autoimmune diseases, including SLE, rheumatoid arthritis (RA), Sjogren's syndrome, Behcet's disease, chronic inflammatory bowel diseases and vasculitis, including giant cell arteritis or ANCA-associated vasculitis (233). In SLE, pericarditis is common, affecting 50\% of patients, and generally occurs during disease flares. Pericarditis is usually associated with other serositis, malar rash, arthritis and leukopenia. The severity of pericarditis correlates with multiple serosal involvement. SLE therapies are normally effective (234236). In RA, about $30 \%$ of patients have asymptomatic pericardial effusion on echocardiography, but $<10 \%$ of cases develop symptomatic pericarditis. The incidence of pericarditis in RA patients is higher in those with more severe forms of RA, and higher levels of rheumatoid factor and anti-cyclic citrullinated peptide antibodies (237). Pericarditis can also be the initial sign of a new autoimmune disorder; thus, workup should be prompted after the first episode. Nevertheless, testing for antibodies in all patients with pericarditis is not recommended in the absence of signs or symptoms consistent with an autoimmune disorder (210).

\section{Pericarditis of Uncertain Classification (Post-cardiac Injury)}

Myocardial infarction, radiotherapy, cardiac surgery or even minor procedures such as the positioning of pacemaker leads, or radiofrequency ablations can cause pericardial layers' inflammation. Oxidative stress, cell death or tissue damage can produce the release of autoantigens and, due to altered expression or post-translational modifications, these autoantigens could trigger tolerance break after epitope spreading (238). The prevalence of anti-nuclear antibodies is $43 \%$ in patients with relapsing pericarditis, while it is $10 \%$ in healthy individuals. Similarly, anti-heart antibodies and anti-intercalated disk antibodies are found in $67.5 \%$ of patients with relapsing pericarditis (210). The presence of these autoantibodies could be explained by the release of autoantigens by physical tissue injury, then the exposure of autoantigens would trigger a T/B-cell autoimmune response. Alternatively, these autoantibodies can be just an epiphenomenon. Myocardial injury can cause the release of DAMPs and the consequent activation of the inflammasome with IL-1 overproduction. This hypothesis is corroborated by good response to anti-IL-1 drugs in patients with relapsing pericarditis secondary to myocardial or pericardial mechanical injury (239).

\section{Pericarditis as a Systemic Disorder With Pleuro-Pulmonary Involvement}

Diseases of the pericardium can be isolated or be part of a systemic condition associated a striking increase in CRP levels, erythrocyte sedimentation rate (ESR) values and neutrophilia (240-242). Approximately 53\% of cases have associated pleuropulmonary involvement, $9 \%$ have hepatic involvement and $5 \%$ have peritoneal involvement (242). These conditions are observed more frequently in the pediatric population. Chest CT scan generally shows bilateral pleural effusion with areas of pulmonary atelectasis. Misdiagnosis with pneumonia can lead to antibiotic therapies, especially at the onset when pericardial effusion is mild. When final diagnosis of pericarditis is reached, NSAIDs (e.g., Ibuprofen $600 \mathrm{mg}$ tid) and corticosteroid therapy can improve the condition. Too rapid steroid tapering can lead to pericarditis recurrence and a corticosteroiddependent condition.

\section{Pericardial Effusion}

Pericardial effusion can be isolated or frequently associated with an underlying pericarditis (243). The symptoms span from absent or mild to severe, especially in case of rapid formation. The pericardium tends to adapt better to slowly progressing effusions, while it tends to give compression phenomena when the effusion develops abundantly and rapidly.

Pericardial effusion can result by pericarditis, edematous syndromes including HF and kidney failure, cancer, infectious diseases (i.e., tuberculosis), serositis and autoimmune diseases, and hypothyroidism $(3,212,244,245)$, even if idiopathic pericardial effusion can often occur. A pericardial effusion is defined as chronic when it lasts for more than 3 months and severe when it exceeds $20 \mathrm{~mm}$ in thickness. Among 100 patients with severe $(>20 \mathrm{~mm}$ ), and chronic (>3 months) idiopathic pericardial effusion, 44 patients were asymptomatic, while 56 presented with symptoms, of these 28 presented with dyspnea; 33 patients had diabetes mellitus (246). One subset of patients was symptomatic with a higher age, more likely to be diabetic, with hypertension, chronic obstructive pulmonary disease and atrial fibrillation; whereas a second subset was generally asymptomatic, younger without significant comorbidities. After a mean follow-up of 50 months, no pathology that could explain the pericardial effusion was identified and complete regression of the effusion was observed in 39\%. Adverse events were observed in 38 patients, of which 8 developed cardiac tamponade (2.2\%/year). Among the 100 patients, 30 underwent pericardiocentesis, 12 underwent pericardial windowing and 3 underwent pericardiotomy. Patients who underwent some invasive procedure presented worse outcomes in terms of relapse or complications than untreated patients. This study seems to emphasize that the risk of developing cardiac tamponade is quite low and therapeutic strategies should be tailored on an individual basis based on symptoms. An echocardiographic evaluation every 3-6 months is recommended for the follow-up of these patients, while invasive techniques such as pericardiocentesis or 
pericardiotomy, if separated from specific symptoms, are not recommended (246). Furthermore, we recently showed that a chronic pericardial effusion is present in $37 \%$ of subjects with pectus excavatum, with the size of effusion being related to the anatomical severity of the condition, and these effusions have a good prognosis (247). Thus, in presence of chronic pericardial effusion not related to pericarditis, often with normal or nearnormal serum CRP, we do not recommend any therapy, in particular, we avoid immunosuppressive therapies since there is no evidence of benefit. Low-dose corticosteroids might be considered in few selected patients on a case-by-case basis, but at present no literature deals with this topic. A study reported good efficacy and safety of intrapericardial triamcinolone in patients affected by autoreactive pericarditis with pericardial effusion (248): the use of an intrapericardial route may avoid the typical side effects of the systemic use of corticosteroids. Thus, intrapericardial use of triamcinolone remains a viable therapeutic option for patients with pericarditis and pericardial effusion. Anti-inflammatory or immunosuppressive therapies are often started because the analysis of pericardial fluid is considered suggestive of inflammation, based on the Light's criteria validated for the evaluation of pleural fluid. Data from a recent study determined the reference values of analytes and cells in pericardial fluid (249). Specifically, proteins are 1.7-4.6 g/dl, albumin 1.19-3.06 g/dl, LDH 141-2613 UI/L, total protein in pericardial fluid/serum ratio $0.29-0.83, \mathrm{LDH}$ in pericardial fluid/serum ratio 0.4-42.99. According to the Light's criteria (250), pleural fluid is defined as inflammatory when at least one of the following criteria is satisfied: fluid/serum protein ratio $>0.5$, fluid/serum $\mathrm{LDH}$ ratio $>0.6$, and fluid $\mathrm{LDH}>2 / 3$ of the upper limit for serum levels. The new reference values observed in this population should lead to a reappraisal concerning the classification of pericardial fluid as exudate or transudate based on Light's criteria. Efforts should be taken to stop interpreting pericardial fluid as an exudate or transudate based on evaluation tools that are not validated for this type of fluid, given the risk of misinterpreting non-inflammatory effusions into inflammatory exudates. Elevated LDH found in physiological pericardial fluid might be caused by the release of LDH by mesothelial cells, which are particularly abundant in normal pericardial fluid (249).

\section{COVID-19 Associated and mRNA COVID-19 Vaccine-Related Acute Pericarditis}

Based on a retrospective cohort study, of 718.365 patients with COVID-19, 10.706 (1.5\%) developed new-onset pericarditis. Sixmonth all-cause mortality was $15.5 \%(n=816)$ for pericarditis and $6.7 \%(n=356)$ in matched controls $(p<0.0001)$, odds ratio 2.55 (95\% CI: 2.24-2.91) (251). At present, only 2 published studies focused the attention toward anti-COVID19 vaccine-related acute pericarditis. Barda et al. reported in Israel an incidence of 26 cases out of 884.828 vaccinated individuals $(3 / 100.000)$ vs. 18 out of 884.828 unvaccinated controls (2/100.000); RR 1.27 ( $\mathrm{p}=$ non-significant) (124). Diaz et al. described 37 cases in US, with an incidence of 1.8/100.000 (252). The mean monthly number of cases of pericarditis during the prevaccine period was 49.1 (95\% CI, 46.4-51.9) vs. 78.8 (95\% CI, 70.3-87.9) during the vaccine period $(P<0.001)$. A total of 15 cases occurred after the first dose and 22 after the second dose; 27 out of 37 subjects were males and median age was 59 years; 13 were admitted to the hospital (median stay, 1 day), none to intensive care. No patient died.

\section{THERAPY OF PERICARDITIS}

\section{NSAIDs}

NSAIDs represent the first line of therapy, exerting their action both on the pathogenesis of pericarditis and on the control of symptoms. Understanding the role of inflammasome in the pathogenesis of relapsing pericarditis explains their effectiveness (Figure 6). Numerous NSAIDs are used for relapsing pericarditis therapy, including ibuprofen, indomethacin and acetylsalicylic acid (ASA). All these NSAIDs are recommended in high doses as the first line of pericarditis treatment by the European Society of Cardiology (Figure 7). The duration of treatment is variable, but in any case, prolonged $(210,253)$.

\section{Colchicine}

The rationale behind the use of colchicine in pericarditis arises from the observation of good efficacy results in the control of serositis during FMF and subsequently in the control of pericarditis associated with other serositis during FMF (254). Colchicine performs its functions by inhibiting the activation of pore formation carried out by $\mathrm{P} 2 \mathrm{X} 2$ and $\mathrm{P} 2 \mathrm{X} 7$ receptors, that concur to the activation of inflammasome, and by inhibiting NACHT-LRRPYD-containing protein 3 inflammasome (255). The combined use of NSAIDs and colchicine has produced positive results on pericarditis in numerous clinical trials, where their use has favored both the control of symptoms and the prevention of relapses (255-261). Colchicine during relapsing pericarditis should be administered early without loading dose and its dosage might be adapted to the patient's weight: in general, we start with a dose of $0.5 \mathrm{mg}$ per day and, if tolerated, the dose is then increased to $0.5 \mathrm{mg}$ BID or $1 \mathrm{mg} \mathrm{OD}$, based on compliance and tolerability. The most frequent side effects are gastrointestinal, with diarrhea that occurs mainly at the beginning of therapy in $\sim 10 \%$. The dosage of colchicine can possibly be reduced in patients with this type of disorder.

\section{Corticosteroids}

The use of corticosteroids in pericarditis remains controversial. If they find their indication for the forms of pericarditis caused by autoimmune processes or in the forms resistant to the combined therapy of NSAIDs and colchicine, the probability of generating dependence for the control of symptoms is high (210). Many patients will experience a recurrence of pericarditis upon discontinuation of corticosteroid therapy, especially when corticosteroid tapering is too rapid, thus leading to a real dependence on corticosteroids and the risk of a prolonged use (253). Chronic use of corticosteroids is burdened by numerous side effects, including weight gain, osteoporosis and possible vertebral collapse, diabetes mellitus and Cushing's syndrome (262). For this reason, the use of corticosteroids should be 


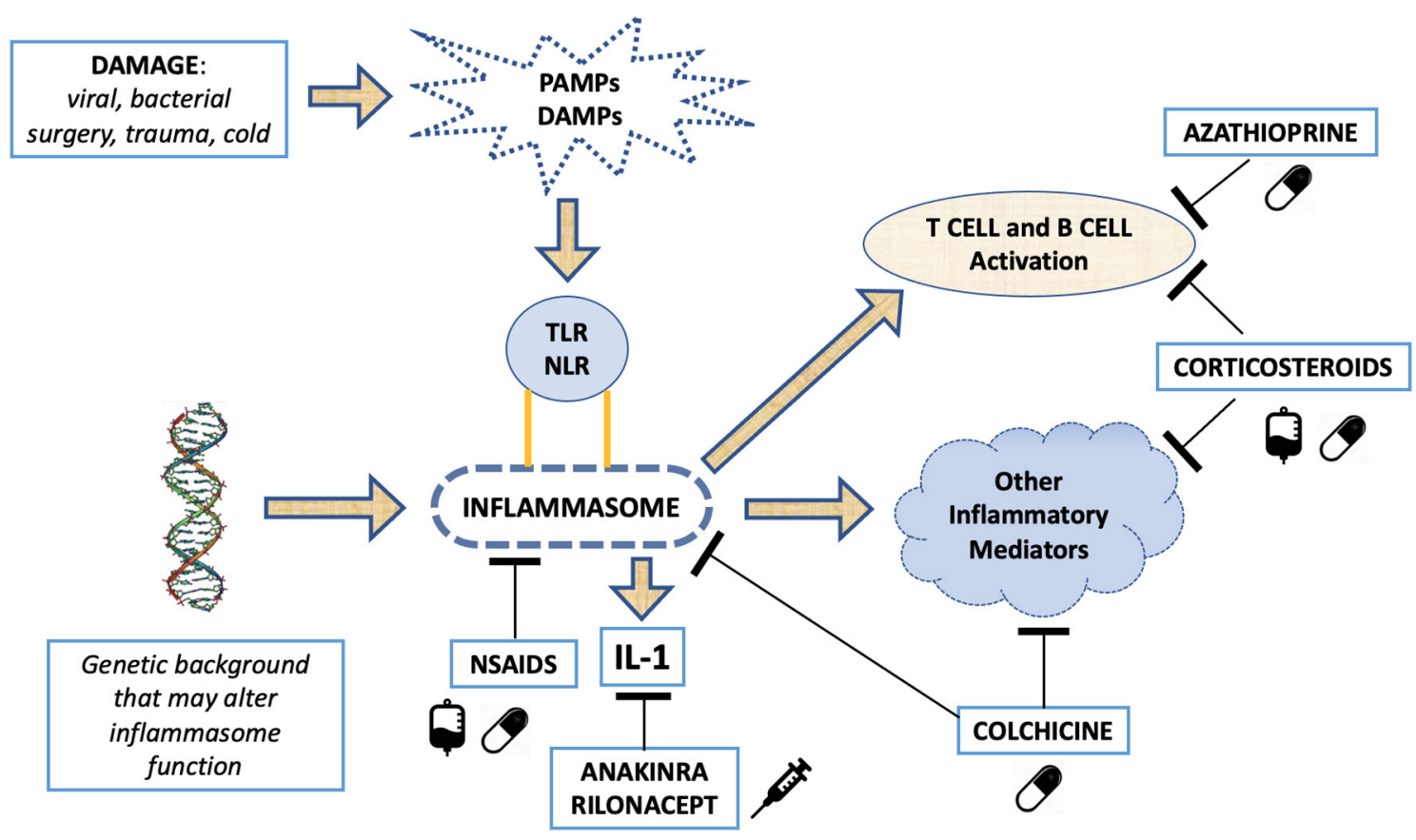

FIGURE 6 | The inflammasome-mediated inflammatory cascade and the location of the effect of currently available drugs for recurrent pericarditis. Non-specific triggers such as structural damage or microbial agents may interact with specific receptors such as NLR and TLR and thus activate the inflammasome. This naturally occurs, but a genetic background may alter the inflammasome response and consequently generate a pathologic response with a sustained inflammatory state. NSAIDs perform their effect directly on inflammasome activation. Azathioprine and corticosteroids carry out their effect mainly on B and T Iymphocytes. While Anakinra and Rilonacept directly inhibit IL-1 effects, both colchicine and corticosteroids perform their action on other inflammatory mediators released after inflammasome activation. Furthermore, colchicine also exerts an inhibitory effect on inflammasome activation. PAMPs, pathogen-associated molecular patterns; DAMPs, damage-associated molecular patterns; TLR, toll-like receptor; NLR, NOD-like Receptor; NSAIDs, non-steroidal antiinflammatory drugs.

restricted to forms of pericarditis on an autoimmune basis or in forms in which NSAIDs and colchicine have been found to be ineffective and a contraindication to the use of anti-IL-1 drugs coexists. Bisphosphonates and vitamin D should be considered when corticosteroids are started, as they are often kept as longterm maintenance therapy.

\section{Azathioprine}

AZA is a prodrug that is converted into 6-mercaptopurine, and which exerts its action at intracellular level through the production of thioinosinic and thioguanilic acids, interfering with the production of adenine and guanine and therefore, consequently, with the production of deoxyribonucleic and ribonucleic acid. Its use in autoimmune diseases and chronic intestinal inflammatory diseases has produced good efficacy and safety data (263). During relapsing pericarditis, AZA can represent an effective therapeutic aid: it is well-tolerated and has shown good efficacy profiles especially as a corticosteroid-sparing agent (264). However, larger clinical trials on its use in relapsing pericarditis are lacking.

\section{Intravenous Immunoglobulins}

The use of IVIG in autoimmune diseases such as autoimmune thrombocytopenic purpura, Guillain-Barré syndrome and autoimmune demyelinating polyneuropathies or in pregnant women with SLE is now well-established (265-268). IVIG carry out their function through the blocking of the Fc-gammaRIIB receptors on macrophages and in general through the blocking of the Fc receptors. IVIG are administered at a dose of 400-500 mg per $\mathrm{kg}$ of body weight with one intravenous administration per day for 5 consecutive days, possibly followed by another cycles of administration at 1 month. The use of IVIG during pericarditis is limited to a few case series, and it may find a rationale in autoimmune-based forms (269).

\section{Emerging Treatments: Anti-IL-1 Agents}

The understanding of the autoinflammatory pathogenetic mechanisms, mediated by the inflammasome, in the genesis of relapsing pericarditis has shed light on IL-1 as possible therapeutic target. All drugs blocking the action of IL-1 can represent an opportunity for the control of relapsing pericarditis $(270,271)$. Three anti-IL-1 drugs are currently being produced, anakinra, rilonacept and canakinumab. These drugs, but especially anakinra and rilonacept, have been studied to identify their efficacy and safety profiles in patients with relapsing pericarditis.

\section{Anakinra}

Anakinra is a short-acting IL-1 receptor antagonist for daily subcutaneous administration with doses of $100 \mathrm{mg}$ qd. It was approved in 2001 by the Food and Drug Administration (FDA) for the treatment of RA and juvenile idiopathic arthritis. 


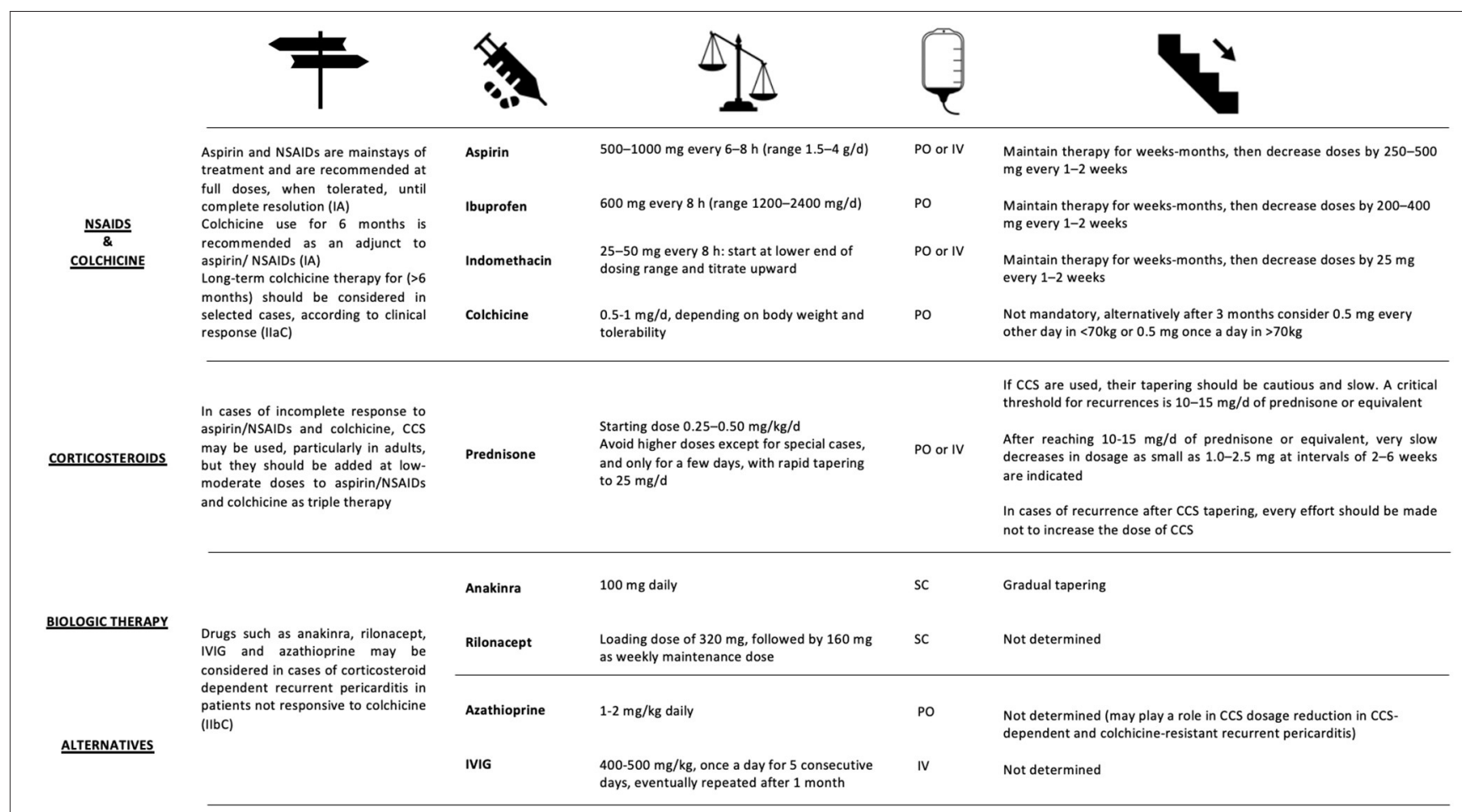

FIGURE 7 | Immunosuppressive treatment strategies used for acute and recurrent pericarditis. In brackets are reported recommendation and level of evidence based on guidelines. NSAIDs, non-steroidal anti-inflammatory drugs; h, hours; d, day; PO, per os; IV, intravenous; CCS, corticosteroids; IVIG, intravenous immunoglobulin; SC, subcutaneous. Adapted from Adler et al. (210).

Anakinra does not require dosage adjustments for the patient's age, gender or body mass index, while dosage adjustments are recommended for patients with renal impairment with a glomerular filtration rate (GFR) $<50 \mathrm{ml} / \mathrm{min}^{*} 1.73 \mathrm{~m}^{2}$ (272). The most common side effect is the formation of reddish, slightly burning and itchy skin plaque at the injection site (273). These cutaneous lesions tend to form mainly in the 1st months of therapy and can be reverted by the use of local ice or topical application of corticosteroids. Transient and mild increases in transaminase levels or leukopenia can also occur. Latent tuberculosis reactivation has been reported during the use of anakinra, leading to screening test for latent tuberculosis before starting anakinra (274). In addition, anakinra is contraindicated in patients with hypersensitivity to $E$. coli derived proteins. The use of anakinra in cardiovascular diseases is currently under investigation in myocardial infarction, HF, AM and pericardial disease (45). In the AIRTRIP study (271), the efficacy of anakinra was tested in a randomized, double-blind placebo-controlled trial in 21 patients with relapsing pericarditis who were colchicineresistant and corticosteroid-dependent. In the group of patients taking anakinra, only $18 \%$ experienced a recurrence vs. $90 \%$ in patients in the placebo arm. This effect also occurred in patients with relapsing pericarditis secondary to post cardiac injury pericarditis. During the AIRTRIP study, only mild adverse events were observed. In the IRAP (International Registry of Anakinra for Pericarditis) registry, the efficacy of anakinra in reducing the dose of corticosteroids was also demonstrated in patients affected by relapsing pericarditis that was colchicine-resistant and corticosteroid-dependent for symptoms control, with a reduction of the percentage of patients needing corticosteroids for symptoms control from 80 to $27 \%(p<0.001)$ (275). Tapering of anakinra in relapsing pericarditis should be very slow, as new disease flares have been reported in patients who abruptly stopped the drug and in patients who discontinued its use in $<3$ months (275).

\section{Rilonacept}

Rilonacept is a dimeric fusion protein formed by ligand-binding domains of IL-1R and the accessory IL-1 receptor protein linked to FC portion of human IgG1. It exerts its actions by blocking both IL-1 $\alpha$ and IL-1B (276). FDA approved its use in CAPS, and recently also in relapsing pericarditis $(277,278)$. The RHAPSODY study tested its use in patients with relapsing pericarditis associated with high CRP levels. RHAPSODY is a multicentric, double-blind, randomized trial in 86 patients with relapsing pericarditis, diagnosed based on the 2015 ESC criteria during at least a second relapse despite NSAIDs, colchicine and corticosteroids treatment or any combination of these three drugs (279). Starting dose was $320 \mathrm{mg}$, followed by weekly doses of $160 \mathrm{mg}$ for 12 weeks of run-in period. All other drugs to prevent relapse were discontinued. All patients achieving a clinical response were then double-blind randomized to continue rilonacept therapy or starting placebo. Only $7 \%$ of patients experienced a new flare of disease in the rilonacept arm, while 
$74 \%$ of patients in the placebo arm had a pericarditis recurrence. Adverse events were reported in 74 out of 86 patients and were all categorized as mild to moderate, with mainly injection site reactions and mild upper respiratory ways infections. In four patients, adverse events led to discontinuation of therapy. Based on the results of the RHAPSODY trial (279), FDA approved rilonacept for the treatment of recurrent pericarditis in March 2021

\section{Canakinumab}

Canakinumab is a human monoclonal antibody directed against IL-1B, which compared to anakinra has a much longer halflife, i.e., about 22-26 days, allowing an administration every 4-8 weeks (150 mg by subcutaneous injection in adults) $(280,281)$. Canakinumab is approved for FMF, CAPS, TRAPS, systemiconset idiopathic juvenile arthritis and gouty arthritis (282-288). Data regarding its use in relapsing pericarditis are limited. Canakinumab was used in a case series where the use of anakinra was avoid due to adverse reactions, and data from this study were encouraging (289), but further evidences seemed contradictory (290). Canakinumab only blocks IL-1 B, while anakinra and rilonacept block both IL-1 $\alpha$ and IL-1B, probably explaining the better results of the latter.

\section{Candidates for Anti-IL-1 Agents}

It is important to identify the right candidate for anakinra and rilonacept $(291,292)$. Patients with an overt inflammatory phenotype, suffering from pericarditis with pleuropulmonary involvement, with elevated CRP levels, fever, neutrophilic leukocytosis, with repeated hospitalizations for pericarditis, are the best candidates for anti-IL-1 therapy. Prior to the administration of anti-IL-1 drugs, guideline-driven therapy should be administered, with the use of a combination of NSAIDs and colchicine. Anti-IL-1 agents could be considered before corticosteroids, and this is particularly true for pediatric patients. Also, anakinra and rilonacept may be used in patients where use of NSAIDs or corticosteroids is contraindicated, such as anticoagulated patients, patients with renal failure, gastrointestinal hemorrhages, ischemic heart disease or recent cardiac surgery. On the contrary, their use is contraindicated in pericardial effusion or in aspecific/atypical presentations of chest pain with normal serum levels of CRP.

\section{IMAGING TO GUIDE IMMUNOSUPPRESSIVE THERAPY IN PERICARDITIS}

Echocardiography is the first-line imaging tool when acute pericarditis is suspected. Although no abnormalities are seen in around $40 \%$ of cases, the presence of new or worsening pericardial effusion is considered diagnostic (293, 294). In uncomplicated cases with no or a small effusion, further imaging is usually not required. In case a moderate or large pericardial effusion is present, its hemodynamic consequences can be assessed with Doppler echocardiography. Echocardiography is

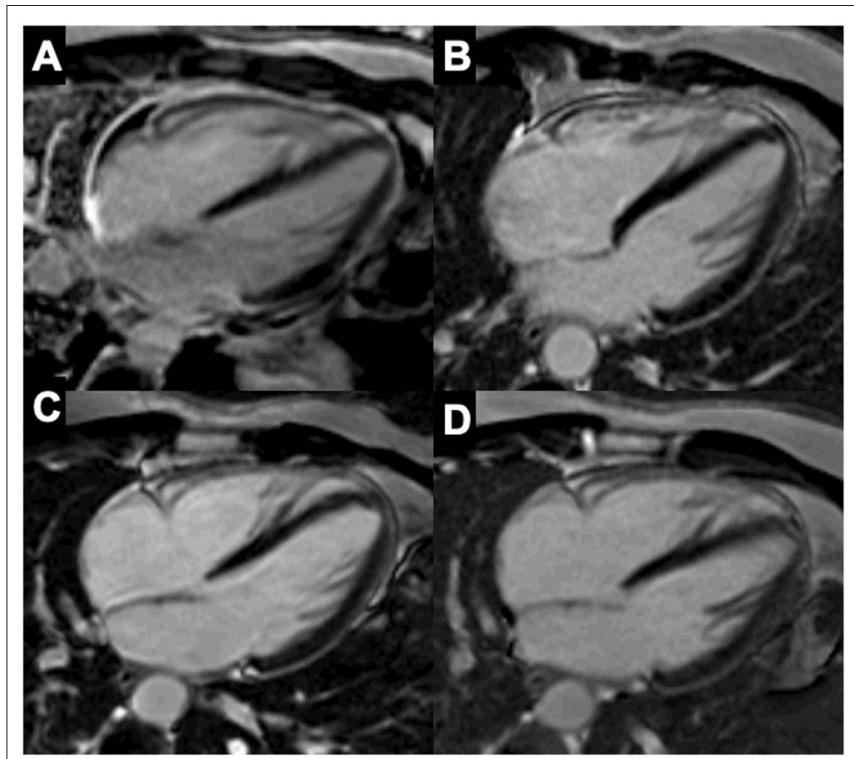

FIGURE 8 | Representative patient with pericarditis and resolution of the pericardial inflammation on sequential CMRI scans. Four-chamber late gadolinium enhancement (LGE) PSIR cardiac MRI images of a 35-year-old male patient who presented with recurrent idiopathic pericarditis under NSAIDs and colchicine. (A) At presentation, there was diffuse pericardial thickening and LGE, and presence of pericardial effusion. High-dose corticosteroids (prednisolone $40 \mathrm{mg}$ once daily) with taper schedule and azathioprine were initiated. (B) Re-evaluation after 3 months showed regression of pericardial LGE and disappearance of pericardial effusion. This allowed to further decrease the dose of steroids. (C) Follow-up cardiac MRI 5-months later showed near resolution of pericardial LGE. A low dose of steroids (prednisolone $4 \mathrm{mg}$ once daily) was maintained. (D) Control after 1 year showed a normal pericardium without LGE. Image courtesy of Bernard Paelinck (Antwerp University Hospital).

also the main tool to guide pericardiocentesis in case of tamponade, and to evaluate residual effusion during follow-up.

Other imaging modalities can be useful in patients with acute pericarditis and poor echocardiographic image quality in specific settings (e.g., complicated course, large effusions), or in dubious cases, e.g., with normal CRP. On CMRI, pericardial thickening $(>3 \mathrm{~mm})$ and LGE, which reflects increased vascularity, are both sensitive and specific signs of active pericarditis (295). Pericardial edema can be assessed by T2-weighted STIR imaging on CMRI but might be difficult to distinguish from pericardial effusion (296). In complicated cases with relapsing pericarditis, CMRI is not only a useful tool to assess constrictive physiology and ongoing pericardial inflammation, but also to guide treatment. In a study by Feng et al. (297), it was shown that constrictive pericarditis can be reversible after anti-inflammatory therapy (NSAIDs, colchicine and/or steroids) if pericardial LGE is present on cardiac MRI. Close follow-up to evaluate improvement of hemodynamics, and pericardial effusion if present, under medical treatment by echocardiography or CMRI is recommended (293). Moreover, CMRI using T2-weighted STIR and LGE sequences can monitor the degree of pericardial inflammation (Figure 8), hereby 
providing important information for the clinician before antiinflammatory or immunosuppressive medication is tapered off (296). Cardiac CT can be used to detect pericardial effusion and pericardial inflammation after contrast but implies ionizing radiation. In chronic forms of constrictive pericarditis, cardiac CT is particularly useful to assess pericardial calcifications for planning of a pericardiotomy. FDG-PET has been used to visualize pericardial inflammation and metabolic activity (298), but it is seldom performed in clinical practice and is not recommended by current guidelines (293). Nevertheless, a small study in 16 patients showed that a high FDG uptake $\left(\mathrm{SUV}_{\max }>3.0\right)$ predicted reversibility of constrictive pericarditis with steroid treatment (299). In this respect, FDG-PET may be useful in patients with non-CMRI-conditional devices to guide immunosuppressive therapy, but further studies are needed to evaluate whether it provides incremental value to CMRI.

\section{CONCLUSIONS}

While therapies for patients with acute and recurrent pericarditis are mainly evidence-based, almost no trials are available for AM, thus immunosuppression in this setting is generally based on expert consensus. Thus, an impelling need of clinical research is

\section{REFERENCES}

1. Ammirati E, Frigerio $\mathrm{M}$, Adler ED, Basso C, Birnie DH, Brambatti $\mathrm{M}$, et al. Management of acute myocarditis and chronic inflammatory cardiomyopathy: an expert consensus document. Circulation Heart Fail. (2020) 13:e007405. doi: 10.1161/CIRCHEARTFAILURE.120. 007405

2. Peretto G, Sala S, De Luca G, Marcolongo R, Campochiaro C, Sartorelli $\mathrm{S}$, et al. Immunosuppressive therapy and risk stratification of patients with myocarditis presenting with ventricular arrhythmias. JACC Clin Electrophysiol. (2020) 6:1221-34. doi: 10.1016/j.jacep.2020.05.013

3. Inciardi RM, Lupi L, Zaccone G, Italia L, Raffo M, Tomasoni D, et al. Cardiac involvement in a patient with coronavirus disease 2019 (COVID-19). JAMA Cardiol. (2020) 5:819-24. doi: 10.1001/jamacardio.2020.1096

4. Larson KF, Ammirati E, Adler ED, Cooper LT, Hong KN, Saponara G, et al. Myocarditis after BNT162b2 and mRNA-1273 vaccination. Circulation. (2021) 144:506-8. doi: 10.1161/CIRCULATIONAHA.121.055913

5. Ammirati E, Cavalotti C, Milazzo A, Pedrotti P, Soriano F, Schroeder JW, et al. Temporal relation between second dose BNT162b2 mRNA Covid-19 vaccine and cardiac involvement in a patient with previous SARS-COV-2 infection. Int J Cardiol Heart Vasc. (2021) 34:100774. doi: 10.1016/j.ijcha.2021.100774

6. Patone M, Mei XW, Handunnetthi L, Dixon S, Zaccardi F, ShankarHari M, et al. Risks of myocarditis, pericarditis, and cardiac arrhythmias associated with COVID-19 vaccination or SARS-CoV-2 infection. Nat Med. (2021). doi: 10.1038/s41591-021-01630-0. [Epub ahead of print].

7. Truong DT, Dionne A, Muniz JC, McHugh KE, Portman MA, Lambert LM, et al. Clinically suspected myocarditis temporally related to COVID-19 vaccination in adolescents and young adults. Circulation. (2021) 145:34556. doi: 10.1161/CIRCULATIONAHA.121.056583

8. Bozkurt B, Kamat I, Hotez PJ. Myocarditis with COVID-19 mRNA Vaccines. Circulation. (2021) 144:47184. doi: 10.1161/CIRCULATIONAHA.121.056135

9. Salem JE, Manouchehri A, Moey M, Lebrun-Vignes B, Bastarache L, Pariente A, et al. Cardiovascular toxicities associated with immune checkpoint inhibitors: an observational, retrospective, pharmacovigilance study. Lancet Oncol. (2018) 19:1579-89. doi: 10.1016/S1470-2045(18)30608-9 to evaluate which immunosuppressive agent can be effective to improve the outcome of patients with AM and the characteristics of patients who can benefit more by immunosuppression. Thus, well-powered multicenter randomized trials are needed to test this hypothesis. In parallel, large prospective registries can better define the main determinants of outcome, even if large retrospective studies consistently demonstrated that presentation of AM complicated by reduced LVEF, HF, VA, AVB, or cardiogenic shock are associated with poor outcome $(11,40)$.

\section{AUTHOR CONTRIBUTIONS}

EA, EB, GV, MG, CV, JL, MP, AC, CP, LT, JM, and AB wrote the draft. $\mathrm{EA}, \mathrm{EB}, \mathrm{GV}, \mathrm{MG}, \mathrm{JM}$, and $\mathrm{AB}$ revised the manuscript. All authors contributed to the article and approved the submitted version.

\section{SUPPLEMENTARY MATERIAL}

The Supplementary Material for this article can be found online at: https://www.frontiersin.org/articles/10.3389/fmed. 2022.838564/full\#supplementary-material

10. Nguyen LS, Cooper LT, Kerneis M, Funck-Brentano C, Silvain J, Brechot $\mathrm{N}$, et al. Systematic analysis of drug-associated myocarditis reported in the World Health Organization pharmacovigilance database. Nat Commun. (2022) 13:25. doi: 10.1038/s41467-021-27631-8

11. Ammirati E, Veronese G, Brambatti M, Merlo M, Cipriani M, Potena L, et al. Fulminant versus acute nonfulminant myocarditis in patients with left ventricular systolic dysfunction. J Am Coll Cardiol. (2019) 74:299311. doi: 10.1016/j.jacc.2019.04.063

12. Cooper LT, Baughman KL, Feldman AM, Frustaci A, Jessup $\mathrm{M}$, Kuhl $\mathrm{U}$, et al. The role of endomyocardial biopsy in the management of cardiovascular disease: a scientific statement from the American Heart Association, the American College of Cardiology, and the European Society of Cardiology. Circulation. (2007) 116:2216-33. doi: 10.1161/CIRCULATIONAHA.107.186093

13. Ammirati E, Veronese G, Bottiroli M, Wang DW, Cipriani M, Garascia A, et al. Update on acute myocarditis. Trends Cardiovasc Med. (2020) 31:370-9. doi: 10.1016/j.tcm.2020.05.008

14. Tschöpe C, Ammirati E, Bozkurt B, Caforio ALP, Cooper LT, Felix SB, et al. Myocarditis and inflammatory cardiomyopathy: current evidence and future directions. Nat Rev Cardiol. (2020) 18:169-93. doi: 10.1038/s41569-020-00435-x

15. Bock CT, Klingel K, Kandolf R. Human parvovirus B19-associated myocarditis. N Engl J Med. (2010) 362:1248-9. doi: 10.1056/NEJMc0911362

16. Bowles NE, Ni J, Kearney DL, Pauschinger M, Schultheiss HP, McCarthy R, et al. Detection of viruses in myocardial tissues by polymerase chain reaction. Evidence of adenovirus as a common cause of myocarditis in children and adults. J Am Coll Cardiol. (2003) 42:466-72. doi: 10.1016/S0735-1097(03)00648-X

17. Veronese G, Ammirati E, Chen C, Klingel K, Suzuki M, Okumura T, et al. Management perspectives from the 2019 Wuhan international workshop on fulminant myocarditis. Int J Cardiol. (2021) 324:1318. doi: 10.1016/j.ijcard.2020.10.063

18. Caforio AL, Pankuweit S, Arbustini E, Basso C, Gimeno-Blanes J, Felix SB, et al. Current state of knowledge on aetiology, diagnosis, management, and therapy of myocarditis: a position statement of the European Society of Cardiology Working Group on Myocardial and Pericardial Diseases. Eur Heart J. (2013) 34:2636-48. doi: 10.1093/eurheartj/eht210 
19. Verdonschot J, Hazebroek M, Merken J, Debing Y, Dennert R, Brunner-La Rocca HP, et al. Relevance of cardiac parvovirus B19 in myocarditis and dilated cardiomyopathy: review of the literature. Eur J Heart Fail. (2016) 18:1430-41. doi: 10.1002/ejhf.665

20. Stewart GC, Lopez-Molina J, Gottumukkala RV, Rosner GF, Anello MS, Hecht JL, et al. Myocardial parvovirus B19 persistence: lack of association with clinicopathologic phenotype in adults with heart failure. Circ Heart Fail. (2011) 4:71-8. doi: 10.1161/CIRCHEARTFAILURE.110.958249

21. Veronese G, Ammirati E, Brambatti M, Merlo M, Cipriani M, Potena L, et al. Viral genome search in myocardium of patients with fulminant myocarditis. Eur J Heart Fail. (2020) 22:1277-80. doi: 10.1002/ejhf.1738

22. Fung G, Luo H, Qiu Y, Yang D, McManus B. Myocarditis. Circ Res. (2016) 118:496-514. doi: 10.1161/CIRCRESAHA.115.306573

23. Klingel K, Selinka HC, Huber M, Sauter M, Leube M, Kandolf R. Molecular pathology and structural features of enteroviral replication. Toward understanding the pathogenesis of viral heart disease. Herz. (2000) 25:216-20. doi: 10.1007/s000590050009

24. Matsuura H, Ichida F, Saji T, Ogawa S, Waki K, Kaneko M, et al. Clinical features of acute and fulminant myocarditis in children- 2nd nationwide survey by Japanese society of pediatric cardiology and cardiac surgery. Circ J. (2016) 80:2362-8. doi: 10.1253/circj.CJ-16-0234

25. Ammirati E, Varrenti M, Veronese G, Fanti D, Nava A, Cipriani M, et al. Prevalence and outcome of patients with acute myocarditis and positive viral search on nasopharyngeal swab. Eur J Heart Fail. (2021) 23:12425. doi: 10.1002/ejhf.2247

26. Bratincsák A, El-Said HG, Bradley JS, Shayan K, Grossfeld PD, Cannavino CR. Fulminant myocarditis associated with pandemic H1N1 influenza A virus in children. J Am Coll Cardiol. (2010) 55:928-9. doi: 10.1016/j.jacc.2010.01.004

27. Gil-Cruz C, Perez-Shibayama C, De Martin A, Ronchi F, van der Borght K, Niederer R, et al. Microbiota-derived peptide mimics drive lethal inflammatory cardiomyopathy. Science. (2019) 366:881-6. doi: 10.1126/science.aav3487

28. Anzai A, Mindur JE, Halle L, Sano S, Choi JL, He S, et al. Selfreactive $\mathrm{CD} 4(+) \mathrm{IL}-3(+) \mathrm{T}$ cells amplify autoimmune inflammation in myocarditis by inciting monocyte chemotaxis. J Exp Med. (2019) 216:36983. doi: 10.1084/jem.20180722

29. Tschope C, Elsanhoury A, Schlieker S, Van Linthout S, Kuhl U. Immunosuppression in inflammatory cardiomyopathy and parvovirus B19 persistence. Eur J Heart Fail. (2019) 21:1468-9. doi: 10.1002/ejhf.1560

30. Frustaci A, Russo MA, Chimenti C. Randomized study on the efficacy of immunosuppressive therapy in patients with virus-negative inflammatory cardiomyopathy: the TIMIC study. Eur Heart J. (2009) 30:1995-2002. doi: 10.1093/eurheartj/ehp249

31. Chen HS, Wang W, Wu SN, Liu JP. Corticosteroids for viral myocarditis. Cochrane Database Syst Rev. (2013) 2013:Cd004471. doi: 10.1002/14651858.CD004471.pub3

32. Cheng CY, Cheng GY, Shan ZG, Baritussio A, Lorenzoni G, Tyminska A, et al. Efficacy of immunosuppressive therapy in myocarditis: A 30-year systematic review and meta analysis. Autoimmun Rev. (2021) 20:102710. doi: 10.1016/j.autrev.2020.102710

33. Kociol RD, Cooper LT, Fang JC, Moslehi JJ, Pang PS, Sabe MA, et al. Recognition and initial management of fulminant myocarditis: a scientific statement from the American Heart Association. Circulation. (2020) 141:e69-92. doi: 10.1161/CIR.0000000000000745

34. Drucker NA, Colan SD, Lewis AB, Beiser AS, Wessel DL, Takahashi M, et al. Gamma-globulin treatment of acute myocarditis in the pediatric population. Circulation. (1994) 89:252-7. doi: 10.1161/01.CIR.89.1.252

35. Robinson J, Hartling L, Vandermeer B, Klassen TP. Intravenous immunoglobulin for presumed viral myocarditis in children and adults. Cochrane Database Syst Rev. (2015) 2015:Cd004370. doi: 10.1002/14651858.CD004370.pub3

36. Mason JW, O'Connell JB, Herskowitz A, Rose NR, McManus BM, Billingham ME, et al. A clinical trial of immunosuppressive therapy for myocarditis. The Myocarditis Treatment Trial Investigators. N Engl J Med. (1995) 333:269-75. doi: 10.1056/NEJM199508033330501

37. Zhou N, Zhao Y, Jiang J, Shen L, Li J, Wan J, et al. Impact of mechanical circulatory support and immunomodulation therapy on outcome of patients with fulminant myocarditis: Chinese registry of fulminant myocarditis. Signal Transduct Target Ther. (2021) 6:350. doi: 10.1038/s41392-021-00700-6

38. Schultheiss HP, Piper C, Sowade O, Waagstein F, Kapp JF, Wegscheider $\mathrm{K}$, et al. Betaferon in chronic viral cardiomyopathy (BICC) trial: Effects of interferon- $\beta$ treatment in patients with chronic viral cardiomyopathy. Clin Res Cardiol. (2016) 105:763-73. doi: 10.1007/s00392-016-0986-9

39. Cooper LT. Myocarditis. N Engl J Med. (2009) 360:152638. doi: 10.1056/NEJMra0800028

40. Ammirati E, Cipriani M, Moro C, Raineri C, Pini D, Sormani $\mathrm{P}$, et al. Clinical presentation and outcome in a contemporary cohort of patients with acute myocarditis. Circulation. (2018) 138:1088-99. doi: 10.1161/CIRCULATIONAHA.118.035319

41. Mele D, Flamigni F, Rapezzi C, Ferrari R. Myocarditis in COVID19 patients: current problems. Intern Emerg Med. (2021) 16:11239. doi: 10.1007/s11739-021-02635-w

42. Mehta P, McAuley DF, Brown M, Sanchez E, Tattersall RS, Manson JJ. COVID-19: consider cytokine storm syndromes and immunosuppression. Lancet. (2020) 395:1033-4. doi: 10.1016/S0140-6736(20)30628-0

43. Lim BK, Choe SC, Shin JO, Ho SH, Kim JM, Yu SS, et al. Local expression of interleukin-1 receptor antagonist by plasmid DNA improves mortality and decreases myocardial inflammation in experimental coxsackieviral myocarditis. Circulation. (2002) 105:1278-81. doi: 10.1161/circ.105.11. 1278

44. Toldo S, Kannan H, Bussani R, Anzini M, Sonnino C, Sinagra G, et al. Formation of the inflammasome in acute myocarditis. Int J Cardiol. (2014) 171:e119-21. doi: 10.1016/j.ijcard.2013.12.137

45. Abbate A, Toldo S, Marchetti C, Kron J, Van Tassell BW, Dinarello CA. Interleukin-1 and the Inflammasome as Therapeutic Targets in Cardiovascular Disease. Circ Res. (2020) 126:126080. doi: 10.1161/CIRCRESAHA.120.315937

46. Cavalli G, Pappalardo F, Mangieri A, Dinarello CA, Dagna L, Tresoldi M. Treating life-threatening myocarditis by blocking interleukin-1. Crit Care Med. (2016) 44:e751-4. doi: 10.1097/CCM.0000000000001654

47. Bello F, Marchi A, Prisco D, Olivotto I, Emmi G. Antiarrhythmic efficacy of anakinra in a young patient with autoimmune lymphocytic myocarditis. Rheumatology (Oxford). (2020) 59:e88-90. doi: 10.1093/rheumatology/keaa207

48. Veronese G, Cipriani M, Bottiroli M, Garascia A, Mondino M, Pedrotti P, et al. Fulminant myocarditis triggered by OC43 subtype coronavirus: a disease deserving evidence-based care bundles. J Cardiovasc Med (Hagerstown). (2020) 21:529-31. doi: 10.2459/JCM.0000000000000989

49. Ammirati E, Cipriani M, Lilliu M, Sormani P, Varrenti M, Raineri $\mathrm{C}$, et al. Survival and left ventricular function changes in fulminant versus nonfulminant acute myocarditis. Circulation. (2017) 136:52945. doi: 10.1161/CIRCULATIONAHA.117.026386

50. Turgeon PY, Massot M, Beaupré F, Belzile D, Beaudoin J, Bernier M, et al. Effect of acute immunosuppression on left ventricular recovery and mortality in fulminant viral myocarditis: a case series and review of literature. CJC Open. (2021) 3:292-302. doi: 10.1016/j.cjco.2020.10.017

51. Kiriakidou M, Ching CL. Systemic lupus erythematosus. Ann Intern Med. (2020) 172:Itc81-96. doi: 10.7326/AITC202006020

52. Barber MRW, Drenkard C, Falasinnu T, Hoi A, Mak A, Kow NY, et al. Global epidemiology of systemic lupus erythematosus. Nat Rev Rheumatol. (2021) 17:515-32. doi: 10.1038/s41584-021-00668-1

53. Jia E, Geng H, Liu Q, Xiao Y, Zhang Y, Xie J, et al. Cardiac manifestations of Han Chinese patients with systemic lupus erythematosus: a retrospective study. Ir J Med Sci. (2019) 188:801-6. doi: 10.1007/s11845-018-1934-7

54. Tanwani J, Tselios K, Gladman DD, Su J, Urowitz MB. Lupus myocarditis: a single center experience and a comparative analysis of observational cohort studies. Lupus. (2018) 27:1296-302. doi: 10.1177/0961203318770018

55. Thomas G, Cohen Aubart F, Chiche L, Haroche J, Hié M, Hervier B, et al. Lupus myocarditis: initial presentation and longterm outcomes in a multicentric series of 29 patients. J Rheumatol. (2017) 44:2432. doi: 10.3899/jrheum.160493

56. Mathian A, Mouries-Martin S, Dorgham K, Devilliers H, Yssel H, Garrido Castillo L, et al. Ultrasensitive serum interferon- $\alpha$ quantification during SLE remission identifies patients at risk for relapse. Ann Rheum Dis. (2019) 78:1669-76. doi: 10.1136/annrheumdis-2019-215571 
57. Mathian A, Mouries-Martin S, Dorgham K, Devilliers H, Barnabei L, Ben Salah E, et al. Monitoring disease activity in systemic lupus erythematosus with single-molecule array digital enzyme-linked immunosorbent assay quantification of serum interferon- $\alpha$. Arthritis Rheumatol. (2019) 71:75665. doi: 10.1002/art.40792

58. Guglin M, Smith C, Rao R. The spectrum of lupus myocarditis: from asymptomatic forms to cardiogenic shock. Heart Fail Rev. (2021) 26:55360. doi: 10.1007/s10741-020-10054-w

59. Cooper LT Jr, Berry GJ, Shabetai R. Idiopathic giant-cell myocarditis-natural history and treatment. Multicenter giant cell myocarditis study group investigators. $N$ Engl J Med. (1997) 336:1860-6. doi: 10.1056/NEJM199706263362603

60. Fanouriakis A, Kostopoulou M, Alunno A, Aringer M, Bajema I, Boletis JN, et al. 2019 update of the EULAR recommendations for the management of systemic lupus erythematosus. Ann Rheum Dis. (2019) 78:736-45. doi: 10.1136/annrheumdis-2019-215089

61. Garcia D, Erkan D. Diagnosis and management of the antiphospholipid syndrome. N Engl J Med. (2018) 378:2010-21. doi: 10.1056/NEJMra1705454

62. Duarte-García A, Pham MM, Crowson CS, Amin S, Moder KG, Pruthi RK, et al. The epidemiology of antiphospholipid syndrome: a population-based study. Arthritis Rheumatol. (2019) 71:1545-52. doi: 10.1002/art.40901

63. Cervera R, Piette JC, Font J, Khamashta MA, Shoenfeld Y, Camps MT, et al. Antiphospholipid syndrome: clinical and immunologic manifestations and patterns of disease expression in a cohort of 1,000 patients. Arthritis Rheum. (2002) 46:1019-27. doi: 10.1002/art.10187

64. Lenz CJ, Mankad R, Klarich K, Kurmann R, McBane RD. Antiphospholipid syndrome and the relationship between laboratory assay positivity and prevalence of non-bacterial thrombotic endocarditis: A retrospective cohort study. J Thromb Haemost. (2020) 18:1408-14. doi: 10.1111/jth.14798

65. Asherson RA, Cervera R, de Groot PG, Erkan D, Boffa MC, Piette JC, et al. Catastrophic antiphospholipid syndrome: international consensus statement on classification criteria and treatment guidelines. Lupus. (2003) 12:5304. doi: 10.1191/0961203303lu394oa

66. Pineton de Chambrun M, Larcher R, Pène F, Argaud L, Demoule A, Jamme $M$, et al. CAPS criteria fail to identify most severely-ill thrombotic antiphospholipid syndrome patients requiring intensive care unit admission. J Autoimmun. (2019) 103:102292. doi: 10.1016/j.jaut.2019. 06.003

67. Hucker WJ, Chatzizisis YS, Steigner ML, Winters GL, Kirshenbaum JM. Myocardial catastrophe: a case of sudden, severe myocardial dysfunction. Circulation. (2014) 130:85462. doi: 10.1161/CIRCULATIONAHA.113.007417

68. Sacré K, Brihaye B, Hyafil F, Serfaty JM, Escoubet B, Zennaro MC, et al. Asymptomatic myocardial ischemic disease in antiphospholipid syndrome: a controlled cardiac magnetic resonance imaging study. Arthritis Rheum. (2010) 62:2093-100. doi: 10.1002/art.27488

69. Pineton de Chambrun M, Larcher R, Pène F, Argaud L, Mayaux J, Jamme $\mathrm{M}$, et al. In-hospital mortality-associated factors in patients with thrombotic antiphospholipid syndrome requiring ICU admission. Chest. (2020) 157:1158-66. doi: 10.1016/j.chest.2019.11.010

70. Rodríguez-Pintó I, Espinosa G, Erkan D, Shoenfeld Y, Cervera R. The effect of triple therapy on the mortality of catastrophic antiphospholipid syndrome patients. Rheumatology (Oxford). (2018) 57:126470. doi: 10.1093/rheumatology/key082

71. Tulai IM, Penciu OM, Raut R, Rudinskaya A. Catastrophic antiphospholipid syndrome presenting as congestive heart failure in a patient with thrombotic microangiopathy. Tex Heart Inst J. (2019) 46:48-52. doi: 10.14503/THIJ-17-6472

72. Berman H, Rodríguez-Pintó I, Cervera R, Morel N, CostedoatChalumeau N, Erkan D, et al. Rituximab use in the catastrophic antiphospholipid syndrome: descriptive analysis of the CAPS registry patients receiving rituximab. Autoimmun Rev. (2013) 12:1085-90. doi: 10.1016/j.autrev.2013.05.004

73. Tinti MG, Carnevale V, Inglese M, Molinaro F, Bernal M, Migliore A, et al. Eculizumab in refractory catastrophic antiphospholipid syndrome: a case report and systematic review of the literature. Clin Exp Med. (2019) 19:281-8. doi: 10.1007/s10238-019-00565-8
74. Baik AH, Oluwole OO, Johnson DB, Shah N, Salem JE, Tsai KK, et al. Mechanisms of cardiovascular toxicities associated with immunotherapies. Circ Res. (2021) 128:1780-801. doi: 10.1161/CIRCRESAHA.120.315894

75. Johnson DB, Reynolds KL, Sullivan RJ, Balko JM, Patrinely JR, Cappelli LC, et al. Immune checkpoint inhibitor toxicities: systems-based approaches to improve patient care and research. Lancet Oncol. (2020) 21:e398404. doi: 10.1016/S1470-2045(20)30107-8

76. Moslehi JJ, Salem JE, Sosman JA, Lebrun-Vignes B, Johnson DB. Increased reporting of fatal immune checkpoint inhibitor-associated myocarditis. Lancet. (2018) 391:933. doi: 10.1016/S0140-6736(18)30533-6

77. Moslehi J, Lichtman AH, Sharpe AH, Galluzzi L, Kitsis RN. Immune checkpoint inhibitor-associated myocarditis: manifestations and mechanisms. J Clin Invest. (2021) 131:e145186. doi: 10.1172/JCI145186

78. Johnson DB, Balko JM, Compton ML, Chalkias S, Gorham J, Xu Y, et al. Fulminant myocarditis with combination immune checkpoint blockade. $N$ Engl J Med. (2016) 375:1749-55. doi: 10.1056/NEJMoa1609214

79. Hu JR, Florido R, Lipson EJ, Naidoo J, Ardehali R, Tocchetti CG, et al. Cardiovascular toxicities associated with immune checkpoint inhibitors. Cardiovasc Res. (2019) 115:854-68. doi: 10.1093/cvr/cvz026

80. Anquetil C, Salem JE, Lebrun-Vignes B, Johnson DB, Mammen $\mathrm{AL}$, Stenzel $\mathrm{W}$, et al. Immune checkpoint inhibitor-associated myositis: expanding the spectrum of cardiac complications of the immunotherapy revolution. Circulation. (2018) 138:7435. doi: 10.1161/CIRCULATIONAHA.118.035898

81. Johnson DB, Manouchehri A, Haugh AM, Quach HT, Balko JM, LebrunVignes B, et al. Neurologic toxicity associated with immune checkpoint inhibitors: a pharmacovigilance study. J Immunother Cancer. (2019) 7:134. doi: 10.1186/s40425-019-0617-x

82. Allenbach Y, Anquetil C, Manouchehri A, Benveniste O, Lambotte $\mathrm{O}$, Lebrun-Vignes $\mathrm{B}$, et al. Immune checkpoint inhibitor-induced myositis, the earliest and most lethal complication among rheumatic and musculoskeletal toxicities. Autoimmun Rev. (2020) 19:102586. doi: 10.1016/j.autrev.2020.102586

83. Lehmann LH, Cautela J, Palaskas N, Baik AH, Meijers WC, Allenbach Y, et al. Clinical strategy for the diagnosis and treatment of immune checkpoint inhibitor-associated myocarditis: a narrative review. JAMA Cardiol. (2021) 6:1329-37. doi: 10.1001/jamacardio.2021.2241

84. Bonaca MP, Olenchock BA, Salem JE, Wiviott SD, Ederhy S, Cohen A, et al. Myocarditis in the setting of cancer therapeutics: proposed case definitions for emerging clinical syndromes in cardio-oncology. Circulation. (2019) 140:80-91. doi: 10.1161/CIRCULATIONAHA.118.034497

85. Wei SC, Meijers WC, Axelrod ML, Anang NAS, Screever EM, Wescott EC, et al. A genetic mouse model recapitulates immune checkpoint inhibitor-associated myocarditis and supports a mechanism-based therapeutic intervention. Cancer Discov. (2021) 11:614-25. doi: 10.1158/2159-8290.CD-20-0856

86. Asnani A, Moslehi JJ, Adhikari BB, Baik AH, Beyer AM, de Boer RA, et al. Preclinical models of cancer therapy-associated cardiovascular toxicity: a scientific statement from the american heart association. Circ Res. (2021) 129:e21-34. doi: 10.1161/RES.0000000000000473

87. Salem JE, Allenbach Y, Vozy A, Brechot N, Johnson DB, Moslehi JJ, et al. Abatacept for severe immune checkpoint inhibitor-associated myocarditis. N Engl J Med. (2019) 380:2377-9. doi: 10.1056/NEJMc1901677

88. Mahmood SS, Fradley MG, Cohen JV, Nohria A, Reynolds KL, Heinzerling LM, et al. Myocarditis in patients treated with immune checkpoint inhibitors. J Am Coll Cardiol. (2018) 71:1755-64. doi: 10.1016/j.jacc.2018.02.037

89. Pradhan R, Nautiyal A, Singh S. Diagnosis of immune checkpoint inhibitorassociated myocarditis: A systematic review. Int J Cardiol. (2019) 296:11321. doi: 10.1016/j.ijcard.2019.07.025

90. Veronese G, Ammirati E. Differences in clinical presentation and outcome between immune checkpoint inhibitor-associated myocarditis and classical acute myocarditis: Same disease, distinct challenges to face. Int J Cardiol. (2019) 296:124-6. doi: 10.1016/j.ijcard.2019.08.038

91. Bermas BL, Zaha VG. Mending broken hearts: a new treatment paradigm for immune checkpoint inhibitor-induced myocarditis. Circulation. (2021) 143:767-9. doi: 10.1161/CIRCULATIONAHA.120. 052307 
92. Palaskas N, Lopez-Mattei J, Durand JB, Iliescu C, Deswal A. Immune checkpoint inhibitor myocarditis: pathophysiological characteristics, diagnosis, and treatment. J Am Heart Assoc. (2020) 9:e013757. doi: 10.1161/JAHA.119.013757

93. Jain V, Mohebtash M, Rodrigo ME, Ruiz G, Atkins MB, Barac A. Autoimmune myocarditis caused by immune checkpoint inhibitors treated with antithymocyte globulin. I Immunother. (2018) 41:3325. doi: 10.1097/CJI.0000000000000239

94. Esfahani K, Buhlaiga N, Thebault P, Lapointe R, Johnson NA, Miller WH. Alemtuzumab for immune-related myocarditis due to PD-1 therapy. $N$ Engl J Med. (2019) 380:2375-6. doi: 10.1056/NEJMc1903064

95. Zhang L, Zlotoff DA, Awadalla M, Mahmood SS, Nohria A, Hassan MZO, et al. Major adverse cardiovascular events and the timing and dose of corticosteroids in immune checkpoint inhibitor-associated myocarditis. Circulation. (2020) 141:20314. doi: 10.1161/CIRCULATIONAHA.119.044703

96. Sheng CC, Amiri-Kordestani L, Palmby T, Force T, Hong CC, Wu JC, et al. 21st century cardio-oncology: identifying cardiac safety signals in the era of personalized medicine. JACC Basic Transl Sci. (2016) 1:38698. doi: 10.1016/j.jacbts.2016.05.008

97. Moslehi JJ. Cardiovascular toxic effects of targeted cancer therapies. N Engl J Med. (2016) 375:1457-67. doi: 10.1056/NEJMra1100265

98. Groarke JD, Cheng S, Moslehi J. Cancer-drug discovery and cardiovascular surveillance. $N$ Engl $\quad J \quad$ Med. (2013) 369:177981. doi: 10.1056/NEJMp1313140

99. Tevaarwerk A, Denlinger CS, Sanft T, Ansbaugh SM, Armenian S, Baker KS, et al. Survivorship, Version 1.2021. J Natl Compr Canc Netw. (2021) 19:67685. doi: 10.6004/jnccn.2021.0028

100. Patrinely JR, Young AC, Quach H, Williams GR, Ye F, et al. Survivorship in immune therapy: Assessing toxicities, body composition and healthrelated quality of life among long-term survivors treated with antibodies to programmed death-1 receptor and its ligand. Eur J Cancer. (2020) 135:21120. doi: $10.1016 /$ j.ejca.2020.05.005

101. Moslehi J. The cardiovascular perils of cancer survivorship. $N$ Engl J Med. (2013) 368:1055-6. doi: 10.1056/NEJMe1215300

102. Bracamonte-Baran W, Gilotra NA, Won T, Rodriguez KM, Talor MV, Oh BC, et al. Endothelial stromal PD-L1 (programmed death ligand 1) modulates CD8(+) T-cell infiltration after heart transplantation. Circ Heart Fail. (2021) 14:e007982. doi: 10.1161/CIRCHEARTFAILURE.120.007982

103. Choudhary A, Brinkley DM, Besharati S, Meijers WC, Atkinson JB, Amancherla K, et al. PD-L1 (programmed death ligand 1) as a marker of acute cellular rejection after heart transplantation. Circ Heart Fail. (2021) 14:e008563. doi: 10.1161/CIRCHEARTFAILURE.121.008563

104. Gentile P, Merlo M, Peretto G, Ammirati E, Sala S, Della Bella P, et al. Postdischarge arrhythmic risk stratification of patients with acute myocarditis and life-threatening ventricular tachyarrhythmias. Eur J Heart Fail. (2021) 23:2045-54. doi: 10.1002/ejhf.2288

105. Peretto G, Sala S, Rizzo S, Palmisano A, Esposito A, De Cobelli F, et al. Ventricular arrhythmias in myocarditis: characterization and relationships with myocardial inflammation. J Am Coll Cardiol. (2020) 75:104657. doi: $10.1016 /$ j.jacc.2020.01.036

106. Lakkireddy D, Turagam MK, Yarlagadda B, Dar T, Hamblin M, Krause $\mathrm{M}$, et al. Myocarditis causing premature ventricular contractions: insights from the MAVERIC Registry. Circ Arrhythm Electrophysiol. (2019) 12:e007520. doi: 10.1161/CIRCEP.119.007520

107. Power JR, Alexandre J, Choudhary A, Ozbay B, Hayek S, Asnani A, et al. Electrocardiographic manifestations of immune checkpoint inhibitor myocarditis. Circulation. (2021) 144:15213. doi: 10.1161/CIRCULATIONAHA.121.055816

108. Li C, Jiang J, Wang F, Zhou N, Veronese G, Moslehi JJ, et al. Longitudinal correlation of biomarkers of cardiac injury, inflammation, and coagulation to outcome in hospitalized COVID-19 patients. J Mol Cell Cardiol. (2020) 147:74-87. doi: 10.1016/j.yjmcc.2020.08.008

109. Alvarez-Garcia J, Jaladanki S, Rivas-Lasarte M, Cagliostro M, Gupta A, Joshi A, et al. New heart failure diagnoses among patients hospitalized for COVID19. J Am Coll Cardiol. (2021) 77:2260-2. doi: 10.1016/j.jacc.2021.03.006

110. Daniels CJ, Rajpal S, Greenshields JT, Rosenthal GL, Chung EH, Terrin M, et al. Prevalence of clinical and subclinical myocarditis in competitive athletes with recent SARS-CoV-2 infection: results from the big ten COVID-19 cardiac registry. JAMA Cardiol. (2021) 6:107887. doi: 10.1001/jamacardio.2021.2065

111. Moulson N, Petek BJ, Drezner JA, Harmon KG, Kliethermes SA, Patel MR, et al. SARS-CoV-2 cardiac involvement in young competitive athletes. Circulation. (2021) 144:25666. doi: 10.1161/CIRCULATIONAHA.121.054824

112. Martinez MW, Tucker AM, Bloom OJ, Green G, DiFiori JP, Solomon G, et al. Prevalence of inflammatory heart disease among professional athletes with prior COVID-19 infection who received systematic return-to-play cardiac screening. JAMA Cardiol. (2021) 6:745-52. doi: 10.1001/jamacardio.2021.0565

113. Bozkurt B, Colvin M, Cook J, Cooper LT, Deswal A, Fonarow GC, et al. Current diagnostic and treatment strategies for specific dilated cardiomyopathies: a scientific statement from the american heart association. Circulation. (2016) 134:e579-646. doi: 10.1161/CIR.0000000000000455

114. Chau VQ, Giustino G, Mahmood K, Oliveros E, Neibart E, Oloomi $\mathrm{M}$, et al. Cardiogenic shock and hyperinflammatory syndrome in young males with COVID-19. Circ Heart Fail. (2020) 13:e007485. doi: 10.1161/CIRCHEARTFAILURE.120.007485

115. Hekimian G, Kerneis M, Zeitouni M, Cohen-Aubart F, Chommeloux J, Brechot N, et al. Coronavirus disease 2019 Acute myocarditis and multisystem inflammatory syndrome in adult intensive and cardiac care units. Chest. (2021) 159:657-62. doi: 10.1016/j.chest.2020.08.2099

116. Basso C, Leone O, Rizzo S, De Gaspari M, van der Wal AC, Aubry MC, et al. Pathological features of COVID-19-associated myocardial injury: a multicentre cardiovascular pathology study. Eur Heart J. (2020) 41:382735. doi: 10.1093/eurheartj/ehaa664

117. Bajaj R, Sinclair HC, Patel K, Low B, Pericao A, Manisty C, et al. Delayedonset myocarditis following COVID-19. Lancet Respir Med. (2021) 9:e32e4. doi: 10.1016/S2213-2600(21)00085-0

118. Most ZM, Hendren N, Drazner MH, Perl TM. Striking similarities of multisystem inflammatory syndrome in children and a myocarditis-like syndrome in adults: overlapping manifestations of COVID-19. Circulation. (2021) 143:4-6. doi: 10.1161/CIRCULATIONAHA.120.050166

119. Belhadjer Z, Méot M, Bajolle F, Khraiche D, Legendre A, Abakka S, et al. Acute heart failure in multisystem inflammatory syndrome in children in the context of global SARS-CoV-2 pandemic. Circulation. (2020) 142:42936. doi: 10.1161/CIRCULATIONAHA. 120.048360

120. Group RC, Horby P, Lim WS, Emberson JR, Mafham M, Bell JL, et al. Dexamethasone in hospitalized patients with Covid-19. N Engl J Med. (2021) 384:693-704. doi: 10.1056/NEJMoa2021436

121. Castiello T, Georgiopoulos G, Finocchiaro G, Claudia M, Gianatti A, Delialis D, et al. COVID-19 and myocarditis: a systematic review and overview of current challenges. Heart Fail Rev. (2022) 27:25161. doi: 10.1007/s10741-021-10087-9

122. Mevorach D, Anis E, Cedar N, Bromberg M, Haas EJ, Nadir E, et al. Myocarditis after BNT162b2 mRNA vaccine against Covid-19 in Israel. $N$ Engl J Med. (2021) 385:2140-9. doi: 10.1056/NEJMoa2109730

123. Witberg G, Barda N, Hoss S, Richter I, Wiessman M, Aviv Y, et al. Myocarditis after Covid-19 vaccination in a large health care organization. N Engl J Med. (2021) 385:2132-9. doi: 10.1056/NEJMoa2110737

124. Barda N, Dagan N, Ben-Shlomo Y, Kepten E, Waxman J, Ohana R, et al. Safety of the BNT162b2 mRNA Covid-19 vaccine in a nationwide setting. $N$ Engl J Med. (2021) 385:1078-90. doi: 10.1056/NEJMoa21 10475

125. Dagan N, Barda N, Kepten E, Miron O, Perchik S, Katz MA, et al. BNT162b2 mRNA Covid-19 vaccine in a nationwide mass vaccination setting. $N$ Engl J Med. (2021) 384:1412-23. doi: 10.1056/NEJMoa2101765

126. Kerneis M, Bihan K, Salem JE. COVID-19 vaccines and myocarditis. Arch Cardiovasc Dis. (2021) 114:515-7. doi: 10.1016/j.acvd.2021.06.001

127. Moosbauer C, Morgenstern E, Cuvelier SL, Manukyan D, Bidzhekov $\mathrm{K}$, Albrecht S, et al. Eosinophils are a major intravascular location for tissue factor storage and exposure. Blood. (2007) 109:995-1002. doi: 10.1182/blood-2006-02-004945

128. Uderhardt S, Ackermann JA, Fillep T, Hammond VJ, Willeit J, Santer P, et al. Enzymatic lipid oxidation by eosinophils propagates coagulation, hemostasis, and thrombotic disease. J Exp Med. (2017) 214:212138. doi: $10.1084 /$ jem. 20161070 
129. Ojima-Uchiyama A, Masuzawa Y, Sugiura T, Waku K, Fukuda T, Makino S. Production of platelet-activating factor by human normodense and hypodense eosinophils. Lipids. (1991) 26:1200-3. doi: 10.1007/BF02536531

130. Marx C, Novotny J, Salbeck D, Zellner KR, Nicolai L, Pekayvaz K, et al. Eosinophil-platelet interactions promote atherosclerosis and stabilize thrombosis with eosinophil extracellular traps. Blood. (2019) 134:185972. doi: 10.1182/blood.2019000518

131. Galdiero MR, Varricchi G, Seaf M, Marone G, Levi-Schaffer F, Marone G. Bidirectional mast cell-eosinophil interactions in inflammatory disorders and cancer. Front Med (Lausanne). (2017) 4:103. doi: $10.3389 /$ fmed.2017.00103

132. Khoury P, Grayson PC, Klion AD. Eosinophils in vasculitis: characteristics and roles in pathogenesis. Nat Rev Rheumatol. (2014) 10:474-83. doi: 10.1038/nrrheum.2014.98

133. Réau V, Vallée A, Terrier B, Plessier A, Abisror N, Ackermann F, et al. Venous thrombosis and predictors of relapse in eosinophil-related diseases. Sci Rep. (2021) 11:6388. doi: 10.1038/s41598-021-85852-9

134. Groh M, Pineton de Chambrun M, Georges JL, Panel K, Lefèvre G, Kahn JE, et al. Recurrent cardiac arrest due to eosinophilia-related coronary vasospasm successfully treated by benralizumab. J Allergy Clin Immunol Pract. (2021) 9:3497-9.e1. doi: 10.1016/j.jaip.2021.04.067

135. Rohmer J, Groh M, Samson M, London J, Jachiet M, Rouzaud D, et al. Distal ischemia as the initial presentation of hypereosinophilic syndrome-related arterial involvement: A case study and literature review. Autoimmun Rev. (2019) 18:828-30. doi: 10.1016/j.autrev.2019.06.004

136. Lefèvre G, Leurs A, Gibier JB, Copin MC, Staumont-Sallé D, Dezoteux F, et al. "Idiopathic eosinophilic vasculitis": another side of hypereosinophilic syndrome? A comprehensive analysis of 117 cases in asthma-free patients. J Allergy Clin Immunol Pract. (2020) 8:1329-40.e3. doi: 10.1016/j.jaip.2019.12.011

137. Brambatti M, Matassini MV, Adler ED, Klingel K, Camici PG, Ammirati E. Eosinophilic myocarditis: characteristics, treatment, and outcomes. J Am Coll Cardiol. (2017) 70:2363-75. doi: 10.1016/j.jacc.2017.09.023

138. Ammirati E, Sirico D, Brevetti L, Scudiero L, Artioli D, Pedrotti P, et al. The key clues to reach the diagnosis of Loeffler endomyocardial fibrosis associated with eosinophilic granulomatosis with polyangiitis. J Cardiovasc Med (Hagerstown). (2017) 18:831-2. doi: 10.2459/JCM.0000000000000496

139. Bondue A, Carpentier C, Roufosse F. Hypereosinophilic syndrome: considerations for the cardiologist. Heart. (2022) 108:164-71. doi: 10.1136/heartjnl-2020-317202

140. Fournier B, Balducci E, Duployez N, Clappier E, Cuccuini W, Arfeuille C, et al. B-ALL With $\mathrm{t}(5 ; 14)(\mathrm{q} 31 ; \mathrm{q} 32)$; IGH-IL3 rearrangement and eosinophilia: a comprehensive analysis of a peculiar IGH-rearranged B-ALL. Front Oncol. (2019) 9:1374. doi: 10.3389/fonc.2019.01374

141. Pagnoux C, Groh M. Optimal therapy and prospects for new medicines in eosinophilic granulomatosis with polyangiitis (Churg-Strauss syndrome). Expert Rev Clin Immunol. (2016) 12:1059-67. doi: 10.1080/1744666X.2016.1191352

142. Cottin V, Bel E, Bottero P, Dalhoff K, Humbert M, Lazor R, et al. Revisiting the systemic vasculitis in eosinophilic granulomatosis with polyangiitis (Churg-Strauss): A study of 157 patients by the Groupe d'Etudes et de Recherche sur les Maladies Orphelines Pulmonaires and the European Respiratory Society Taskforce on eosinophilic granulomatosis with polyangiitis (Churg-Strauss). Autoimmun Rev. (2017) 16:1-9. doi: 10.1016/j.autrev.2016.09.018

143. Leurs A, Chenivesse C, Lopez B, Gibier JB, Clément G, Groh M, et al. C-Reactive protein as a diagnostic tool in differential diagnosis of hypereosinophilic syndrome and antineutrophil cytoplasmic antibodynegative eosinophilic granulomatosis with polyangiitis. $J$ Allergy Clin Immunol Pract. (2019) 7:1347-51.e3. doi: 10.1016/j.jaip.2018. 10.002

144. Tennenbaum J, Groh M, Venditti L, Campos-Gazeau F, Chalayer E, De Broucker T, et al. FIP1L1-PDGFRA-associated hypereosinophilic syndrome as a treatable cause of watershed infarction. Stroke. (2021) 52:e605e9. doi: 10.1161/STROKEAHA.121.034191

145. Rohmer J, Couteau-Chardon A, Trichereau J, Panel K, Gesquiere C, Ben Abdelali R, et al. Epidemiology, clinical picture and long-term outcomes of FIP1L1-PDGFRA-positive myeloid neoplasm with eosinophilia: Data from 151 patients. Am J Hematol. (2020) 95:1314-23. doi: 10.1002/ajh. 25945

146. Kardaun SH, Sidoroff A, Valeyrie-Allanore L, Halevy S, Davidovici $\mathrm{BB}$, Mockenhaupt $\mathrm{M}$, et al. Variability in the clinical pattern of cutaneous side-effects of drugs with systemic symptoms: does a DRESS syndrome really exist? $\mathrm{Br} J$ Dermatol. (2007) 156:609-11. doi: 10.1111/j.1365-2133.2006.07704.x

147. Ma G, Holland CV, Wang T, Hofmann A, Fan CK, Maizels RM, et al. Human toxocariasis. Lancet Infect Dis. (2018) 18:e14-e24. doi: 10.1016/S1473-3099(17)30331-6

148. Pitini V, Arrigo C, Azzarello D, La Gattuta G, Amata C, Righi M, et al. Serum concentration of cardiac Troponin $\mathrm{T}$ in patients with hypereosinophilic syndrome treated with imatinib is predictive of adverse outcomes. Blood. (2003) 102:3456-7. doi: 10.1182/blood-2003-07-2393

149. Husain Z, Reddy BY, Schwartz RA. DRESS syndrome: Part II. Management and therapeutics. J Am Acad Dermatol. (2013) 68:709.e1-9. doi: 10.1016/j.jaad.2013.01.032

150. Nguyen E, Yanes D, Imadojemu S, Kroshinsky D. Evaluation of cyclosporine for the treatment of DRESS syndrome. JAMA Dermatol. (2020) 156:7046. doi: 10.1001/jamadermatol.2020.0048

151. Schmid-Grendelmeier P, Steiger P, Naegeli MC, Kolm I, Lang CCV, Maverakis E, et al. Benralizumab for severe DRESS in two COVID-19 patients. J Allergy Clin Immunol Pract. (2021) 9:481-3.e2. doi: 10.1016/j.jaip.2020.09.039

152. Groh M, Pagnoux C, Baldini C, Bel E, Bottero P, Cottin V, et al. Eosinophilic granulomatosis with polyangiitis (Churg-Strauss) (EGPA) Consensus Task Force recommendations for evaluation and management. Eur J Intern Med. (2015) 26:545-53. doi: 10.1016/j.ejim.2015.04.022

153. Yates $M$, Watts RA, Bajema IM, Cid MC, Crestani B, Hauser T, et al. EULAR/ERA-EDTA recommendations for the management of ANCA-associated vasculitis. Ann Rheum Dis. (2016) 75:158394. doi: 10.1136/annrheumdis-2016-209133

154. Wechsler ME, Akuthota P, Jayne D, Khoury P, Klion A, Langford CA, et al. Mepolizumab or placebo for eosinophilic granulomatosis with polyangiitis. N Engl J Med. (2017) 376:1921-32. doi: 10.1056/NEJMoa1702079

155. Guntur VP, Manka LA, Denson JL, Dunn RM, Dollin YT, Gill M, et al. Benralizumab as a steroid-sparing treatment option in eosinophilic granulomatosis with polyangiitis. J Allergy Clin Immunol Pract. (2021) 9:1186-93.e1. doi: 10.1016/j.jaip.2020.09.054

156. Canzian A, Venhoff N, Urban ML, Sartorelli S, Ruppert AM, Groh M, et al. Use of biologics to treat relapsing and/or refractory eosinophilic granulomatosis with polyangiitis: data from a european collaborative study. Arthritis Rheumatol. (2021) 73:498-503. doi: 10.1002/art.41534

157. Roufosse F, Kahn JE, Rothenberg ME, Wardlaw AJ, Klion AD, Kirby SY, et al. Efficacy and safety of mepolizumab in hypereosinophilic syndrome: A phase III, randomized, placebo-controlled trial. J Allergy Clin Immunol. (2020) 146:1397-405. doi: 10.1016/j.jaci.2020.08.037

158. Kuang FL, Legrand F, Makiya M, Ware J, Wetzler L, Brown T, et al. Benralizumab for PDGFRA-negative hypereosinophilic syndrome. $\mathrm{N} \mathrm{Engl} \mathrm{J}$ Med. (2019) 380:1336-46. doi: 10.1056/NEJMoa1812185

159. Schneider U, Jenni R, Turina J, Turina M, Hess OM. Long-term follow up of patients with endomyocardial fibrosis: effects of surgery. Heart. (1998) 79:362-7. doi: 10.1136/hrt.79.4.362

160. Fassnacht F, Roumier M, Fouret P, Levy V, Varnous S, Russel S, et al. Successful heart transplantation for unreversible endomyocardial fibrosis related to FIP1L1-PDGFRA chronic eosinophilic leukemia. Transplantation. (2015) 99:e176-7. doi: 10.1097/TP.0000000000000939

161. Groh M, Masciocco G, Kirchner E, Kristen A, Pellegrini C, Varnous S, et al. Heart transplantation in patients with eosinophilic granulomatosis with polyangiitis (Churg-Strauss syndrome). J Heart Lung Transplant. (2014) 33:842-50. doi: 10.1016/j.healun.2014.02.023

162. Heidecker B, Williams SH, Jain K, Oleynik A, Patriki D, Kottwitz J, et al. Virome sequencing in patients with myocarditis. Circ Heart Fail. (2020) 13:e007103. doi: 10.1161/CIRCHEARTFAILURE.120.007103

163. Kandolin R, Lehtonen J, Salmenkivi K, Raisanen-Sokolowski A, Lommi J, Kupari M. Diagnosis, treatment, and outcome of giant-cell myocarditis in the era of combined immunosuppression. Circ Heart Fail. (2013) 6:1522. doi: 10.1161/CIRCHEARTFAILURE.112.969261 
164. Amancherla K, Qin J, Wang Y, Axelrod ML, Balko JM, Schlendorf KH, et al. RNA-sequencing reveals a distinct transcriptomic signature for giant cell myocarditis and identifies novel druggable targets. Circ Res. (2021) 129:451-3. doi: 10.1161/CIRCRESAHA.121.319317

165. Nordenswan HK, Lehtonen J, Ekstrom K, Raisanen-Sokolowski A, Mayranpaa MI, Vihinen T, et al. Manifestations and outcome of cardiac sarcoidosis and idiopathic giant cell myocarditis by 25-year nationwide cohorts. J Am Heart Assoc. (2021) 10:e019415. doi: 10.1161/JAHA.120.019415

166. Ma JI, Ammirati E, Brambatti M, Adler E. Biventricular intravascular microaxial blood pumps and immunosuppression as a bridge to recovery in giant cell myocarditis. J Am Coll Cardiol Case Rep. (2020) 2:14848. doi: 10.1016/j.jaccas.2020.05.107

167. Ammirati E, Oliva F, Belli O, Bonacina E, Pedrotti P, Turazza FM, et al. Giant cell myocarditis successfully treated with antithymocyte globuline and extracorporeal membrane oxygenation for 21 days. J Cardiovasc Med (Hagerstown). (2016) 17(Suppl. 2):e151-3. doi: 10.2459/JCM.0000000000000250

168. Montero S, Aissaoui N, Tadie JM, Bizouarn P, Scherrer V, Persichini R, et al. Fulminant giant-cell myocarditis on mechanical circulatory support: Management and outcomes of a French multicentre cohort. Int $J$ Cardiol. (2018) 253:105-12. doi: 10.1016/j.ijcard.2017.10.053

169. Bang V, Ganatra S, Shah SP, Dani SS, Neilan TG, Thavendiranathan P, et al. Management of patients with giant cell myocarditis: JACC review topic of the week. J Am Coll Cardiol. (2021) 77:1122-34. doi: 10.1016/j.jacc.2020.11.074

170. Elamm CA, Al-Kindi SG, Bianco CM, Dhakal BP, Oliveira GH. Heart transplantation in giant cell myocarditis: analysis of the united network for organ sharing registry. J Card Fail. (2017) 23:566-9. doi: 10.1016/j.cardfail.2017.04.015

171. Yafasova A, Fosbol EL, Schou M, Gustafsson F, Rossing K, Bundgaard H, et al. Long-term adverse cardiac outcomes in patients with sarcoidosis. J Am Coll Cardiol. (2020) 76:767-77. doi: 10.1016/j.jacc.2020.06.038

172. Birnie DH, Sauer WH, Bogun F, Cooper JM, Culver DA, Duvernoy CS, et al. HRS expert consensus statement on the diagnosis and management of arrhythmias associated with cardiac sarcoidosis. Heart Rhythm. (2014) 11:1305-23. doi: 10.1016/j.hrthm.2014.03.043

173. Rosenbaum AN, Kolluri N, Elwazir MY, Kapa S, Abou Ezzeddine OF, Bois JP, et al. Identification of a novel presumed cardiac sarcoidosis category for patients at high risk of disease. Int J Cardiol. (2021) 335:6672. doi: 10.1016/j.ijcard.2021.04.022

174. Baughman RP, Judson MA, Teirstein A, Yeager H, Rossman M, Knatterud $\mathrm{GL}$, et al. Presenting characteristics as predictors of duration of treatment in sarcoidosis. QJM. (2006) 99:307-15. doi: 10.1093/qjmed/hcl038

175. Ekstrom K, Lehtonen J, Hanninen H, Kandolin R, Kivisto S, Kupari M. Magnetic resonance imaging as a predictor of survival free of life-threatening arrhythmias and transplantation in cardiac sarcoidosis. J Am Heart Assoc. (2016) 5:3040. doi: 10.1161/JAHA.115.003040

176. Kandolin R, Lehtonen J, Airaksinen J, Vihinen $T$, Miettinen $H$, Kaikkonen $\mathrm{K}$, et al. Usefulness of cardiac troponins as markers of early treatment response in cardiac sarcoidosis. Am J Cardiol. (2015) 116:960-4. doi: 10.1016/j.amjcard.2015.06.021

177. Sadek MM, Yung D, Birnie DH, Beanlands RS, Nery PB. Corticosteroid therapy for cardiac sarcoidosis: a systematic review. Can J Cardiol. (2013) 29:1034-41. doi: 10.1016/j.cjca.2013.02.004

178. Yazaki Y, Isobe M, Hiroe M, Morimoto S, Hiramitsu S, Nakano T, et al. Prognostic determinants of long-term survival in Japanese patients with cardiac sarcoidosis treated with prednisone. Am J Cardiol. (2001) 88:100610. doi: 10.1016/S0002-9149(01)01978-6

179. Kandolin R, Lehtonen J, Airaksinen J, Vihinen T, Miettinen H, Ylitalo $\mathrm{K}$, et al. Cardiac sarcoidosis: epidemiology, characteristics, and outcome over 25 years in a nationwide study. Circulation. (2015) 131:62432. doi: 10.1161/CIRCULATIONAHA.114.011522

180. Kato Y, Morimoto S, Uemura A, Hiramitsu S, Ito T, Hishida H. Efficacy of corticosteroids in sarcoidosis presenting with atrioventricular block. Sarcoidosis Vasc Diffuse Lung Dis. (2003) 20:133-7.

181. Fussner LA, Karlstedt E, Hodge DO, Fine NM, Kalra S, Carmona EM, et al. Management and outcomes of cardiac sarcoidosis: a 20-year experience in two tertiary care centres. Eur J Heart Fail. (2018) 20:171320. doi: 10.1002/ejhf.1319

182. Futamatsu H, Suzuki J, Adachi S, Okada H, Otomo K, Ohara T, et al. Utility of gallium-67 scintigraphy for evaluation of cardiac sarcoidosis with ventricular tachycardia. Int J Cardiovasc Imaging. (2006) 22:4438. doi: 10.1007/s10554-005-9043-x

183. Rosenthal DG, Parwani P, Murray TO, Petek BJ, Benn BS, De Marco T, et al. Long-term corticosteroid-sparing immunosuppression for cardiac sarcoidosis. J Am Heart Assoc. (2019) 8:e010952. doi: 10.1161/JAHA.118.010952

184. Tiede I, Fritz G, Strand S, Poppe D, Dvorsky R, Strand D, et al. CD28dependent Racl activation is the molecular target of azathioprine in primary human CD4+ T lymphocytes. J Clin Invest. (2003) 111:113345. doi: 10.1172/JCI16432

185. Ballul T, Borie R, Crestani B, Daugas E, Descamps V, Dieude P, et al. Treatment of cardiac sarcoidosis: A comparative study of steroids and steroids plus immunosuppressive drugs. Int J Cardiol. (2019) 276:20811. doi: 10.1016/j.ijcard.2018.11.131

186. Vorselaars ADM, Wuyts WA, Vorselaars VMM, Zanen P, Deneer VHM, Veltkamp M, et al. Methotrexate vs. azathioprine in second-line therapy of sarcoidosis. Chest. (2013) 144:805-12. doi: 10.1378/chest.12-1728

187. Broos CE, van Nimwegen M, Hoogsteden HC, Hendriks RW, Kool M, van den Blink B. Granuloma formation in pulmonary sarcoidosis. Front Immunol. (2013) 4:437. doi: 10.3389/fimmu.2013.00437

188. Drent M, Cremers JP, Jansen TL, Baughman RP. Practical eminence and experience-based recommendations for use of TNF- $\alpha$ inhibitors in sarcoidosis. Sarcoidosis Vasc Diffuse Lung Dis. (2014) 31:91-107.

189. Baughman RP, Drent M, Kavuru M, Judson MA, Costabel U, du Bois $\mathrm{R}$, et al. Infliximab therapy in patients with chronic sarcoidosis and pulmonary involvement. Am J Respir Crit Care Med. (2006) 174:795802. doi: $10.1164 / \mathrm{rccm} .200603-402 \mathrm{OC}$

190. Vorselaars AD, Crommelin HA, Deneer VH, Meek B, Claessen AM, Keijsers $\mathrm{RG}$, et al. Effectiveness of infliximab in refractory FDG PET-positive sarcoidosis. Eur Respir J. (2015) 46:175-85. doi: 10.1183/09031936.00227014

191. Sweiss NJ, Noth I, Mirsaeidi M, Zhang W, Naureckas ET, Hogarth DK, et al. Efficacy results of a 52-week trial of adalimumab in the treatment of refractory sarcoidosis. Sarcoidosis Vasc Diffuse Lung Dis. (2014) 31:46-54.

192. Kandolin R, Lehtonen J, MIDFIN. Infliximab in cardiac sarcoidosis. Eur Heart J. (2017) 38(suppl_1):12498. doi: 10.1111/joim.12498

193. Harper LJ, McCarthy M, Ribeiro Neto ML, Hachamovitch R, Pearson K, Bonanno B, et al. Infliximab for refractory cardiac sarcoidosis. Am J Cardiol. (2019) 124:1630-5. doi: 10.1016/j.amjcard.2019.07.067

194. Grijalva CG, Chen L, Delzell E, Baddley JW, Beukelman T, Winthrop KL, et al. Initiation of tumor necrosis factor- $\alpha$ antagonists and the risk of hospitalization for infection in patients with autoimmune diseases. JAMA. (2011) 306:2331-9. doi: 10.1001/jama.2011.1692

195. Chung ES, Packer M, Lo KH, Fasanmade AA, Willerson JT. Randomized, double-blind, placebo-controlled, pilot trial of infliximab, a chimeric monoclonal antibody to tumor necrosis factor-alpha, in patients with moderate-to-severe heart failure: results of the anti-TNF Therapy Against Congestive Heart Failure (ATTACH) trial. Circulation. (2003) 107:313340. doi: 10.1161/01.CIR.0000077913.60364.D2

196. Pascual-Salcedo D, Plasencia C, Ramiro S, Nuño L, Bonilla G, Nagore D, et al. Influence of immunogenicity on the efficacy of long-term treatment with infliximab in rheumatoid arthritis. Rheumatology (Oxford). (2011) 50:1445-52. doi: 10.1093/rheumatology/ker124

197. Birnie D, Beanlands RSB, Nery P, Aaron SD, Culver DA, DeKemp RA, et al. Cardiac sarcoidosis multi-center randomized controlled trial (CHASM CSRCT). Am Heart J. (2020) 220:246-52. doi: 10.1016/j.ahj.2019.10.003

198. Ferreira VM, Schulz-Menger J, Holmvang G, Kramer CM, Carbone I, Sechtem $U$, et al. Cardiovascular magnetic resonance in nonischemic myocardial inflammation: expert recommendations. J Am Coll Cardiol. (2018) 72:3158-76. doi: 10.1016/j.jacc.2018.09.072

199. Peretto G, Sala S, Basso C, Rizzo S, Radinovic A, Frontera A, et al. Inflammation as a predictor of recurrent ventricular tachycardia after ablation in patients with myocarditis. J Am Coll Cardiol. (2020) 76:164456. doi: $10.1016 /$ j.jacc.2020.08.012 
200. Peretto G, Sala S, De Luca G, Campochiaro C, Sartorelli S, Cappelletti AM, et al. Impact of systemic immune-mediated diseases on clinical features and prognosis of patients with biopsy-proved myocarditis. Int J Cardiol. (2019) 280:110-6. doi: 10.1016/j.ijcard.2018.11.104

201. Mavrogeni S, Schwitter J, van Rossum A, Nijveldt R, Aletras A, Kolovou G, et al. Cardiac magnetic resonance imaging in myocardial inflammation in autoimmune rheumatic diseases: An appraisal of the diagnostic strengths and limitations of the Lake Louise criteria. Int J Cardiol. (2018) 252:2169. doi: 10.1016/j.ijcard.2017.11.032

202. Ise $T$, Hasegawa $T$, Morita $Y$, Yamada N, Funada A, Takahama H, et al. Extensive late gadolinium enhancement on cardiovascular magnetic resonance predicts adverse outcomes and lack of improvement in LV function after steroid therapy in cardiac sarcoidosis. Heart. (2014) 100:116572. doi: 10.1136/heartjnl-2013-305187

203. Merinopoulos I, Gunawardena T, Stirrat C, Cameron D, Eccleshall SC, Dweck MR, et al. Diagnostic applications of ultrasmall superparamagnetic particles of iron oxide for imaging myocardial and vascular inflammation. JACC Cardiovasc Imaging. (2021) 14:1249-64. doi: 10.1016/j.jcmg.2020.06.038

204. Moon H, Park HE, Kang J, Lee H, Cheong C, Lim YT, et al. Noninvasive assessment of myocardial inflammation by cardiovascular magnetic resonance in a rat model of experimental autoimmune myocarditis. Circulation. (2012) 125:2603-12. doi: 10.1161/CIRCULATIONAHA.111.075283

205. Stirrat CG, Alam SR, MacGillivray TJ, Gray CD, Dweck MR, Dibb K, et al. Ferumoxytol-enhanced magnetic resonance imaging in acute myocarditis. Heart. (2018) 104:300-5. doi: 10.1136/heartinl-2017-311688

206. Terasaki F, Azuma A, Anzai T, Ishizaka N, Ishida Y, Isobe M, et al. JCS 2016 guideline on diagnosis and treatment of cardiac sarcoidosis- digest version. Circ J. (2019) 83:2329-88. doi: 10.1253/circj.CJ-19-0508

207. Shelke AB, Aurangabadkar HU, Bradfield JS, Ali Z, Kumar KS, Narasimhan C. Serial FDG-PET scans help to identify steroid resistance in cardiac sarcoidosis. Int $J$ Cardiol. (2017) 228:717-22. doi: 10.1016/j.ijcard.2016.11.142

208. Ning N, Guo HH, Iagaru A, Mittra E, Fowler M, Witteles R. Serial cardiac FDG-PET for the diagnosis and therapeutic guidance of patients with cardiac sarcoidosis. J Card Fail. (2019) 25:307-11. doi: 10.1016/j.cardfail.2019. 02.018

209. Maisch B, Seferović PM, Ristić AD, Erbel R, Rienmüller R, Adler Y, et al. Guidelines on the diagnosis and management of pericardial diseases executive summary; The Task force on the diagnosis and management of pericardial diseases of the European society of cardiology. Eur Heart J. (2004) 25:587-610. doi: 10.1016/j.ehj.2004.02.002

210. Adler Y, Charron P, Imazio M, Badano L, Baron-Esquivias G, Bogaert J, et al. 2015 ESC Guidelines for the diagnosis and management of pericardial diseases: The Task Force for the Diagnosis and Management of Pericardial Diseases of the European Society of Cardiology (ESC)Endorsed by: The European Association for Cardio-Thoracic Surgery (EACTS). Eur Heart J. (2015) 36:2921-64. doi: 10.1093/eurheartj/ehv318

211. Imazio $\mathrm{M}$, Brucato $\mathrm{A}$, Derosa FG, Lestuzzi C, Bombana E, Scipione F, et al. Aetiological diagnosis in acute and recurrent pericarditis: when and how. J Cardiovasc Med (Hagerstown). (2009) 10:217-30. doi: 10.2459/JCM.0b013e328322f9b1

212. Chang SA. Tuberculous and infectious pericarditis. Cardiol Clin. (2017) 35:615-22. doi: 10.1016/j.ccl.2017.07.013

213. Perricone C, Katz D, Ciccacci C, Ceccarelli F, Valesini G, Shoenfeld Y, et al. The heart matters: contribution of genetic factors in recurrent pericarditis. Isr Med Assoc J. (2019) 21:487-90.

214. Alsarah A, Alsara O, Laird-Fick HS. Cardiac manifestations of familial mediterranean fever. Avicenna $J$ Med. (2017) 7:158-63. doi: 10.4103/ajm.AJM_78_17

215. Hintenberger R, Falkinger A, Danninger K, Pieringer H. Cardiovascular disease in patients with autoinflammatory syndromes. Rheumatol Int. (2018) 38:37-50. doi: 10.1007/s00296-017-3854-7

216. Erken E, Erken E. Cardiac disease in familial Mediterranean fever. Rheumatol Int. (2018) 38:51-8. doi: 10.1007/s00296-017-3853-8

217. Imazio M, Brucato A, Pluymaekers N, Breda L, Calabri G, Cantarini $\mathrm{L}$, et al. Recurrent pericarditis in children and adolescents: a multicentre cohort study. J Cardiovasc Med (Hagerstown). (2016) 17:707-12. doi: 10.2459/JCM.0000000000000300

218. Kilic A, Varkal MA, Durmus MS, Yildiz I, Yildirim ZN, Turunc G, et al. Relationship between clinical findings and genetic mutations in patients with familial Mediterranean fever. Pediatr Rheumatol Online J. (2015) 13:59. doi: 10.1186/s12969-015-0057-1

219. Gaggiano C, Vitale A, Obici L, Merlini G, Soriano A, Viapiana O, et al. Clinical features at onset and genetic characterization of pediatric and adult patients with TNF- $\alpha$ receptor-associated periodic syndrome (TRAPS): A series of 80 cases from the AIDA network. Mediators Inflamm. (2020) 2020:8562485. doi: 10.1155/2020/8562485

220. Navallas M, Inarejos Clemente EJ, Iglesias E, Rebollo-Polo M, Zaki FM, Navarro OM. Autoinflammatory diseases in childhood, part 1: monogenic syndromes. Pediatr Radiol. (2020) 50:415-30. doi: 10.1007/s00247-019-04536-9

221. Cantarini L, Rigante D, Merlini G, Vitale A, Caso F, Lucherini OM, et al. The expanding spectrum of low-penetrance TNFRSF1A gene variants in adults presenting with recurrent inflammatory attacks: clinical manifestations and long-term follow-up. Semin Arthritis Rheum. (2014) 43:818-23. doi: 10.1016/j.semarthrit.2013.12.002

222. Cantarini L, Lucherini OM, Brucato A, Barone L, Cumetti D, Iacoponi F, et al. Clues to detect tumor necrosis factor receptor-associated periodic syndrome (TRAPS) among patients with idiopathic recurrent acute pericarditis: results of a multicentre study. Clin Res Cardiol. (2012) 101:52531. doi: $10.1007 / \mathrm{s} 00392-012-0422-8$

223. Welzel T, Kuemmerle-Deschner JB. Diagnosis and management of the cryopyrin-associated periodic syndromes (CAPS): what do we know today? J Clin Med. (2021) 10(1). doi: 10.3390/jcm10010128

224. Insalaco A, Prencipe G, Buonuomo PS, Ceccherini I, Bracaglia C, Pardeo $\mathrm{M}$, et al. A novel mutation in the CIAS1/NLRP3 gene associated with an unexpected phenotype of cryopyrin-associated periodic syndromes. Clin Exp Rheumatol. (2014) 32:123-5. doi: 10.1186/1546-0096-11-S2-P189

225. Brucato A, Brambilla G. Recurrent idiopathic pericarditis: familial occurrence. Int J Cardiol. (2005) 102:529. doi: 10.1016/j.ijcard.2004.06.012

226. Zong Z, Zhang Z, Wu L, Zhang L, Zhou F. The functional deubiquitinating enzymes in control of innate antiviral immunity. Adv Sci (Weinh). (2021) 8:2002484. doi: 10.1002/advs.202002484

227. Jiang L, Shao Y, Tian Y, Ouyang C, Wang X. Nuclear alarmin cytokines in inflammation. J Immunol Res. (2020) 2020:7206451. doi: 10.1155/2020/7206451

228. Yang X, Lin G, Han Z, Chai J. Structural biology of NOD-like receptors. $A d v$ Exp Med Biol. (2019) 1172:119-41. doi: 10.1007/978-981-13-9367-9_6

229. Sundaram B, Kanneganti TD. Advances in understanding activation and function of the NLRC4 inflammasome. Int J Mol Sci. (2021) 22:1048. doi: $10.3390 /$ ijms 22031048

230. Vong CT, Tseng HHL, Yao P, Yu H, Wang S, Zhong Z, et al. Specific NLRP3 inflammasome inhibitors: promising therapeutic agents for inflammatory diseases. Drug Discov Today. (2021) 26:1394-408. doi: 10.1016/j.drudis.2021.02.018

231. Dinarello CA. Overview of the IL-1 family in innate inflammation and acquired immunity. Immunol Rev. (2018) 281:8-27. doi: 10.1111/imr.12621

232. Camprubí D, Mitjavila F, Arostegui JI, Corbella X. Efficacy of anakinra in an adult patient with recurrent pericarditis and cardiac tamponade as initial manifestations of tumor necrosis factor receptor-associated periodic syndrome due to the R92Q TNFRSF1A variant. Int J Rheum Dis. (2017) 20:510-4. doi: 10.1111/1756-185X.13029

233. Gawrysiak W, Skrypnik K, Suliburska J, Skrypnik D, Bogdański P. [Cardiac complications in rheumatoid arthritis, systemic lupus erythematosus and systemic sclerosis]. Przegl Lek. (2017) 74:179-82.

234. Ward NKZ, Linares-Koloffon C, Posligua A, Gandrabur L, Kim WY, Sperber K, et al. Cardiac manifestations of systemic lupus erythematous: an overview of the incidence, risk factors, diagnostic criteria, pathophysiology and treatment options. Cardiol Rev. (2022) 30:38-43. doi: 10.1097/CRD.0000000000000358

235. Dein E, Douglas H, Petri M, Law G, Timlin H. Pericarditis in lupus. Cureus. (2019) 11:e4166. doi: 10.7759/cureus.4166

236. Ryu S, Fu W, Petri MA. Associates and predictors of pleurisy or pericarditis in SLE. Lupus Sci Med. (2017) 4:e000221. doi: 10.1136/lupus-2017-000221 
237. El Hasbani G, Masri BK, Rebeiz AG, Uthman I. Recurrent pericarditis as an initial presentation of rheumatoid arthritis. Am J Med. (2020) 133:e501. doi: 10.1016/j.amjmed.2019.07.038

238. Lazaros G, Oikonomou V, Oikonomou E, Aznaouridis K, Vlachopoulos C, Vogiatzi G, et al. Recurrence of pericardial effusion after pericardiocentesis: does catheter-induced acute pericardial inflammation play a role? Am J Med Sci. (2021) 361:676-8. doi: 10.1016/j.amjms.2020.10.012

239. Tombetti E, Mulè A, Tamanini S, Matteucci L, Negro E, Brucato A, et al. Novel pharmacotherapies for recurrent pericarditis: current options in 2020. Curr Cardiol Rep. (2020) 22:59. doi: 10.1007/s11886-020-01308-y

240. Andreis A, Imazio M, Casula M, Avondo S, Brucato A. Recurrent pericarditis: an update on diagnosis and management. Intern Emerg Med. (2021) 16:551-8. doi: 10.1007/s11739-021-02639-6

241. Wu MA, Costedoat-Chalumeau N, Maestroni S, Brucato A. Acute pericarditis or a systemic disease with pleuropulmonary involvement? Intern Emerg Med. (2019) 14:731-3. doi: 10.1007/s11739-019-02057-9

242. Lazaros G, Antonopoulos AS, Imazio M, Solomou E, Lazarou E, Vassilopoulos D, et al. Clinical significance of pleural effusions and association with outcome in patients hospitalized with a first episode of acute pericarditis. Intern Emerg Med. (2019) 14:745-51. doi: 10.1007/s11739-019-02041-3

243. Imazio M, Lazaros G, Brucato A. [Ten questions about pericardial effusion]. G Ital Cardiol. (2018) 19:339-45. doi: 10.1714/2922.29367

244. Chahine J, Ala CK, Gentry JL, Pantalone KM, Klein AL. Pericardial diseases in patients with hypothyroidism. Heart. (2019) 105:102733. doi: 10.1136/heartjnl-2018-314528

245. Ghosh AK, Crake T, Manisty C, Westwood M. Pericardial disease in cancer patients. Curr Treat Options Cardiovasc Med. (2018) 20:60. doi: 10.1007/s11936-018-0654-7

246. Imazio M, Lazaros G, Valenti A, De Carlini CC, Maggiolini S, Pivetta E, et al. Outcomes of idiopathic chronic large pericardial effusion. Heart. (2019) 105:477-81. doi: 10.1136/heartjnl-2018-313532

247. Conte E, Agalbato C, Lauri G, Mushtaq S, Carollo C, Bonomi A, et al. Prevalence and prognosis of pericardial effusion in patients affected by pectus excavatum: A case-control study. Int J Cardiol. (2021) 344:17983. doi: 10.1016/j.ijcard.2021.10.005

248. Maisch B, Ristić AD, Pankuweit S. Intrapericardial treatment of autoreactive pericardial effusion with triamcinolone; the way to avoid side effects of systemic corticosteroid therapy. Eur Heart J. (2002) 23:1503-8. doi: 10.1053/euhj.2002.3152

249. Buoro S, Tombetti E, Ceriotti F, Simon C, Cugola D, Seghezzi M, et al. What is the normal composition of pericardial fluid? Heart. (2021) 107:158490. doi: 10.1136/heartjnl-2020-317966

250. Light RW. The Light criteria: the beginning and why they are useful 40 years later. Clin Chest Med. (2013) 34:21-6. doi: 10.1016/j.ccm.2012.11.006

251. Buckley BJR, Harrison SL, Fazio-Eynullayeva E, Underhill P, Lane DA, Lip GYH. Prevalence and clinical outcomes of myocarditis and pericarditis in 718,365 COVID-19 patients. Eur J Clin Invest. (2021) 51:e13679. doi: 10.1111/eci.13679

252. Diaz GA, Parsons GT, Gering SK, Meier AR, Hutchinson IV, Robicsek A. Myocarditis and pericarditis after vaccination for COVID-19. JAMA. (2021) 326:1210-2. doi: 10.1001/jama.2021.13443

253. Imazio M, Brucato A, Maestroni S, Cumetti D, Dominelli A, Natale $\mathrm{G}$, et al. Prevalence of C-reactive protein elevation and time course of normalization in acute pericarditis: implications for the diagnosis, therapy, and prognosis of pericarditis. Circulation. (2011) 123:10927. doi: 10.1161/CIRCULATIONAHA.110.986372

254. Liantinioti G, Argyris AA, Protogerou AD, Vlachoyiannopoulos P. The role of colchicine in the treatment of autoinflammatory diseases. Curr Pharm Des. (2018) 24:690-4. doi: 10.2174/1381612824666180116095658

255. Leung YY, Yao Hui LL, Kraus VB. Colchicine-Update on mechanisms of action and therapeutic uses. Semin Arthritis Rheum. (2015) 45:34150. doi: 10.1016/j.semarthrit.2015.06.013

256. Imazio $\mathrm{M}$, Brucato $\mathrm{A}$, Trinchero $\mathrm{R}$, Spodick D, Adler Y. Colchicine for pericarditis: hype or hope? Eur Heart J. (2009) 30:532-9. doi: 10.1093/eurheartj/ehn608

257. Markel G, Imazio M, Brucato A, Adler Y. Colchicine for the prevention of recurrent pericarditis. Isr Med Assoc J. (2008) 10:69-72.
258. Lazaros G, Imazio M, Brucato A, Vlachopoulos C, Lazarou E, Vassilopoulos $\mathrm{D}$, et al. The role of colchicine in pericardial syndromes. Curr Pharm Des. (2018) 24:702-9. doi: 10.2174/1381612824666180116101823

259. Imazio M, Brucato A, Cemin R, Ferrua S, Maggiolini S, Beqaraj F, et al. A randomized trial of colchicine for acute pericarditis. N Engl J Med. (2013) 369:1522-8. doi: 10.1056/NEJMoa1208536

260. Imazio M, Brucato A, Cemin R, Ferrua S, Belli R, Maestroni S, et al. Colchicine for recurrent pericarditis (CORP): a randomized trial. Ann Intern Med. (2011) 155:409-14. doi: 10.7326/0003-4819-155-7-201110040-00359

261. Imazio M, Belli R, Brucato A, Cemin R, Ferrua S, Beqaraj F, et al. Efficacy and safety of colchicine for treatment of multiple recurrences of pericarditis (CORP-2): a multicentre, double-blind, placebo-controlled, randomised trial. Lancet. (2014) 383:2232-7. doi: 10.1016/S0140-6736(13)62709-9

262. Hayashi R, Wada H, Ito K, Adcock IM. Effects of glucocorticoids on gene transcription. Eur J Pharmacol. (2004) 500:5162. doi: 10.1016/j.ejphar.2004.07.011

263. Sandborn WJ. A review of immune modifier therapy for inflammatory bowel disease: azathioprine, 6-mercaptopurine, cyclosporine, and methotrexate. Am J Gastroenterol. (1996) 91:423-33.

264. Vianello F, Cinetto F, Cavraro M, Battisti A, Castelli M, Imbergamo S, et al. Azathioprine in isolated recurrent pericarditis: a single centre experience. Int J Cardiol. (2011) 147:477-8. doi: 10.1016/j.ijcard.2011.01.027

265. Eftimov F, Winer JB, Vermeulen M, de Haan R, van Schaik IN. Intravenous immunoglobulin for chronic inflammatory demyelinating polyradiculoneuropathy. Cochrane Database Syst Rev. (2013) 2013:Cd001797. doi: 10.1002/14651858.CD001797.pub3

266. Hughes RA, Swan AV, van Doorn PA. Intravenous immunoglobulin for Guillain-Barré syndrome. Cochrane Database Syst Rev. (2014) 2014:Cd002063. doi: 10.1002/14651858.CD002063.pub6

267. Salib M, Clayden R, Clare R, Wang G, Warkentin TE, Crowther MA, et al. Difficulties in establishing the diagnosis of immune thrombocytopenia: An agreement study. Am J Hematol. (2016) 91:E327-9. doi: 10.1002/ajh.24404

268. Kaneko Y, Nimmerjahn F, Ravetch JV. Anti-inflammatory activity of immunoglobulin G resulting from Fc sialylation. Science. (2006) 313:6703. doi: 10.1126/science.1129594

269. Imazio M, Lazaros G, Picardi E, Vasileiou P, Carraro M, Tousoulis D, et al. Intravenous human immunoglobulins for refractory recurrent pericarditis: a systematic review of all published cases. J Cardiovasc Med (Hagerstown). (2016) 17:263-9. doi: 10.2459/JCM.0000000000000260

270. Lazaros G, Imazio M, Brucato A, Vassilopoulos D, Vasileiou P, Gattorno $\mathrm{M}$, et al. Anakinra: an emerging option for refractory idiopathic recurrent pericarditis: a systematic review of published evidence. J Cardiovasc Med (Hagerstown). (2016) 17:256-62. doi: 10.2459/JCM.0000000000000266

271. Brucato A, Imazio M, Gattorno M, Lazaros G, Maestroni S, Carraro M, et al. Effect of anakinra on recurrent pericarditis among patients with colchicine resistance and corticosteroid dependence: The AIRTRIP randomized clinical trial. JAMA. (2016) 316:1906-12. doi: 10.1001/jama.2016.15826

272. Yang BB, Baughman S, Sullivan JT. Pharmacokinetics of anakinra in subjects with different levels of renal function. Clin Pharmacol Ther. (2003) 74:8594. doi: 10.1016/S0009-9236(03)00094-8

273. Kaiser C, Knight A, Nordström D, Pettersson T, Fransson J, FlorinRobertsson E, et al. Injection-site reactions upon Kineret (anakinra) administration: experiences and explanations. Rheumatol Int. (2012) 32:2959. doi: 10.1007/s00296-011-2096-3

274. Goletti D, Petrone L, Ippolito G, Niccoli L, Nannini C, Cantini F. Preventive therapy for tuberculosis in rheumatological patients undergoing therapy with biological drugs. Expert Rev Anti Infect Ther. (2018) 16:50112. doi: $10.1080 / 14787210.2018 .1483238$

275. Imazio M, Andreis A, De Ferrari GM, Cremer PC, Mardigyan V, Maestroni $S$, et al. Anakinra for corticosteroid-dependent and colchicine-resistant pericarditis: The IRAP (International Registry of Anakinra for Pericarditis) study. Eur J Prev Cardiol. (2020) 27:956-64. doi: 10.1177/2047487319879534

276. Radin A, Marbury T, Osgood G, Belomestnov P. Safety and pharmacokinetics of subcutaneously administered rilonacept in patients with well-controlled end-stage renal disease (ESRD). J Clin Pharmacol. (2010) 50:835-41. doi: 10.1177/0091270009351882

277. Hoffman HM, Throne ML, Amar NJ, Sebai M, Kivitz AJ, Kavanaugh A, et al. Efficacy and safety of rilonacept (interleukin-1 Trap) in 
patients with cryopyrin-associated periodic syndromes: results from two sequential placebo-controlled studies. Arthritis Rheum. (2008) 58:244352. doi: 10.1002/art.23687

278. Hoffman HM, Throne ML, Amar NJ, Cartwright RC, Kivitz AJ, Soo Y, et al. Long-term efficacy and safety profile of rilonacept in the treatment of cryopryin-associated periodic syndromes: results of a 72-week open-label extension study. Clin Ther. (2012) 34:2091103. doi: 10.1016/j.clinthera.2012.09.009

279. Klein AL, Imazio M, Cremer P, Brucato A, Abbate A, Fang F, et al. Phase 3 trial of interleukin-1 trap rilonacept in recurrent pericarditis. $N$ Engl J Med. (2021) 384:31-41. doi: 10.1056/NEJMoa2027892

280. Chioato A, Noseda E, Colin L, Matott R, Skerjanec A, Dietz AJ. Bioequivalence of canakinumab liquid pre-filled syringe and reconstituted lyophilized formulations following $150 \mathrm{mg}$ subcutaneous administration: a randomized study in healthy subjects. Clin Drug Investig. (2013) 33:8018. doi: 10.1007/s40261-013-0127-4

281. Chakraborty A, Tannenbaum S, Rordorf C, Lowe PJ, Floch D, Gram H, et al. Pharmacokinetic and pharmacodynamic properties of canakinumab, a human anti-interleukin-1 $\beta$ monoclonal antibody. Clin Pharmacokinet. (2012) 51:e1-18. doi: 10.2165/11599820-000000000-00000

282. Sahin A, Derin ME, Albayrak F, Karakaş B, Karagöz Y. Assessment of effectiveness of anakinra and canakinumab in patients with colchicineresistant/unresponsive familial Mediterranean fever. Adv Rheumatol. (2020) 60:12. doi: 10.1186/s42358-020-0117-1

283. Feist E, Quartier P, Fautrel B, Schneider R, Sfriso P, Efthimiou P, et al. Efficacy and safety of canakinumab in patients with Still's disease: exposure-response analysis of pooled systemic juvenile idiopathic arthritis data by age groups. Clin Exp Rheumatol. (2018) 36:668-75.

284. Landmann EC, Walker UA. Pharmacological treatment options for cryopyrin-associated periodic syndromes. Expert Rev Clin Pharmacol. (2017) 10:855-64. doi: 10.1080/17512433.2017.1338946

285. Gattorno M, Obici L, Cattalini M, Tormey V, Abrams K, Davis $\mathrm{N}$, et al. Canakinumab treatment for patients with active recurrent or chronic TNF receptor-associated periodic syndrome (TRAPS): an open-label, phase II study. Ann Rheum Dis. (2017) 76:173-8. doi: 10.1136/annrheumdis-2015-209031

286. Ruperto N, Brunner HI, Quartier P, Constantin T, Wulffraat N, Horneff G, et al. Two randomized trials of canakinumab in systemic juvenile idiopathic arthritis. N Engl J Med. (2012) 367:2396-406. doi: 10.1056/NEJMoa1205099

287. Ridker PM, Everett BM, Thuren T, MacFadyen JG, Chang WH, Ballantyne $\mathrm{C}$, et al. Antiinflammatory therapy with canakinumab for atherosclerotic disease. N Engl J Med. (2017) 377:1119-31. doi: 10.1056/NEJMoa1707914

288. Çakan M, Karadag S G, Ayaz NA. Canakinumab in colchicine resistant familial Mediterranean fever and other pediatric rheumatic diseases. Turk J Pediatr. (2020) 62:167-74. doi: 10.24953/turkjped.2020.02.001

289. Kougkas N, Fanouriakis A, Papalopoulos I, Bertsias G, Avgoustidis N, Repa A, et al. Canakinumab for recurrent rheumatic disease associatedpericarditis: a case series with long-term follow-up. Rheumatology (Oxford). (2018) 57:1494-5. doi: 10.1093/rheumatology/key077

290. Signa S, D’Alessandro M, Consolini R, Miniaci A, Bustaffa M, Longo C, et al. Failure of anti Interleukin-1 $\beta$ monoclonal antibody in the treatment of recurrent pericarditis in two children. Pediatr Rheumatol Online J. (2020) 18:51. doi: 10.1186/s12969-020-00438-5

291. Imazio M, Andreis A, Piroli F, Lazaros G, Gattorno M, Lewinter $M$, et al. Anti-interleukin 1 agents for the treatment of recurrent pericarditis: a systematic review and meta-analysis. Heart. (2021) 27:132430. doi: 10.1093/eurheartj/ehab724.1829

292. Andreis A, Imazio M, Giustetto C, Brucato A, Adler Y, De Ferrari GM. Anakinra for constrictive pericarditis associated with incessant or recurrent pericarditis. Heart. (2020) 106:1561-5. doi: 10.1136/heartjnl-2020-316898
293. Cosyns B, Plein S, Nihoyanopoulos P, Smiseth O, Achenbach S, Andrade MJ, et al. European Association of Cardiovascular Imaging (EACVI) position paper: Multimodality imaging in pericardial disease. Eur Heart J Cardiovasc Imaging. (2015) 16:12-31. doi: 10.1093/ehjci/ jeu128

294. Jain V, Chhabra G, Chetrit M, Bansal A, Berglund F, Montanè B, et al. Role of non-invasive multimodality imaging in autoimmune pericarditis. Eur Heart J Cardiovasc Imaging. (2021) 22:1228-40. doi: 10.1093/ehjci/je ab131

295. Taylor AM, Dymarkowski S, Verbeken EK, Bogaert J. Detection of pericardial inflammation with late-enhancement cardiac magnetic resonance imaging: initial results. Eur Radiol. (2006) 16:569-74. doi: 10.1007/s00330-005-0025-0

296. Chetrit M, Xu B, Kwon DH, Ramchand J, Rodriguez RE, Tan CD, et al. Imaging-guided therapies for pericardial diseases. JACC Cardiovasc Imaging. (2020) 13:1422-37. doi: 10.1016/j.jcmg.2019.08.027

297. Feng D, Glockner J, Kim K, Martinez M, Syed IS, Araoz P, et al. Cardiac magnetic resonance imaging pericardial late gadolinium enhancement and elevated inflammatory markers can predict the reversibility of constrictive pericarditis after antiinflammatory medical therapy: a pilot study. Circulation. (2011) 124:1830-7. doi: 10.1161/CIRCULATIONAHA.111.026070

298. Xu B, Huang SS, Jellis C, Flamm SD. Diagnosis of active pericarditis by positron emission tomography (PET)/cardiac magnetic resonance (CMR) imaging. Eur Heart J. (2018) 39:179. doi: 10.1093/eurheartj/ ehx629

299. Chang SA, Choi JY, Kim EK, Hyun SH, Jang SY, Choi JO, et al. [(18)F]Fluorodeoxyglucose PET/CT predicts response to steroid therapy in constrictive pericarditis. J Am Coll Cardiol. (2017) 69:750-2. doi: 10.1016/j.jacc.2016.11.059

Conflict of Interest: EA received a grant from the Italian Ministry of Health (GR2019-12368506). AB: Institution received funding from Kiniksa Pharmaceuticals, Ltd., as an investigative site; unrestricted research grant from SOBI and ACARPIA; travel and accommodation for advisory committee from SOBI and Kiniksa. JM has served on advisory boards for Bristol Myers Squibb, Pfizer, Takeda, Audentes, Deciphera, Janssen, ImmunoCore, Myovant, Cytokinetics, AstraZeneca, ProteinQure, and Pharmacyclics. JM was supported by the National Institutes of Health (R01HL141466, R01HL155990, and R01HL156021). MG received consulting fees from Astrazeneca and GlaxoSmithKline.

The remaining authors declare that the research was conducted in the absence of any commercial or financial relationships that could be construed as a potential conflict of interest.

Publisher's Note: All claims expressed in this article are solely those of the authors and do not necessarily represent those of their affiliated organizations, or those of the publisher, the editors and the reviewers. Any product that may be evaluated in this article, or claim that may be made by its manufacturer, is not guaranteed or endorsed by the publisher.

Copyright (C) 2022 Ammirati, Bizzi, Veronese, Groh, Van de Heyning, Lehtonen, Pineton de Chambrun, Cereda, Picchi, Trotta, Moslehi and Brucato. This is an open-access article distributed under the terms of the Creative Commons Attribution License (CC BY). The use, distribution or reproduction in other forums is permitted, provided the original author(s) and the copyright owner(s) are credited and that the original publication in this journal is cited, in accordance with accepted academic practice. No use, distribution or reproduction is permitted which does not comply with these terms. 